\title{
Common ownership, price informativeness, and corporate investment
}

\author{
IN JI JANG \\ NAMHO KANG \\ ARI YEZEGEL*
}

November 2019

\begin{abstract}
*Jang: Bentley University. Email: ijang@ bentley.edu. Kang: Bentley University, Finance Department. Email: nkang@bentley.edu. Yezegel: Bentley University, 175 Forest Street Waltham, MA 02452-4705. Email: ayezegel@ bentley.edu. We would like to thank Jacquelyn Gillette, Ahmet Kurt, Kristina Minnick, Mahdi Mohseni, Sugata Roychowdhury, Chi Zhang, and seminar participants at Bentley University and University of Massachusetts at Lowell.
\end{abstract}




\title{
Common ownership, price informativeness, and corporate investment
}

\author{
November 2019
}

\begin{abstract}
Using financial institution mergers as exogenous shocks to common ownership, we find that stock prices of commonly held firms incorporate future earnings news more efficiently and are less sensitive to noise traders. We identify two potential mechanisms: (1) information diffusion between connected firms, and (2) active trading by common owners. We find that the investment sensitivity to Tobin's Q for commonly held firms is higher, indicating that managers of such firms rely more on market prices for information. Our findings suggest that common ownership has a positive effect on information production and influences real corporate decision by improving price informativeness.
\end{abstract}

Key words: Common Ownership; Market efficiency; Investment; Information Acquisition 


\section{Introduction}

Over the period from 1950 to 2010, institutional investors' average percentage holdings in U.S. public companies increased from seven to sixty-seven percent. ${ }^{1}$ This remarkable growth in institutional ownership was fueled in part by the fierce push towards passive investing through exchange-traded funds (ETF), as well as the growth in active investing by large institutions. As a result, firms are now frequently interconnected through a diverse group of institutional investors with varying incentives and risk preference, and differing levels of information capabilities.

One of the consequences of the growth of institutional investing is the increasing prevalence of common ownership. Common owners are institutional investors who hold large ownership stakes in multiple companies in the same industry. Figure 1 plots the average percentage holdings owned by common owners over the period 1980-2013. The figure reveals that common ownership grew from nearly zero percent in 1980 to approximately ten percent in 2013. In tandem with the rise in common ownership, researchers have begun to scrutinize the effects of common ownership on product markets and show that the investment styles of common owners cause firms to increase coordination and reduce competition (Azar, Schmalz, and Tecu 2018; He and Huang 2017). Further, regulators are currently investigating the effects of common ownership on capital markets and calling for new rules that are intended to help protect investors and consumers. $^{2}$

In this paper, we focus on the capital market implications of common ownership. Specifically, we examine whether common ownership improves the informational efficiency of stock prices, and influences managers' investment decisions. While the effects of common ownership at the product market level have

\footnotetext{
${ }^{1}$ https://www.sec.gov/news/speech/2013-spch041913laahtm.

$2{ }$ On December $6^{\text {th }}$, 2018, Securities Exchange Commission (SEC) Commissioner Robert J. Jackson Jr., in his testimony to the Federal Trade Commission (FTC), characterized common ownership as "an investor protection problem" and urged "the SEC to pursue new rules requiring clearer summary disclosure of the voting behavior of institutional investors relative to other voters' views on corporate elections." For a full transcript of Commissioner's testimony, visit https://www.sec.gov/news/testimony/jackson-testimony-ftc-120618. Further, the FTC, and the Department of Justice (DOJ) are also examining the impact of common ownership. See https://www.lexology.com/library/detail.aspx?g=a4eedc74-e414-4348-bb63-91d5726a1661.
} 
been explored, there is scant evidence on the capital market implications of common ownership. We aim to contribute to this growing literature by empirically testing whether share prices of companies become more or less efficient following an increase in common ownership.

We argue that exogenous shocks to common ownership reduce information costs, which then contributes to an improvement in the overall efficiency of stock prices. Specifically, when an institution develops sizeable ownership in multiple companies that are subject to similar competitive and economic forces, the institution also experiences efficiency gains in private information production through economies of scale (Kacperczyk, Sialm, and Zheng 2005). The efficiency gains come from common owners' ability to rely on their information acquisition efforts for one company to produce information for peer companies, consequently lowering average information costs per security. The lower information costs that common owners face incentivizes them to acquire more information (Grossman and Stiglitz 1980) and/or information of higher quality (Verrecchia 1982), which in turn contributes to price informativeness.

Further, we hypothesize that common owners' information activities contribute to information diffusion between connected firms and thereby add to price informativeness. Many studies show that blockholders have stronger incentives to gather costly information (Edmans 2009; Rubin 2007; Boehmer and Kelley 2009). Common owners, as block-holders in multiple companies in the same industry, frequently meet with analysts, directors, and managers, which helps them benefit from a constant influx of information about the companies that they are investigating as well as the peer companies (Azar, Schmalz and Tecu 2018; McCahery, Sautner and Starks 2016). They, therefore, have greater opportunities to incorporate information about peer companies that can be helpful in evaluating the focal firm, relative to investors who lack significant ownership in peer companies. Hence, common owners' trades are more likely to reveal the fundamental information of peer firms, contributing to the level of information diffusion between connected firms.

In order to study the effects of common ownership on price informativeness, we identify financial institution mergers as a source of identification for common ownership and use the resulting changes in 
ownership structures as exogenous shocks to common ownership (He and Huang 2017). The goal of this identification strategy is to isolate our analysis from the effects of changes in common ownership that coincide with, or result from, significant changes in firm fundamentals. Using this identification strategy, we begin our analysis by investigating the extent to which current returns reflect information about future earnings. Lundholm and Myers (2002) show that efficient stock prices "bring the future forward", reflecting greater amount of future earnings news. To the extent that common ownership has a positive effect on price efficiency, we should observe that current stock returns of commonly held firms incorporate a greater amount of future earnings news. Consistent with this hypothesis, we find that firms with positive shocks to common ownership experience an increase in the extent to which their share prices reflect future earnings information. We also find that the positive relation between current returns and current earnings is weaker for commonly held firms, suggesting that the relative importance of current earnings in explaining current returns diminishes as this information becomes reflected in share prices during the previous years.

We, additionally, analyze an alternative measure of price efficiency: variance ratios. ${ }^{3}$ The premise of this analysis is that liquidity shocks subsequently revert, whereas fundamental information leads to permanent price changes (Ben-David, Franzoni, and Moussawi 2018; Saffi and Sigurdsson 2011). If common owners are informed, then their trades should push stock prices to converge to their intrinsic values. ${ }^{4}$ We find that shocks to common ownership lead to a significant reduction in the variance ratio, suggesting that the extent to which share prices are influenced by noise traders and short-term liquidity shocks is reduced for stocks owned by common owners.

One of the primary economic arguments underlying our hypotheses is that common owners use information that they acquire concerning peer companies to value the firm in question. We argue that this information acquisition strategy helps common owners reduce their average information cost per

\footnotetext{
${ }^{3}$ We calculate the variance ratio as the absolute value of the ratio of the five-day return volatility to five times daily return volatility minus one.

${ }^{4}$ For example, Edmans (2009) argues that informed trading by block holders help impound fundamental information into prices.
} 
investment. Further, as a positive externality, this information strategy helps information flow more quickly across different securities. To the extent that common owners serve as a conduit for the flow of information, we should see a stronger improvement in price informativeness for shares of companies that are less informationally connected. We exploit geographical distance as a measure of the connectedness between companies to test whether common owners generate incremental informational benefit for companies that are less connected. Prior research shows that information spreads among geographically close investors or companies through word-of-mouth and social interactions (Ivkovic and Weisbenner 2005; Hong, Kubik and Stein 2004, Hong, Kubik and Stein 2005). Further, companies that are located in industry-geographic clusters tend to have more efficient share prices (Engelberg, Ozoguz and Wang 2018) and are less costly for sell-side analysts to cover (Jennings, Lee and Matsumoto 2017). ${ }^{5}$ Hence, companies that are geographically distant from each other are less likely to be informationally connected. We predict that in such circumstances, common owners possess greater opportunities to contribute to price informativeness by serving as a medium for information to flow across securities.

We find empirical support for this prediction. When there is an exogenous shock to the level of common ownership for two companies that are geographically distant from each other, the effect of common ownership on price efficiency is significantly larger than its effect for two companies that are closely located. In addition, we use an alternative proxy for the level of connection between companies, namely Facebook Social Connectedness Index (SCI), which measures the social connection level between the areas where the two companies are headquartered. We find similar results using the SCI. The average efficiency gain attributable to common ownership is significantly higher for firms that are less socially connected.

Our results also indicate that common ownership triggers an increase in the level of private information that is reflected in share prices. Specifically, we document a positive relation between PIN,

\footnotetext{
${ }^{5}$ The key conclusion from these papers is that physical proximity enhances information spillovers among peer firms and reduces external users' information collection and production costs.
} 
which is a measure of informed trading, and exogenous shocks to common ownership. In addition, we show that average bid-ask spreads decline in response to increases in common ownership. The decline in bid-ask spreads amid increases in informed trading, although seemingly contradictory, is consistent with findings from recent research (Collin-Dufresne and Fos 2015; Kacperczyk and Pagnotta 2019).

To further investigate the potential channels through which common owners affect market efficiency, we delve deeper into common owners' trading activities. We begin by examining the relation between stock returns and institutional holding changes. Within this empirical framework, we test whether exogenous shocks to common ownership enhance the return-trade correlation, which would suggest that trades become more informative. We find that the trading activities of common owners becomes significantly more correlated with contemporaneous returns for treatment firms following exogenous shocks to common ownership. These results show that increases in common ownership for treatment firms lead to more informative trading by common owners and highlights trading as one of the mechanisms through which common owners' information gets incorporated into share prices. To further substantiate this conclusion, we conduct an additional analysis where we sort treatment firms into two groups: firms for which common owners actively trade and firms with non-active trading. We find that the price efficiency obtained following an exogenous shock to common ownership is stronger for treatment firms with active trading compared to firms with non-active trading by common owners.

The empirical relation that we document between common ownership and price efficiency produces a directly related question: do managers of companies with common ownership rely more on share prices to make investment decisions ${ }^{6}$ We examine this research question within the investment sensitivity to Tobin's $Q$ framework. Specifically, we investigate whether investment-to- $Q$ sensitivity increases after a firm experiences a positive shock to common ownership. We document a positive change in investmentto- $Q$ sensitivity following a shock to common ownership, suggesting that managers of commonly owned

\footnotetext{
${ }^{6}$ Chen, Goldstein and Jiang (2007) document that the sensitivity of corporate investment to stock prices is higher when stock prices are more informative. Edmans (2009), additionally, shows that informed trading by block holders induce efficient investment.
} 
companies rely more on the information conveyed in share prices to make investment decisions, presumably because they recognize the incremental informativeness of share prices.

We conduct a series of robustness tests to strengthen the statistical validity of our empirical analyses. As part of this effort, we first repeat our analyses using an alternative control group and find similar results. We then perform a falsification test where we re-estimate our main analyses using pseudoevent dates that are set to be four years prior to actual merger dates. This analysis detects no statistical association between the false shocks to common ownership and price efficiency or investment-to- $Q$ sensitivity. Finally, following Lewellen and Lowry's (2019) suggestion, we exclude mergers that took place during the financial crisis of 2007-2009 and find similar results.

We contribute to the existing literature on several dimensions. First, our findings extend the stream of research on the implications of common ownership. Recent research shows that increases in common ownership trigger higher product prices (Azar, Schmalz, and Tecu 2018), lead to improved market share and operating profitability (He and Huang 2017), encourage more collaboration and diffusion of innovation among commonly held firms (Chemmanur, Shen, and Xie 2016; Kostovetsky and Manconi 2016), and increase voluntary disclosure (Park et al. 2019; Pawliczek and Skinner 2018). These findings, collectively, suggest that an increase in common ownership weakens industry-wide competition and boosts managers' willingness to cooperate with peer companies, while it encourages commonly held firms to disclose more. Further, several papers examine the effect of common ownership on corporate governance. He, Huang, and Zhao (2019), for example, find common ownership increases active voting. Anton et al. (2016) study the effect of common ownership on the executive compensation, while Edmans, Levit, and Reilly (2016) argue that common ownership strengthens governance through channels of both voice and exit. The central contribution of our paper is to show that one of the consequences of common ownership is an increase in price efficiency. We attribute the increase in efficiency to the reduction in information costs and improved information diffusion between companies, which manifest in more informed trading, particularly by common owners. 
Second, our paper extends prior work that investigates the effects of institutional investors, especially ETF holders, on share price efficiency. A growing body of evidence shows that institutions can propagate non-fundamental volatility due to demand shocks caused by flows from their investors (Coval and Stafford 2007; Lou 2012). Recently, several papers study the effect of ETF on price efficiency and find an inverse relation between ETF ownership and price efficiency (Ben-David, Franzoni, and Moussawi 2018; Israeli, Lee, and Sridharan 2017). We document the opposite relation between common ownership and price efficiency based on a quasi-natural experiment setting. These results suggest that investors who have significant ownership in multiple companies appear to invest more resources to analyze the companies in their portfolio, while investors who own companies through an ETF appear to be liquidity-motivated investors.

Third, we contribute to the literature on investment sensitivity to share prices. The literature shows that when price movement is noisy, investment sensitivity to stock prices weakens. Antoniou, Subrahmanyam, and Tosun (2018), for example, show that managers of firms with high ETF ownership rely less on stock prices due to noisy prices. Further, Lou and Wang (2018) study liquidity driven mutual fund trading as a source of noisy prices. Our findings support the notion that managers of commonly held firms are more sensitive to their share prices because of the higher level of price efficiency.

Finally, at a practical level, our research intends to contribute to the ongoing debate among regulatory bodies on the consequences of common ownership. Common ownership has recently been under scrutiny from regulators in the U.S. including the Securities and Exchange Commission (SEC), Federal Trade Commission (FTC), and the Department of Justice (DOJ). By studying the capital market consequences of common ownership, we contribute to this debate and help develop a more comprehensive understanding of the overall implications of common ownership. 


\section{Hypotheses development}

We hypothesize that common owners' information-based activities contribute to price informativeness by improving the level and quality of information production. Our hypothesis rests on the notion that common owners face greater incentives to obtain and interpret new information as the information they collect on their investments can complement common owners' analyses of peer firms by placing them in a broader context (Shroff, Verdi and Yost 2017). Common owners, consequently, can spread their information search and processing costs over a larger set of companies and attain lower information costs. Consistently, we predict that the efficiency gains that investors achieve by holding multiple stocks increases their willingness to obtain new information (Grossman and Stiglitz 1980) or information of higher precision (Verrechia 1982).

Common owners are in a strong position to help speed up information diffusion by serving as a conduit for information to flow across companies. Shareholders with large investments exert significant effort to influence corporate policy on a wide range of issues including governance decisions, disclosure policies, and product market strategies (Appel, Gormley, and Keim 2016; Azar, Schmalz, and Tecu 2018; Boone and White 2015; Dimson, Karakas, and Li 2015). Survey results, as well as anecdotal evidence, indicate that asset managers frequently attend private meetings with board members and corporate executives where they communicate their concerns with the goal of influencing corporate decision-making (McCahery, Sautner, and Starks 2016). Common owners' engagement with high level corporate officers and board members places them in a unique position to benefit from a continuous inflow of information about the company of interest as well as its competitors.

Further, common owners can directly contribute to price efficiency by trading on their private information when they observe that share prices differ from their intrinsic values (Edmans 2009). In addition, common owners' informational advantage may discourage uninformed trading activity and help share prices reflect more of informed traders' private information. We, therefore, predict that common ownership reduces non-fundamental volatility by facilitating informed trading. 
Conversely, prior research on index investing emphasizes the passive nature of this investment style and conjectures that such a strategy weakens information production and dampens market efficiency (Kacperczyk, Nosal and Sundaresan 2018; Breugem and Buss 2019; Bond and Garcia 2019) and reduces the extent to which share prices reflect fundamental information (Israeli, Lee, and Sridharan 2017; Glosten, Nallareddy, and Zou 2019). If common owners become less engaged in information search and acquisition activities and thereby adopt a passive investment style, we should observe no relation or an inverse relation between shocks to common ownership and price efficiency.

Hypothesis 1A: Common ownership enhances price efficiency.

Hypothesis 1B: Common ownership weakens price efficiency.

To the extent that common owners affect price informativeness, their ownership may have real consequences on corporate policy. There is agreement among scholars that share prices can contain information that corporate managers lack (e.g., Chen, Goldstein, and Jiang 2007; Dow, Goldstein, and Guembel 2006; Dye and Sridhar 2002). The notion of share prices conveying information beyond what managers know about the company yields the possibility of managers learning from prices, which assigns a greater role to financial markets. According to this view, managers make corporate decisions (e.g., investment) based on the information available to them as well as the incremental information conveyed through share prices. Investors, therefore, influence corporate managers' decision by affecting share prices through their informed trading activities. Consistent with this notion, Edmans (2009) demonstrates that, due to the guiding feature of prices, investors with large ownership stakes can influence corporate behavior without directly intervening in management.

Indeed, the extant literature shows that changes in price informativeness caused by new rules or institutional investing have real effects on corporate investment. Edmans, Jayaraman and Schneemeier (2017) use the enactment of insider trading laws passed around the world as an exogenous shock to the incremental information in share prices, and find that investment-to- $Q$ sensitivity increases after the 
enactment of new insider trading rules. Conversely, Antoniou, Subrahmanyam, and Tosun (2018) find that firms with high ETF ownership experience a decrease in the investment-to- $Q$ sensitivity, due to the noisy nature of ETF trading.

In summary, managers' use of information in share prices to make investment decisions is likely to vary in relation to price informativeness (Chen, Goldstein, and Jiang 2007; Edmans, Jayaraman, and Schneemeier 2017). To the extent that common ownership increases overall price efficiency and/or the amount of information in prices that managers lack, managers are likely to alter the weight that they place on share prices as they make investment decisions. We, therefore, hypothesize that the investment-to- $Q$ sensitivity is related to the extent common ownership affects the informativeness of share prices. If common ownership increases (resp., decreases) price efficiency, then we predict a positive (resp., inverse) relation between common ownership and investment-to- $Q$ sensitivity.

Hypothesis 2A: Investment-to- $Q$ sensitivity increases with the level of common ownership.

Hypothesis $2 \mathrm{~B}$ : Investment-to- $Q$ sensitivity decreases with the level of common ownership.

\section{Main Variables and Methodology}

We compile security data (e.g., return, price, shares) from Center for Research in Security Prices (CRSP), financial statement data from Compustat, institutional ownership and financial institution merger data from Thompson Reuters. Our sample consists of firms that were subject to financial institution mergers from 1983 to 2011. Since the variables in our analyses are measured over the period of $t+1$ to $t+3$, our final sample spans the period of 1980-2014. We provide descriptions of our main variables and their summary statistics below. 


\subsection{Common Ownership Variables}

Common ownership measures the level of interconnectedness of a firm with other firms in the same industry through institutional block-holders. An institution is defined as a cross-holding institution if the institution block-holds at least five percent of the outstanding shares in a given firm and simultaneously block-holds at least one or more of the same industry peers. We use the four-digit SIC industry classification to define industries.

We follow He and Huang (2017) and measure common ownership using five different variables: CrossDummy, NConnected, NCross, AvgNum, and TotalCrossOwn. CrossDummy is an indicator variable that takes a value of one if a firm is block-held by a cross-holding institution during any of the four quarters of a fiscal year and zero otherwise. NConnected equals the number of same industry peers that are connected with the firm through shared cross-holding institutions. NCross equals the number of unique institutions that cross-hold the firm. AvgNum is the average number of same-industry peers block-held by institutions that block-hold the firm. TotalCrossOwn is the sum of all percentage holdings of institutions that crosshold the firm. With the exception of the CrossDummy variable, we first calculate common ownership variables in a given quarter, then average across the four quarters in a fiscal year.

\subsection{Price Efficiency and Corporate Investment Variables}

This section describes the key variables that measure price efficiency and corporate investment. In addition to the key variables described below, our empirical analyses use various firm characteristics that might affect stock returns, volatility, as well as firms' investment decisions. Appendix A provides detailed definitions of all variables that we use in our analyses.

Our main empirical tests of price efficiency analyze price informativeness in relation to future earnings. Lundholm and Myers (2002) estimate the relation between earnings and returns to measure the degree to which the future earnings news is incorporated into current stock prices. To test whether share 
prices of commonly-held companies reflect future earnings information more efficiently, we apply their method to our difference-in-difference setting where we regress annual returns on current and future earnings.

We measure annual returns $\left(R E T_{i, t}\right)$ as the buy-and-hold return for firm $i$ during the 12-month period ending three months after the end-date of fiscal year $t$. Current earnings, $X_{i, t}$, represents income available to common shareholders of firm $i$ before extraordinary items during fiscal year $t$, deflated by market value of equity three months after the end of fiscal year $t-1$. Future earnings, $X 2_{i, t}$, equals the sum of income available to common shareholders of firm $i$ before extraordinary items for the two year period following year $t$, deflated by market value of equity three months after the end of fiscal year $t-1$. We also calculate future returns, $R 2_{i, t}$, as firm $i$ 's buy-and-hold return for the two-year period following year $t$, starting three months after the current fiscal year-end date.

Our alternative measure of price efficiency is the variance ratio, estimated following Lo and MacKinlay (1988), O’Hara and Ye (2011), and Ben-David, Franzoni, and Moussawi (2018). The variance ratio is defined as the absolute value of the variance of five-day returns $\left(r_{5, i t}\right)$ in a given quarter divided by five times the variance of one-day returns $\left(r_{1, i t}\right)$ in the same quarter minus one (Eq. 2).

$$
V R_{i, t}=\operatorname{abs}\left(\frac{\operatorname{VAR}\left(r_{5, i, t}\right)}{5 * \operatorname{Var}\left(r_{1, i, t}\right)}-1\right)
$$

To the extent that autocorrelations in security returns are stronger, the variance ratio will deviate from zero. The variance ratio, therefore, is lower for firms with more efficient stock prices.

Finally, we study the relation between corporate investment and Tobin's $Q$ to test whether managers' investment behavior is affected by common ownership. To study the investment- $Q$ relation, we use four different proxies to measure the level of corporate investment: CAPXRND, Investment, RND, and DisExp. CAPXRND represents capital expenditures plus research and development expenses scaled by lagged total assets. Investment is the sum of research and development expenses, capital expenditures and 
acquisition costs minus receipts from sale of PPE scaled by lagged total assets. $R N D$ equals research and development expenditures scaled by lagged total assets. DisExp is the sum of research and development expenditures and advertising expenses scaled by lagged total assets. Finally, $Q_{i t}$ is the market value of equity plus the book value of total assets minus book value of equity, scaled by book value of total assets.

\subsection{Summary Statistics}

Table 1 presents the descriptive statistics (Panel A) and the correlation matrix (Panel B) for the variables employed in our analysis. The statistics in Panel A reveal that common ownership is highly pervasive in our sample. For instance, 77.7 percent of the firm-years in our sample are held by a cross-holding institution, and on average, firms in our sample are connected to 5.3 peer firms through cross-holding institutions. In addition, cross-holding institutions hold 10.9 percent of total shares outstanding of the sample firms. Finally, the average annual raw return (RET) for firm-years in our sample equals 17.5 percent, while the $\log$ of the book-to-market ratio (BTM) equals -0.70 , and 69.4 percent of the shares of the sample firms are held by institutional investors.

Panel B reports Pearson correlations in the upper right corner, and Spearman correlations in the lower left corner. As expected, the five common ownership variables are highly correlated, although the correlations are sufficiently low, which indicates that those variables capture distinct aspects of common ownership. In addition, common ownership variables exhibit significant positive correlations with size and institutional ownership, suggesting that larger firms that have higher institutional ownership are more likely to be block-held by cross-holding institutions. 


\section{Main Empirical Analysis: Common Ownership and Price Efficiency}

This section provides the results of our main empirical analyses, and establishes the link between common ownership and price efficiency. We utilize a difference-in-difference (DiD) approach, exploiting financial institution mergers as a source of exogenous shock to common ownership.

\subsection{Financial Institution Mergers}

The endogenous nature of the relation between common ownership and price efficiency makes it challenging to investigate the causal effect of common ownership on price efficiency. Specifically, firms with efficient prices may attract more cross-holding institutions potentially due to less information acquisition costs. Further, omitted variables can affect both the cross-holding decision of an institution and the price efficiency of a firm, biasing cross-sectional coefficient estimates. To the extent that such forces are at work, the inference that common ownership leads to higher price efficiency based on pooled analyses may be biased. To address these potential concerns, we follow prior work in the literature (e.g., Azar, Schmalz, and Tecu 2018; He and Huang 2017; Lewellen and Lowry 2018) and use financial institution mergers as a plausibly exogenous shock to common ownership.

The extant literature uses financial institution mergers as a quasi-natural experiment based on the premise that these institutions often merge for reasons other than the fundamentals of their portfolio firms. Since the acquirer usually maintains the existing portfolio holdings of the target institution due to liquidity and transaction costs concerns (e.g., Holthausen, Leftwich, and Mayers 1990), mergers generate meaningful exogenous variations in firms' common ownership. Specifically, if a firm is block-held by one of the merging institutions before the merger, and at the same time the other party of the merger block-holds one of the industry peers, then the firm is more likely to be cross-held by the merged institution after the merger, thereby increasing the extent of common ownership in the firm. 
We use institution mergers that took place between the years 1983 and 2011. ${ }^{7}$ Following He and Huang (2017), we identify treatment firms as those that are block-held by one of the merging institutions during the quarter before the merger announcement date, and the other party of the merger holds at least one same-industry peer but not the firm itself, during the same quarter before the merger. Treatment firms are likely to experience an increase in common ownership after the merger because they are more likely to establish new linkages with the same industry peers through the merger. Control firms, on the other hand, are those that are block-held by one of the merging institutions (this holds for the treatment), but the other merging institution does not block-hold same-industry peers. The control firms, therefore, are unlikely to experience an increase in common ownership due to the merger.

It is important to note that we identify treatment and control firms based on ex-ante holdings information rather than actual post-merger holdings, because relying on the latter might introduce selection bias. Since control firms are also block-held by the same merging institutions, any firm characteristics that may be related to investment styles or management skills of the merging institutions can also be controlled for. In addition, since the merging institutions block-hold both treatment and control firms, the treatment effect is unlikely to be due to block-holding. Our final difference-in-difference (DiD) sample consists of 2,989 unique firms including 217 treated firms.

\subsection{Effect of Financial Institution Mergers on Common Ownership}

In order to validate our use of financial institution mergers as an exogenous shock to common ownership, we examine whether mergers are associated with future changes in the level of common ownership for treatment and control firms. Panels A and B of Table 2 provide summary statistics of the common ownership variables during the pre- and post-institution merger periods, respectively. Panel A demonstrates

\footnotetext{
${ }^{7}$ The list of mergers can be found in Table A1 of He and Huang (2017). From the list, we exclude the mergers for which no treatment firm is identified.
} 
that there are no significant differences in common ownership variables, except for NConnected and AvgNum, between treatment and control groups before the merger. In Panel B, however, we find that all five proxies of common ownership significantly increase for treatment firms in post-merger period.

Panel C reports the DiD tests using the common ownership variables as the dependent variables. Treat is an indicator variable that equals one if a firm is identified as a treatment firm and zero if it is considered a control firm. Post is an indicator variable that equals one for the post-merger period and zero for the pre-merger period. The pre- and post-merger periods are $t-3$ to $t-1$ and $t+1$ to $t+3$, respectively, where year $t$ is the announcement year of the merger. These results confirm that firms in the treatment group undergo a significant increase in common ownership during the post-merger period. For example, during the post-merger period, treatment firms experience a $5.8 \%(=0.012+0.046)$ increase in likelihood of being commonly owned by the merging institutions. Given that $74 \%$ of treatment firms were commonly held prior to mergers, the increase is economically significant. We find similar results across all proxies of common ownership.

\subsection{Price Informativeness}

The results in Table 2 provide an empirical basis to use financial institution mergers as exogenous shocks to common ownership. Having established the effect of mergers on common ownership, we next examine whether the extent to which future earnings information are reflected in share price changes for treatment firms after the merger.

Lundholm and Myers (2002) study the relation between earnings and returns to measure how well share prices reflect current and future earnings. A firm's return over a year should reflect a portion of unexpected current earnings realization and a portion that is due to expected changes about future earnings. Our first hypothesis that common ownership leads to an increase in price informativeness implies that current year's returns reflect more of future earnings information for treatment firms after the merger. 
We estimate the following generalized difference-in-difference (DiD) regression ${ }^{8}$ :

$$
\begin{aligned}
\text { Ret }_{i, t}=\beta_{1} X_{i, t} & \times \text { Treat } \times \text { Post }+\beta_{2} X 2_{i, t} \times \text { Treat } \times \text { Post }+\beta_{3} X_{i, t}+\beta_{4} X 2_{i, t}+\beta_{5} X_{i, t} \times \text { Treat } \\
& +\beta_{6} X 2_{i, t} \times \text { Treat }+\beta_{7} X_{i, t} \times \text { Post }+\beta_{8} X 2_{i, t} \times \text { Post }+\beta_{9} \text { Treat }+\beta_{10} \text { Post } \\
& +\beta_{11} \text { Treat } \times \text { Post }+\gamma^{\prime} Z_{i, t}+\varepsilon_{i, t}
\end{aligned}
$$

Descriptions of the dependent variable, RET, and main independent variables, $X$ and $X 2$, are provided in Section 3.2. $\boldsymbol{Z}$ constitutes a vector of control variables and various fixed effects. We include past earnings (lagged $X$ ), and future returns $\left(R 2_{i, t}\right)$, and interactions of these variables with Treat and Post dummies, to account for possible under or over-reaction to past and current earnings. To control for firm size, we include the inverse of market value of equity (invME). We also control for book-to-market (BTM), negative earnings $(L O S S)$ and institutional ownership $(I O){ }^{9}$

Hypothesis 1A predicts that common ownership is positively associated with the level of price informativeness because common owners' information activities help information in future earnings become quickly reflected in current share prices. We, therefore, predict that the coefficient on our main variable of interest, $X 2 \times$ Post $\times$ Treat will be positive. To the extent that future earnings news is impounded into prices, current earnings are likely to become less value-relevant. If, for example, investors fully anticipate future earnings, then they would choose to rely less on current earnings to make trading decisions. Consistent with this argument, we predict that the coefficient on $X 2 \times$ Post $\times$ Treat will be negative.

Table 3 reports the results of our analysis. We include firm and year fixed effects to account for unobserved heterogeneity across firms and years. A firm may serve as a treatment firm in one merger and/or a control firm in another merger. Therefore, we also use merger fixed effects to mitigate concerns related to unobserved merger-specific heterogeneity in treatment/control firms, as well as institution-specific

\footnotetext{
${ }^{8}$ To estimate Equation (4), we use a sample period that spans from $t-4$ to $t-2$ and $t+1$ to $t+3$ as the pre- and post-merger periods to avoid any overlap in the construction of the explanatory variables, $X 2$ and $R 2$. For other DiD tests, we use $t-3$ to $t-1$ and $t+1$ to $t+3$ as the pre- and post-merger periods.

${ }^{9} \mathrm{IO}$ represents an orthogonalized institutional ownership measure. First, we obtain residuals from a regression of total institutional ownership on CrossDummy and TotalCrossOwn. Then, we rank the residuals into decile and scale the decile scores at zero to one to obtain $I O$.
} 
investment styles or management skills. We base our discussion on the most stringent fixed effects structure, which consists of Firm $\times$ Merger and Year $\times$ Merger interaction variables, presented in columns (9) and (10). Our results, however, are similar when we rely on different fixed effect structures that are presented in columns $(1)-(8)$.

In Column (10), the coefficient on future earnings, $X 2$, is estimated to be $0.753(p<0.01)$, suggesting that current returns are positively associated with future earnings during the pre-merger period. The coefficient on $X 2 \times$ Post is not statistically significant, suggesting that, as expected, mergers appear to have no impact on the extent to which share prices of control firms reflect future earnings. Importantly, the coefficient estimate for the interaction term, X2 $\times$ Post $\times$ Treat, equals $1.977(p<0.05)$, which indicates that firms that undergo a shock to common ownership experience a significant increase in the degree to which their share prices reflect future earnings information. The coefficient is economically significant, implying that a one percent increase in future earnings leads to return that are approximately two percentage points greater for treatment firms compared to control firms during the post-merger period. ${ }^{10}$

We additionally find that share prices react to contemporaneous earnings to a lesser degree for treatment firms, relative to control firms during the post-merger period. Specifically, in Column (10), the coefficient estimate on the interaction variable, $X \times$ Post $\times$ Treat, equals $-3.219(p<0.05)$. These results, together with the positive coefficient on $X 2 \times$ Post $\times$ Treat, indicate that share prices become more forward looking and current earnings news becomes less relevant when common ownership increases. ${ }^{11}$ Overall, our inferences from the DiD analyses provide evidence in support of a causal link between common ownership and price informativeness with respect to future earnings.

\footnotetext{
${ }^{10}$ Under the assumption of perfect foresight and the price-to-earnings ratio of 10 , a $1 \%$ increase in future earnings will lead to a $10 \%$ increase in current return. Therefore, the coefficient of two implies $20 \%$ of the future earnings information is reflected in the current prices.

${ }^{11}$ Lundholm and Myers (2002) find that more disclosure activity 'brings the future forward', therefore stock returns depend more on future earnings news and less on current earnings.
} 


\subsection{Variance Ratios}

In this section, we use variance ratios, defined in Eq. (1), as an alternative measure of price efficiency. Variance ratios measure the transitory component of stock prices. If stock prices are affected by liquidity trading, the price movements are more likely to be temporary, inducing a negative autocorrelation. Similarly, under-reaction of stock prices to news, due to the obscure information environment, would result in a positive autocorrelation. However, if stock price movements are due to fundamental information, the price movements will follow a random walk. The variance ratio, therefore, is lower for firms with more efficient stock prices.

According to Hypothesis $1 \mathrm{~A}$, share prices of companies with greater common ownership are more efficient than firms with less common ownership. To test the effect of common ownership on variance ratios, we estimate following regression model:

$$
V R_{i, q}=\beta_{1} \text { Treat }+\beta_{2} \text { Post }+\beta_{3} \text { Treat } \times \text { Post }+\gamma^{\prime} Z_{i, q}+\varepsilon_{i . q}
$$

where $V R_{i, q}$ is the variance ratio for firm $i$ in quarter $q$, and $\mathbf{Z}$ is a vector of control variables. The sample period is $t-3$ to $t-1$ and $t+1$ to $t+3$, where $t$ is the merger announcement year. Based on the hypothesis that common ownership enhances price efficiency, we expect $\beta_{3}$ to be negative. The estimation results of Equation (3), reported in Table 4, are consistent with this prediction.

All specifications in Table 4 reveal a statistically significant decline in variance ratios for treatment firms' during the post-merger period. In Column (10), for example, we find that the coefficient on Treat $\times$ Post is estimated to be $-0.017(p<0.05)$. This coefficient is economically meaningful, implying a 5.4 percent decrease compared to the average variance ratio (7.3 percent of the standard deviation). These findings suggest that stock prices of commonly held firms are more efficient and less likely to be affected by trading activities of liquidity investors. 


\section{Channels: How Does Common Ownership Increase Price Efficiency?}

A natural follow-up question to our findings thus-far is "how does common ownership increase price efficiency?" In this section, we identify channels through which common ownership increases firms' price informativeness. First, we examine whether cross-holding institutions enhance the information flow between peer companies by exploiting cross-sectional variations in the geographical and social distance between connected firms. We, then, investigate whether there is a significant increase in informed trading activities for firms with higher common ownership. Finally, we examine whether the increase in price informativeness is related to the actual trading activities of cross-holding institutions.

\subsection{Geographical Distance and Social Connectedness}

Do common owners contribute to the flow of information between connected firms? Common owners are institutional investors who hold sizeable stakes in multiple companies in the same industry. Therefore, once two companies become connected through a common owner, information diffusion between commonlyheld firms is additionally facilitated by the common owner, which is likely to produce efficiency gains. In addition, this improvement in efficiency would be more pronounced among firms for which information diffusion was previously difficult due to frictions. We, therefore, conjecture that the efficiency gain due to common ownership is stronger for firms that have higher information frictions. Testing this conjecture requires a measure of friction.

We estimate the frictions in information diffusion using the geographical distance and level of social connectedness between firms that are commonly owned. Prior evidence indicates that information spreads between geographically close investors and that geographically proximate investors have an informational advantage over remote investors (Coval and Moskowitz 1999, 2001; Hong Kubik and Stein 2005; Malloy 2005). In addition to geographical distance, social networks help overcome informational and 
cultural frictions in investment and trades (Hong, Kubik and Stein 2004); Bailey, Cao, Kuchler, Stroebel and Wong 2018).

When a firm and its peers are geographically distant, information transfer among these firms is costlier (Jennings et al. 2017). For example, let us assume that Firm A and Firm B are in the same industry, but geographically remote (or have weak social connectedness). An investor, who has an information advantage for Firm A due to geographical proximity, produces private information regarding Firm A that is pertinent for Firm B. However, she is unfamiliar with Firm B, and lacks incentive to use the information to trade shares of Firm B. Now assume a cross-holding institution that block-holds both firms. Since the cross-holding institution has sizeable stakes in both firms, it has stronger incentive to use the information obtained about Firm A to trade shares of Firm B. The cross-holding institution, therefore, helps information flow between the two firms, and such information can now be impounded into the stock price of Firm B. Based on the intuition above, we expect to find a stronger efficiency gain in treatment firms where geographical distance (social connection) is larger (weaker) before the merger.

The analysis in Table 5 tests this conjecture. We re-define the treatment group from the subsample of firms in the original treatment group that are above (below) median of the geographical distance (or social connectedness) during the year immediately before the merger announcement year. The geographical distance (social connectedness) is the distance (proportion of friendship links) between treatment firms that are connected through an institution merger. Geographical distance is measured based on the ZIP codes of headquarters of connected firms. ${ }^{12}$ We measure social connectedness using the Social Connectedness Index (SCI) developed by Bailey, Cao, Kuchler, Stroebel and Wong (2018). SCI uses Facebook data to measure the frequency of friendship links between users located in different U.S. counties. The index values are normalized to facilitate comparison across county-pairs and provide a measure of the relative differences in the total number of friendship links.

\footnotetext{
${ }^{12}$ We obtain ZIP code data from the SEC filings to ensure that we identify the historical location of the companies in our sample. When the ZIP code is unavailable through this approach, however, we use Compustat ZIP code data.
} 
Table 5 Panels A and B use geographical distance as a proxy for information friction. Panel A reports the results of regressions of returns on future earnings (Eq 2) and Panel B presents the estimation results of the variance ratio regression model (Eq 3). For Columns (1) through (4), Treat is an indicator variable that equals one if a firm is identified as a treatment with below median geographical distant peers and zero otherwise, while for Columns (5) through (8), Treat is an indicator variable that equals one if a firm is identified as a treatment with above median geographical distant peers and zero otherwise.

The estimation results show that future earnings information is impounded into current returns more efficiently for firms with distant peers (Panel A) and that the reduction in variance ratios is greater for treatment firms for which peer firms are geographically distant from each other (Panel B). These results, collectively, show that our key inferences are driven by treatment firms with geographically remote peers.

In Panels $\mathrm{C}$ and $\mathrm{D}$, we repeat our analyses using the SCI as our proxy for friction in information flow. Similar to Panels A and B, we divide the treatment firms based on the median value of social connectedness with their peers. Our analysis based on the social connection measure produces results that are similar to those based on geographical distance. We find that current returns become more informative with respect to future earnings information for treatment firms with weaker social connectedness. Similarly, variance ratios decline more for treatment firms with less socially connected peers. A comparison of the magnitudes of coefficients reported in Table 5 with those in Tables 3 and 4 suggests that results are primarily driven by the treatment sample with distant peers and less socially connected peers. Our findings suggest that common ownership enhances information flow between firms for which information flow was previously more difficult due to higher information frictions.

\subsection{Probability of Informed Trading (PIN) and Bid-Ask Spread}

In this section, we examine the information environment of treatment firms after financial institution mergers. Block-holders have strong incentives to gather information concerning the fundamental value of 
a firm and trade based on that information, inducing prices to reflect more of the fundamental value (Edmans 2009). Moreover, Bushee and Goodman (2007) and Maffett (2012) argue that large institutional investors can execute profitable trades based on their private information. A cross block-holding institution, being a block-holder of one firm and a same-industry peer at the same time, can generate informational advantages over other investors. We, therefore, hypothesize that common owners develop competitive advantages in acquiring and processing information by having access to and spreading their aggregate information costs across a larger number of firms in the same industry. Given these advantages, the presence of common owners in a firm may induce more informed trading for the firm.

Panel A of Table 6 examines whether common ownership increases the likelihood of informed trading. We regress the probability of informed trading (PIN) on Treat and Post indicators along with other control variables and fixed effects. PIN is calculated following Chen, Goldstein and Jiang's (2007) approach. Treat and Post represent indicator variables as defined in Section 4. The sample period is $t-3$ to $t-1$ year and $t+1$ to $t+3$, where $t$ is the merger announcement year.

We find that the probability of informed trading significantly increases for the treatment firms after the merger relative to control firms. In Column (8) we find that treatment firm's PIN increases by 0.015 ( $p$ $<0.05)$ more than the control group during the post-merger period. This implies treatment firms experience a $8.6 \%$ increase compared to its mean (a $15.8 \%$ increase compared to its standard deviation) during the post-merger period. These results are robust throughout various specifications.

In Panel B, we use bid-ask spreads as the dependent variable. The extant literature shows that informed trading is associated with lower bid-ask spread (e.g., Colllin-Dufresne and Fos 2015 and Admati and Pfleiderer 1988). In particular, Kacperczyk and Pagnotta (2019) argue that if market markers learn from informed traders fast enough, then the bid-ask spread is lower on average with the presence of informed trading. Moreover, Park et al. (2019) find that common ownership encourages firms to disclose more information voluntarily, potentially reducing information asymmetry. Based on these arguments, we hypothesize that common ownership reduces information asymmetry (adverse selection). 
Consistent with this hypothesis, we find that the bid-ask spread decreases for treatment firms compared to control firms in the post-merger period. For example, Model (9) shows that, on average, the bid-ask spread of treatment firms is smaller by $-0.010(p<0.05)$ compared to control firms' post-merger period. Overall, our results in Table 6 imply that common ownership induces more informed trading and reduces information asymmetry.

\subsection{Holdings Changes and Stock Returns}

In an effort to shed more light on how common owners' information is impounded into stock prices, we further examine whether trading activities of common owners are related to price efficiency. If, as we predict, cross-holding institutions produce more information, then their trades should be more strongly correlated with contemporaneous returns. To empirically test this conjecture, we investigate the contemporaneous relation between stock returns and the trading activities of the merging institutions.

We examine whether merging institutions' trading activities are more informative for treatment firms during the post-merger period compared to control firms. Specifically, we estimate the following empirical model:

$$
\begin{gathered}
\text { Ret }_{i, t}=\beta_{1} \Delta H_{i, t}+\beta_{2} \Delta H_{i, t} \times \text { Post }+\beta_{3} \Delta H_{i, t} \times \text { Treat }+\beta_{4} \Delta H_{i, t} \times \text { Treat } \times \text { Post } \\
+\beta_{5} \text { Treat } \times \text { Treat }+\beta_{6} \text { Treat }+\beta_{7} \text { Post }+\Gamma^{\prime} Z_{i, t}+\varepsilon_{i, t}
\end{gathered}
$$

where the holding change $(\Delta H)$ of a merging institution for firm $i$ is defined as $H_{i, t}-H_{i, t-l}$ and $H_{i, t}$ equals the percentage holding by the institution in year $t$ of firm $i$. In Equation (4), the main parameter of interest is the coefficient on $\Delta H_{i, t} \times$ Treat $\times$ Post. A positive coefficient on this interaction variable would imply that merged institutions' trading activities are more informative for treatment firms relative to control firms after mergers. 
Table 7 reports the estimation results of Equation (4). The coefficients on holdings changes $(\Delta H)$ are estimated to be statistically indistinguishable from zero in all models. These results imply that trades of merged institution are unrelated to the returns of the sample firms during the pre-merger period. In contrast, the coefficients on the interaction variable, $\Delta H_{i, t} \times$ Treat $\times$ Post, are positive and statistically significant in all specifications, implying that trading activities of merged institutions are more positively correlated with returns of treatment firms relative to control firms during the post-merger period. These results suggest that the trades of institutions that become common owners as a result of mergers begin to convey more information after mergers. As a result, stock prices of treatment firms become more informative. Our findings, in this section, point towards trading activities as a mechanism through which common ownership enhances price efficiency. ${ }^{13}$

\subsection{Active Trading and Price Informativeness}

In this section we directly examine the relation between price informativeness and the trading activity of merging institutions. If trading by cross-holding institutions help share prices become more informative, we should observe the increase in price efficiency to be more prominent among treatment firms for which there is more active trading.

To test this relation, we divide the sample of treatment firms into two groups; firms with higher level of active trading by merging institutions, and firms with lower level of active trading. Specifically, we introduce an indicator variable, "Above" ("Below"), that equals one if the absolute value of holdings changes $(|\Delta H|)$ by the merging institution during year (quarter) $t$ is above (below) the median value, zero

\footnotetext{
${ }^{13}$ We acknowledge that post-merger holding changes of merging institutions may be related to some unobservable that is specific to the mergers, such as liquidity needs or institutions' portfolio objectives. Therefore, one may argue that using the information about merging institutions' holdings may raise an endogeneity concern. However, we think our results are unlikely to suffer from this endogeneity concern for the following reasons. First, the treatment firms are determined based on pre-merger information, rather than post-merger holdings information. Second, post-merger holding changes that are motivated by non-fundamental reasons, such as portfolio rebalancing due to fund policies, mostly occur in year $t$, which is omitted from our analysis. Finally, if trading activities for treatment firms are not motivated by fundamental information, $\beta_{4}$ is likely to be biased down, which would go against finding the results.
} 
otherwise. ${ }^{14} \mathrm{We}$, then, interact the variable Above (Below) with Treat to analyze whether the effect of common ownership is stronger in the subsample of treatment firms that are above (below) the median of $|\Delta H|$.

Table 8 Panel A reports the DiD regression results of stock returns on future earnings. We find that stock prices of treatment firms with active trading institutions incorporate future earnings information more efficiently. The coefficients on $X 2 \times$ Treat $\times$ Post $\times$ Above are positive and statistically significant in all specifications. Conversely, for treatment firms with below median trading activities, the coefficient on the interaction variable is not statistically significant, implying that the efficiency gains come, primarily, from treatment firms for which institutions actively trade.

Panel B reports regression results for variance ratios. Both treatment groups with above and below median level of active trading activities display a significant decrease in variance ratio. However, the magnitude of the coefficient estimates are higher for the "Above" treatment group. Model (8), for example, shows that the coefficient for the "Above" group is -0.032 and statistically significant at the one-percent significance level, while the coefficient of "Below" is two thirds of the "Above" group in absolute terms at a ten-percent significance level. The differential in magnitudes between the two interaction variables is also evident in other model specifications, although to a smaller degree.

Overall, our analyses show that common owners' active trading enhances the efficiency of treatment firms' share prices. We conclude that cross-holding institutions help facilitate information flow between connected peers through their trading activities, which leads to more informative stock prices.

\footnotetext{
${ }^{14}$ Note that by using the absolute value of holdings change, we focus on the level of trading activities rather than the direction of those activities.
} 


\section{Investment-to- $Q$ Sensitivity}

To the extent that common ownership has a positive effect on the price efficiency of a firm's share prices, managers are more likely to rely on stock prices as they make managerial decisions. In this section, we examine whether the effect of common ownership on price informativeness has real consequences on one of the most important corporate policy decisions that managers make: investments. Specifically, we examine whether the investment-to- $Q$ sensitivity changes due to institutional common ownership.

As we did with prior analyses, we use a quasi-natural experiment based on financial institution mergers to produce evidence relevant to our understanding of the causal relation between common ownership and investment-to- $Q$ sensitivity. Specifically, we estimate the $\mathrm{DiD}$ regression presented below:

$$
\begin{aligned}
\text { Investment }_{i, t} & =\beta_{1} Q_{i, t-1}+\beta_{2} \text { Treat } \times Q_{i, t-1}+\beta_{3} \text { Post } \times Q_{i, t-1}+\beta_{4} \text { Treat } \times \text { Post } \times Q_{i, t-1} \\
& +\beta_{5} \text { Treat }+\beta_{6} \text { Post }+\beta_{7} \text { Treat } \times \text { Post }+\gamma^{\prime} Z_{i, t}+\varepsilon_{i, t}
\end{aligned}
$$

Table 9 reports the results of regressing the four investment measures on Tobin's $Q$, Treat, Post and the interactions among these variables along with control variables. We use CAPXRND, Investment, $R \& D$, and DisExp as measures of corporate investment. The sample periods are $t-3$ to $t-1$ (pre-merger period) and $t+1$ to $t+3$ (post-merger period), where year $t$ is the merger announcement year.

Our primary variable of interest in Table 9 is the triple interaction term, Treat $\times$ Post $\times Q$. The coefficient on this variable is positive and statistically significant for all four investment proxies. The positive and statistically significant coefficients indicate that treatment firms experience an increase in their investment-to- $Q$ sensitivity following shocks to common ownership, relative to control firms. For instance, when we include Firm $\times$ Merger and Year $\times$ Merger fixed effects, investment-to- $Q$ sensitivity increases for treatment firms by $3.545(p<0.1), 5.917(p<0.1), 3.598(p<0.05)$, and $3.855(p<0.05)$ for each of the investment measures. Overall, our results support the conclusion that managers of commonly held companies rely to a greater extent on stock prices when making investment decisions. Combining our 
results in the previous sections, we argue that as firms' share prices become more efficient due to common ownership, managers rely more on stock prices, leading to a greater investment-to- $Q$ sensitivity.

\section{Robustness Checks and Falsification Tests}

In this section, we conduct a series of robustness tests. First, we construct an alternative control sample to mitigate concerns of control firms in the main analyses being in different industries from the treatment firms. Therefore, following Lewellen and Lowry (2019), we construct an alternative control sample based on size and industry. For each treatment firm, we first select firms in the same four-digit SIC industry but not block-held by the merging institutions. We then match the five firms closest in size to each treatment firm. Since firms that are in different industries might face different information environments, our robustness check ensures that the informational efficiency gain due to common ownership is not driven by differences in industry or size between treatment and control firms. We re-estimate our DiD analyses using this alternative control sample and report our results in Table 10.

Panel A of Table 10 presents the estimation results of regressing annual returns on current and future earnings, as we did previously (Table 3), using the alternative control sample. We find that treatment firms experience an increase in price informativeness. Specifically, their share prices begin to reflect future earnings more efficiently after an increase in common ownership. In Panel B, we conduct the variance ratio test using the alternative control sample. We find that treatment firms experience a significant decrease in their variance ratio after mergers, which is consistent with our main analysis in Table 4. In Panel C, we also examine whether our findings regarding the investment-to- $Q$ sensitivity analyses are robust to different control sample choices. We find robust evidence suggesting that increases in common ownership leads to a stronger investment-to- $Q$ sensitivity. Our results, overall, are robust to the use of a different control sample. 
We, next, perform a placebo (falsification) test by using the $t-4$ period as the "pseudo-event" year. The main objective of the falsification test is to provide assurance that the parallel trend assumption is not violated in our DiD setting. We define $t-4$ as the "psuedo-event" year and re-define the POST dummy such that it equals one for years $t-3$ through $t-1$ and zero for years $t-7$ through $t-5$. Re-defining the time periods allows us to check whether there are any pre-trends and/or differences between treatment and control firms during the seven years prior to the actual event year. We use the same set of control and treatment firms as in Tables 3, 4, and 9. These results are reported in Table 11.

We find no significant relation between future earnings and stock returns for treatment firms after we re-define the POST variable. The triple interaction term, $X 2 \times$ Post $\times$ Treat, is not statistically significant in any of the models. These results show that the extent to which information in future earnings is incorporated into stock prices does not differ between treatment and control firms after the "pseudo-event" year. In Panel B, we report results for variance ratios. We find that the coefficient for Treat $\times$ Post is also not statistically significant in any of the specifications. In Panel $\mathrm{C}$, we examine the investment-to- $Q$ sensitivity and find no significant difference between treatment and control firms during the re-defined post period. Overall, our evidence in Table 11 supports the conclusion that there are no significant differences between treatment and control firms in price informativeness and investment-to- $Q$ sensitivity in years prior to the actual event year.

Lewellen and Lowry (2019) argue that the effects researchers attribute to common ownership in the current literature are driven by differential responses by firms to the financial crisis. To address this concern, we exclude the financial crisis period and re-estimate our analyses. Specifically, we estimate the main difference-in-difference test, excluding the institutional mergers for which effective dates are in the period of the financial crisis. We define the financial crisis period as the period of $07 / 2007$ to $12 / 2009$. Table 12 reports these estimation results. In Panel A, our results suggest that returns of treatment firms reflect more of future earnings information during the post-merger period. Panel B reports a significant and negative coefficients on Post $\times$ Treat, indicating that our results on the variance ratio are not sensitive to 
the exclusion of the financial crisis period. Lastly, the results of the investment-to- $Q$ sensitivity analysis are unaffected by excluding mergers that took place during the financial crisis period. Overall, our results are not driven by a differential rate of recovery from the financial crisis.

\section{Conclusion}

This paper investigates the effect of common ownership on share price efficiency and corporate investment. Using financial institution mergers as a source of identification, we find that positive shocks to common ownership lead to a stronger relation between current stock returns and future earnings news. Hence, stock prices of commonly held firms appear to reflect a greater amount of future earnings news. We also show that common ownership is associated with a reduction in variance ratios, suggesting that share prices of commonly held firms are less influenced by noise traders or short-term liquidity shock. These findings suggest that common ownership has a positive effect on price informativeness.

We investigate the potential mechanisms through which common ownership can affect price efficiency. Among treatment firms, geographically and socially distant peers experience greater postmerger efficiency gain. The probability of informed trading increases for treatment firms, and trading activities of merging institutions are more informative for treatment firms. In addition, the post-merger efficiency gain is greater for treatment firms for which merging institutions actively trade. These results suggest that common owners contribute to price efficiency by facilitating information diffusion and informed trading.

Finally, we ask whether managers of commonly held companies rely more on share prices in making investment decisions. We document a positive link between common ownership and investmentto- $Q$ sensitivity, indicating that common owners influence managers' investment decision by affecting price informativeness. 


\section{References}

Admati, A. R., and Pfleiderer, P., 1988, Selling and trading on information in financial markets. American Economic Review 78, 96-103.

Anton, M., Ederer, F., Gine M., and Schmalz, M. C., 2016, Common ownership, competition and top management incentives. Working Paper.

Antoniou, C., Subrahmanyam A., and Tosun, O. K., 2018, ETF Ownership and corporate investment. Working Paper.

Appel, I. R., Gormley T., and Keim., D., 2016, Passive investors, not passive owners. Journal of Financial Economics 121, 111-141.

Azar, J., Schmalz, M.C., and Tecu, I., 2018, Anticompetitive effects of common ownership. Journal of Finance 73, 1513-1565.

Bailey, M., Cao, R., Kuchler, T., Stroebel, J., and Wong, A., 2018, Social connectedness: measurement, determinants, and effects. Journal of Economic Perspectives 32, 259-280.

Ben-David, I., Franzoni, F., and Moussawi, R., 2018, Do ETFs increase volatility?. Journal of Finance 73, 2471-2535.

Ben-David, I., Franzoni, F., Moussawi, R., and Sedunov, J., 2018, The granular nature of large instituitonal investors. Working Paper.

Boehmer, E., and Kelley, E. K., 2009, Institutional investors and the informational efficiency of prices. Review of Financial Studies 22, 3563-3594.

Bond, P., and Garcia, D., 2018, The equilibrium consequences of indexing. Working paper.

Boone, A. L., and White, J. W., 2015, The effect of institutional ownership on firm transparency and information production. Journal of Financial Economics 117, 508-533.

Bushee, B. J., and Goodman, T. H., 2007, Which institutional investors trade based on private information about earnings and returns?. Journal of Accounting Research 45, 289-321.

Breugem, M., Buss, A., and Peress, J., 2019, Learning from interest rates: Implications for stock-market efficiency. Working Paper

Chemmanur, T., Shen, Y., and Xie, J., 2016, Innovation beyond firm boundaries : Common blockholders, strategic alliances, and corporate innovation. Working paper.

Chen, Q., Goldstein, I., and Jiang, W., 2007, Price informativeness and investment sensitivity to stock price. Review of Financial Studies 20, 619-650. 
Collin-Dufresne, P., and Fos, V., 2015, Do prices reveal the presence of informed trading? Journal of Finance 70, 1555-1582.

Coval, J. D., and Moskowitz, T. J., 1999, Home bias at home: Local equity preference in domestic portfolios. Journal of Finance 54, 2045-2073.

Coval, J. D., and Moskowitz, T. J., 2001, The geography of investment: Informed trading and asset prices. Journal of political Economy 109, 811-841.

Coval, J., and Stafford, E., 2007, Asset fire sales (and purchases) in equity markets. Journal of Financial Economics 86, 479-512.

Dimson, E., Karakaş, O. and Li, X., 2015, Active ownership. Review of Financial Studies 28, 3225-3268.

Dow, J., Goldstein, I., and Guembel, A., 2006, Commitment to overinvest and price informativeness. Working Paper.

Dye, R. A., and Sridhar, S. S., 2002, Resource allocation effects of price reactions to disclosures. Contemporary Accounting Research 19, 385-410.

Edmans, A., 2009, Blockholder trading, market efficiency, and managerial myopia. Journal of Finance 64, 2481-2513.

Edmans, A., Jayaraman, S. and Schneemeier, J., 2017, The source of information in prices and investmentprice sensitivity. Journal of Financial Economics 126, 74-96.

Edmans, A., Levit, D., and Reilly, D., 2016, Governing multiple firms. Working Paper.

Engelberg, J., Ozoguz, A., and Wang, S. 2018, Know thy neighbor: Industry clusters, information spillovers, and market efficiency. Journal of Financial and Quantitative Analysis 53, 1937-1961.

Glosten, L., Nallareddy, S., and Zou, Y. 2016, ETF trading and informational efficiency of underlying securities. Working Paper.

Grossman, S. J., and Stiglitz, J. E., 1980, On the impossibility of informationally efficient markets. American Economic Review 70, 393-408.

He, J. J., and Huang, J., 2017, Product market competition in a world of cross ownership: Evidence from institutional blockholdings. Review of Financial Studies 30, 2674-2718.

He, J. J., Huang, J. and Zhao, S., 2019, Internalizing governance externalities: The role of institutional cross-ownership. Journal of Financial Economics 134, 400-418.

Holthausen, R.W., Leftwich, R.W. and Mayers, D., 1990, Large-block transactions, the speed of response, and temporary and permanent stock-price effects. Journal of Financial Economics 26, 71-95.

Hong, H., Kubik, J. D., and Stein, J. C., 2004, Social interaction and stock-market participation. Journal of 
Finance 59, 137-163.

Hong, H., Kubik, J. D., and Stein, J. C., 2005, Thy neighbor's portfolio: Word-of-mouth effects in the holdings and trades of money managers. Journal of Finance 60, 2801-2824.

Israeli, D., Lee, C.M., and Sridharan, S.A., 2017, Is there a dark side to exchange traded funds? An information perspective. Review of Accounting Studies 22, 1048-1083.

Ivković, Z., and Weisbenner, S., 2005, Local does as local is: Information content of the geography of individual investors' common stock investments. Journal of Finance 60, 267-306.

Jennings, J., Lee, J., and Matsumoto, D. A., 2017, The effect of industry co-location on analysts' information acquisition costs. The Accounting Review 92, 103-127.

Kacperczyk, M. T., Nosal, J. B., and Sundaresan, S., 2018, Market power and price informativeness. Working Paper

Kacperczyk, M. T., and Pagnotta, E., 2019, Becker meets Kyle: Inside insider trading. Working Paper

Kacperczyk, M., Sialm, C. and Zheng, L., 2005, On the industry concentration of actively managed equity mutual funds. Journal of Finance 60, 1983-2011.

Kostovetsky, L., and Manconi, A., 2016, Common institutional ownership and diffusion of innovation. Working Paper.

Lewellen, K., and Lowry, M., 2018, Does common ownership really increase firm coordination? Working Paper.

Lo, A. W., and MacKinlay, A.C., 1988, Stock market prices do not follow random walks: Evidence from a simple specification test. Review of Financial Studies 1, 41-66.

Lou, D., 2012, A flow-based explanation for return predictability. Review of Financial Studies 25, 34573489.

Lou, X., and Wang, A. Y., 2018, Flow-induced trading pressure and corporate investment. Journal of Financial and Quantitative Analysis 53, 171-201.

Lundholm, R., and Myers, L.A., 2002, Bringing the future forward: The effect of disclosure on the returnsearnings relation. Journal of Accounting Research 40, 809-839.

Maffett, M., 2012, Financial reporting opacity and informed trading by international institutional investors. Journal of Accounting and Economics 54, 201-220.

Malloy, C. J., 2005, The geography of equity analysis. Journal of Finance 60, 719-755.

McCahery, J.A., Sautner, Z. and Starks, L.T., 2016, Behind the scenes: The corporate governance preferences of institutional investors. Journal of Finance 71, 2905-2932. 
O'Hara, M., and Ye, M., 2011, Is market fragmentation harming market quality?. Journal of Financial Economics 100, 459-474.

Park, J., Sani, J., Shroff, N. and White, H., 2019, Disclosure incentives when competing firms have common ownership. Journal of Accounting and Economics 67, 387-415.

Pawliczek, A., and Skinner, A. N., 2018, Common ownership and voluntary disclosure. Working Paper.

Rubin, A., 2007, Ownership level, ownership concentration and liquidity. Journal of Financial Markets 10, 219-248.

Saffi, P.A. and Sigurdsson, K., 2010, Price efficiency and short selling. Review of Financial Studies 24, 821-852.

Shroff, N., Verdi, R. S., and Yost, B. P., 2017, When does the peer information environment matter?. Journal of Accounting and Economics 64, 183-214.

Verrecchia, R. E., 1982, Information acquisition in a noisy rational expectations. Econometrica 50, 14151430.

Verrecchia, R. E., 2001, Essays on disclosure. Journal of Accounting and Economics 32, 97-180. 


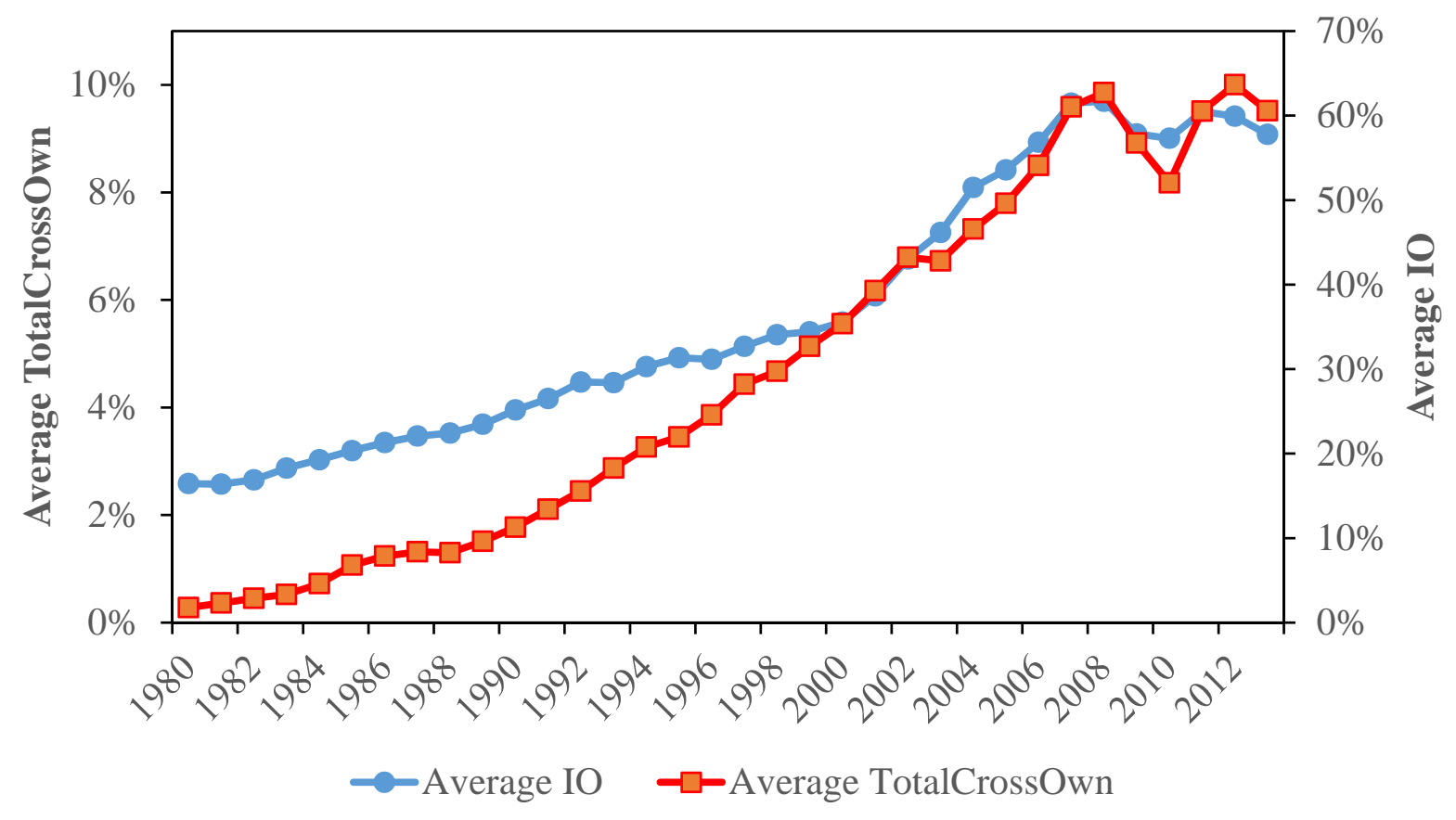

\section{Figure 1. Trends in Common Ownership}

This figure plots the trends in common ownership and total institutional ownership from 1980 to 2013. The blue line with circles plots the average institutional ownership (Average IO), while the red line with squares shows the average percentage holding by common owners (Average TotalCrossOwn). For each year, we obtain annual institutional ownership in a firm by taking average of quarterly institutional ownership of the firm. Then, Average IO for the year is calculated from the average institutional ownership across all the firms in the sample. TotalCrossOwn is the sum of percentage holdings by all cross-holding institutions in a firm. Cross-holding institution is defined as an institution that block-holds (at least 5\%) the firm and block-holds at least one same-industry peer (SIC 4 digits) in the same quarter. We first calculate TotalCrossOwn for each quarter for each firm. Then we calculate yearly average TotalCrossOwn for each firm. Then, Average TotalCrossOwn for the year is obtained from the average of TotalCrossOwn across all the firms in the sample. 
Table 1: Summary Statistics

This table provides the summary statistics of main variables in the difference-in-difference tests that use financial institution mergers during 1980-2014 as exogenous shocks to common ownership. Panel A shows the descriptive statistics of key variables, and Panel B reports the correlations. The upper right corner of Panel B reports Pearson correlations and the lower left corner of the panel provides Spearman correlations. The variable definitions are provided in Appendix A. The sample consists US public firms that are block-held by merging institutions during the period of $t-3$ to $t-1$ and $t+1$ to $t+3$, where year $t$ is the merger announcement year.

Panel A: Descriptive Statistics

\begin{tabular}{|c|c|c|c|c|c|c|c|c|c|c|c|c|c|c|c|c|c|}
\hline \multicolumn{2}{|c|}{ Variable } & \multicolumn{2}{|c|}{$\mathrm{N}$} & \multicolumn{2}{|c|}{ Mean } & \multicolumn{2}{|c|}{ STD } & \multicolumn{2}{|c|}{$\mathrm{P} 10$} & \multicolumn{2}{|c|}{$\mathrm{P} 25$} & \multicolumn{2}{|c|}{ Median } & \multicolumn{2}{|c|}{ P75 } & \multicolumn{2}{|c|}{ P90 } \\
\hline \multicolumn{2}{|c|}{ CrossDummy } & \multicolumn{2}{|c|}{15239} & \multicolumn{2}{|c|}{0.777} & \multicolumn{2}{|c|}{0.416} & 0.0 & & 1.0 & & 1. & & 1.0 & 000 & 1.0 & \\
\hline NConnec & & 152 & & 5.3 & 318 & 8. & & $0 . c$ & & 0.2 & & 2. & & 5.7 & 750 & 15. & \\
\hline NCross & & 152 & & 1.3 & 315 & 1. & & $0 . c$ & & 0.2 & & 1. & & $2 . c$ & 000 & $3 . c$ & \\
\hline AvgNur & & 152 & & $2 . \varepsilon$ & 833 & 4. & & $0 . c$ & & 0.2 & & 1. & & 3.4 & 438 & 7.5 & \\
\hline TotalCross & Own & 152 & & 0.1 & 109 & 0. & & $0 . c$ & & $0 . c$ & & 0. & & 0.1 & 169 & 0.2 & \\
\hline 10 & & 152 & & 0.6 & 694 & 0. & & 0.2 & & 0.5 & & 0. & & $0 . \varepsilon$ & 896 & 0.5 & \\
\hline RET & & 152 & & 0.1 & 175 & 0. & & -0. & & -0 . & & 0. & & 0.3 & 351 & 0.7 & \\
\hline$x$ & & 152 & & $0 . c$ & 007 & 0. & & -0 . & & $0 . c$ & & 0. & & $0 . c$ & 075 & 0.1 & \\
\hline R2 & & 132 & & 0.3 & 329 & 0. & & 0.1 & & 0. & & 0. & & 0.4 & 497 & 0.6 & \\
\hline$x 2$ & & 144 & & 0.0 & 044 & 0. & & -0 . & & -0 . & & 0. & & 0.1 & 171 & 0.2 & \\
\hline SIZE & & 152 & & 13. & 154 & 1. & & 11. & & 12. & & 13 & & 14. & 142 & 15. & \\
\hline BTM & & 147 & & -0. & 699 & 0. & & -1 . & & -1 . & & -0 & & -0 & 199 & 0.2 & \\
\hline$Q$ & & 127 & & $1 . \varepsilon$ & 891 & 1. & & 0.5 & & 1. & & 1. & & 2.1 & 101 & 3.2 & \\
\hline CAPXRN & & 130 & & 10. & 682 & 12 & & 1.7 & & 3.5 & & 7. & & 13. & 358 & 22. & \\
\hline Investme & & 131 & & 14. & 469 & 19 & & $2 .($ & & 4.5 & & 9. & & 17. & 936 & 31. & \\
\hline RND & & 131 & & 4.2 & 492 & 9. & & $0 . c$ & & $0 . c$ & & 0. & & 5.2 & 258 & 14. & \\
\hline DisExp & & 131 & & & 961 & & & $0 . c$ & & $0 . c$ & & 2. & & 7.6 & 692 & 16. & \\
\hline VR & & 445 & & 0.3 & 314 & 0. & & 0.6 & & 0. & & 0. & & 0.4 & 453 & 0.6 & \\
\hline Panel B: Correlat & tions & & & & & & & & & & & & & & & & \\
\hline Variable & CrossDummy & NConnected & NCross & AvgNum & TotalCrossOwn & 10 & RET & $\mathrm{x}$ & $\mathrm{R} 2$ & $\mathrm{X} 2$ & SIZE & BTM & $\mathrm{Q}$ & CAPXRND & Investment & RND & DisExp \\
\hline CrossDummy & & 0.321 & 0.581 & 0.368 & 0.551 & 0.341 & -0.038 & -0.026 & 0.105 & -0.018 & 0.173 & -0.007 & -0.015 & 0.018 & 0.014 & 0.074 & 0.048 \\
\hline & & {$[0.00]$} & {$[0.00]$} & {$[0.00]$} & {$[0.00]$} & {$[0.00]$} & {$[0.00]$} & {$[0.00]$} & {$[0.00]$} & {$[0.03]$} & {$[0.00]$} & {$[0.41]$} & {$[0.09]$} & {$[0.05]$} & {$[0.12]$} & {$[0.00]$} & {$[0.00]$} \\
\hline NConnected & 0.725 & & 0.660 & 0.904 & 0.628 & 0.208 & -0.026 & -0.048 & 0.014 & -0.027 & 0.112 & -0.095 & 0.110 & 0.221 & 0.144 & 0.321 & 0.267 \\
\hline & {$[0.00]$} & & {$[0.00]$} & {$[0.00]$} & {$[0.00]$} & {$[0.00]$} & {$[0.00]$} & {$[0.00]$} & {$[0.12]$} & {$[0.00]$} & {$[0.00]$} & {$[0.00]$} & {$[0.00]$} & {$[0.00]$} & {$[0.00]$} & {$[0.00]$} & {$[0.00]$} \\
\hline NCross & 0.726 & 0.891 & & 0.502 & 0.953 & 0.392 & -0.054 & -0.044 & 0.082 & -0.033 & 0.127 & 0.014 & 0.006 & 0.066 & 0.044 & 0.150 & 0.112 \\
\hline & {$[0.00]$} & {$[0.00]$} & & {$[0.00]$} & {$[0.00]$} & {$[0.00]$} & {$[0.00]$} & {$[0.00]$} & {$[0.00]$} & {$[0.00]$} & {$[0.00]$} & {$[0.10]$} & {$[0.48]$} & {$[0.00]$} & {$[0.00]$} & {$[0.00]$} & {$[0.00]$} \\
\hline AvgNum & 0.725 & 0.982 & 0.820 & & 0.477 & 0.160 & -0.018 & -0.045 & 0.019 & -0.021 & 0.116 & -0.090 & 0.105 & 0.213 & 0.136 & 0.300 & 0.248 \\
\hline & {$[0.00]$} & {$[0.00]$} & {$[0.00]$} & & {$[0.00]$} & {$[0.00]$} & {$[0.03]$} & {$[0.00]$} & {$[0.03]$} & {$[0.01]$} & {$[0.00]$} & {$[0.00]$} & {$[0.00]$} & {$[0.00]$} & {$[0.00]$} & {$[0.00]$} & [0.00] \\
\hline TotalCrossOwn & 0.725 & 0.871 & 0.974 & 0.805 & & 0.387 & -0.053 & -0.063 & 0.055 & -0.055 & 0.111 & 0.005 & 0.019 & 0.075 & 0.042 & 0.157 & 0.120 \\
\hline & {$[0.00]$} & {$[0.00]$} & {$[0.00]$} & {$[0.00]$} & & {$[0.00]$} & {$[0.00]$} & {$[0.00]$} & {$[0.00]$} & {$[0.00]$} & {$[0.00]$} & {$[0.52]$} & {$[0.04]$} & {$[0.00]$} & {$[0.00]$} & {$[0.00]$} & {$[0.00]$} \\
\hline 10 & 0.328 & 0.339 & 0.424 & 0.302 & 0.417 & & -0.047 & 0.134 & 0.396 & -0.052 & 0.528 & -0.119 & 0.025 & -0.140 & -0.069 & -0.102 & -0.090 \\
\hline & {$[0.00]$} & {$[0.00]$} & {$[0.00]$} & {$[0.00]$} & {$[0.00]$} & & {$[0.00]$} & {$[0.00]$} & {$[0.00]$} & {$[0.00]$} & {$[0.00]$} & {$[0.00]$} & {$[0.00]$} & {$[0.00]$} & {$[0.00]$} & {$[0.00]$} & {$[0.00]$} \\
\hline RET & -0.043 & -0.053 & -0.061 & -0.045 & -0.066 & -0.009 & & 0.002 & 0.026 & 0.099 & -0.163 & 0.135 & 0.234 & 0.120 & 0.116 & 0.063 & 0.075 \\
\hline & {$[0.00]$} & {$[0.00]$} & {$[0.00]$} & {$[0.00]$} & {$[0.00]$} & {$[0.28]$} & & {$[0.84]$} & {$[0.00]$} & {$[0.00]$} & {$[0.00]$} & {$[0.00]$} & {$[0.00]$} & {$[0.00]$} & {$[0.00]$} & {$[0.00]$} & {$[0.00]$} \\
\hline$x$ & -0.076 & -0.140 & -0.118 & -0.128 & -0.126 & 0.077 & 0.300 & & 0.152 & 0.263 & 0.190 & -0.199 & 0.032 & -0.058 & 0.012 & -0.131 & -0.117 \\
\hline & {$[0.00]$} & {$[0.00]$} & {$[0.00]$} & {$[0.00]$} & {$[0.00]$} & {$[0.00]$} & {$[0.00]$} & & {$[0.00]$} & {$[0.00]$} & {$[0.00]$} & {$[0.00]$} & {$[0.00]$} & {$[0.00]$} & {$[0.17]$} & {$[0.00]$} & {$[0.00]$} \\
\hline $\mathrm{R} 2$ & 0.138 & 0.105 & 0.142 & 0.102 & 0.119 & 0.451 & 0.094 & 0.185 & & 0.077 & 0.592 & -0.066 & 0.002 & -0.129 & -0.095 & -0.161 & -0.151 \\
\hline & {$[0.00]$} & {$[0.00]$} & {$[0.00]$} & {$[0.00]$} & {$[0.00]$} & {$[0.00]$} & {$[0.00]$} & {$[0.00]$} & & {$[0.00]$} & {$[0.00]$} & {$[0.00]$} & {$[0.85]$} & {$[0.00]$} & {$[0.00]$} & {$[0.00]$} & {$[0.00]$} \\
\hline$x 2$ & -0.069 & -0.126 & -0.106 & -0.115 & -0.116 & 0.025 & 0.404 & 0.500 & 0.152 & & 0.051 & -0.015 & -0.011 & -0.053 & -0.029 & -0.075 & -0.060 \\
\hline & {$[0.00]$} & {$[0.00]$} & {$[0.00]$} & {$[0.00]$} & {$[0.00]$} & {$[0.00]$} & {$[0.00]$} & {$[0.00]$} & {$[0.00]$} & & {$[0.00]$} & {$[0.08]$} & {$[0.24]$} & {$[0.00]$} & {$[0.00]$} & {$[0.00]$} & {$[0.00]$} \\
\hline SIZE & 0.164 & 0.143 & 0.150 & 0.141 & 0.144 & 0.531 & -0.083 & 0.116 & 0.629 & 0.045 & & -0.334 & 0.127 & -0.103 & -0.064 & -0.096 & -0.092 \\
\hline & {$[0.00]$} & {$[0.00]$} & {$[0.00]$} & {$[0.00]$} & {$[0.00]$} & {$[0.00]$} & {$[0.00]$} & {$[0.00]$} & {$[0.00]$} & {$[0.00]$} & & {$[0.00]$} & {$[0.00]$} & {$[0.00]$} & {$[0.00]$} & {$[0.00]$} & {$[0.00]$} \\
\hline BTM & -0.003 & -0.023 & 0.035 & -0.029 & 0.026 & -0.130 & 0.117 & 0.023 & -0.089 & 0.068 & -0.357 & & -0.639 & -0.238 & -0.205 & -0.263 & -0.285 \\
\hline & {$[0.73]$} & {$[0.01]$} & {$[0.00]$} & {$[0.00]$} & {$[0.00]$} & {$[0.00]$} & {$[0.00]$} & {$[0.00]$} & {$[0.00]$} & {$[0.00]$} & {$[0.00]$} & & {$[0.00]$} & {$[0.00]$} & {$[0.00]$} & {$[0.00]$} & {$[0.00]$} \\
\hline Q & -0.010 & 0.049 & -0.029 & 0.054 & -0.021 & 0.100 & 0.253 & 0.002 & 0.089 & 0.043 & 0.244 & -0.786 & & 0.353 & 0.257 & 0.396 & 0.415 \\
\hline & {$[0.27]$} & {$[0.00]$} & {$[0.00]$} & {$[0.00]$} & {$[0.02]$} & {$[0.00]$} & {$[0.00]$} & {$[0.84]$} & {$[0.00]$} & {$[0.00]$} & {$[0.00]$} & {$[0.00]$} & & {$[0.00]$} & {$[0.00]$} & {$[0.00]$} & {$[0.00]$} \\
\hline CAPXRND & 0.034 & 0.197 & 0.078 & 0.196 & 0.078 & -0.089 & 0.083 & -0.096 & -0.110 & -0.085 & -0.031 & -0.293 & 0.368 & & 0.611 & 0.703 & 0.615 \\
\hline & {$[0.00]$} & {$[0.00]$} & {$[0.00]$} & {$[0.00]$} & {$[0.00]$} & {$[0.00]$} & {$[0.00]$} & {$[0.00]$} & {$[0.00]$} & {$[0.00]$} & {$[0.00]$} & {$[0.00]$} & {$[0.00]$} & & {$[0.00]$} & {$[0.00]$} & {$[0.00]$} \\
\hline Investment & 0.026 & 0.159 & 0.062 & 0.157 & 0.060 & -0.025 & 0.127 & -0.015 & -0.066 & -0.018 & 0.001 & -0.299 & 0.377 & 0.801 & & 0.477 & 0.413 \\
\hline & {$[0.00]$} & {$[0.00]$} & {$[0.00]$} & {$[0.00]$} & {$[0.00]$} & {$[0.00]$} & {$[0.00]$} & [0.09] & {$[0.00]$} & [0.04] & {$[0.94]$} & {$[0.00]$} & {$[0.00]$} & {$[0.00]$} & & {$[0.00]$} & {$[0.00]$} \\
\hline RND & 0.076 & 0.232 & 0.122 & 0.230 & 0.114 & -0.040 & 0.003 & -0.216 & -0.103 & -0.172 & -0.023 & -0.242 & 0.308 & 0.544 & 0.462 & & 0.875 \\
\hline & {$[0.00]$} & {$[0.00]$} & {$[0.00]$} & {$[0.00]$} & {$[0.00]$} & {$[0.00]$} & {$[0.76]$} & {$[0.00]$} & {$[0.00]$} & {$[0.00]$} & {$[0.01]$} & {$[0.00]$} & {$[0.00]$} & {$[0.00]$} & {$[0.00]$} & & {$[0.00]$} \\
\hline DisExp & 0.048 & 0.267 & 0.112 & 0.248 & 0.120 & -0.090 & 0.075 & -0.117 & -0.151 & -0.060 & -0.092 & -0.285 & 0.415 & 0.615 & 0.413 & 0.875 & \\
\hline & {$[0.00]$} & {$[0.00]$} & {$[0.00]$} & {$[0.00]$} & {$[0.00]$} & {$[0.00]$} & {$[0.00]$} & {$[0.00]$} & {$[0.00]$} & {$[0.00]$} & {$[0.00]$} & {$[0.00]$} & {$[0.00]$} & {$[0.00]$} & {$[0.00]$} & {$[0.00]$} & \\
\hline
\end{tabular}


Table 2: Institutional Merger - The Effects on the Common Ownership

This table provides the analyses of the effect of institution mergers on the common ownership. Panels A and B provide the summary statistics of the common ownership variables pre and post institutional mergers, respectively. Panel $\mathrm{C}$ reports the difference-in-difference tests using the common ownership variables as the dependent variables. A firm is classified as a treatment if it is block-held by one of the merging institutions during the quarter immediately before the merger announcement date and at least one of its same-industry rivals are block-held by the other party to the merger during the same pre-merger quarter. A firm is considered as a control if it is block-held by the same institution (that holds the treatment) and none of its same-industry rivals are block-held by the other party to the merger during the same pre-merger quarter. Treat is a dummy variable that equals one if a firm is a treatment stock and zero if it is a control. Post is a dummy that equals one for the post-merger period and zero for the pre-merger period. The sample period is $t-3$ to $t-1$ and $t+1$ to $t+3$, where year $t$ is the merger announcement year.

Panel A: Pre-M\&A Period

\begin{tabular}{cccccccccc}
\hline Variable & \multicolumn{3}{c}{ Controls } & \multicolumn{3}{c}{ Treatment } & \multicolumn{3}{c}{ Treatment - Controls } \\
\cline { 2 - 10 } & $\mathrm{N}$ & Mean & Median & $\mathrm{N}$ & Mean & Median & Mean Diff & $\mathrm{t}$ Value & $\operatorname{Pr}>|\mathrm{t}|$ \\
\hline CrossDummy & 7071 & 0.75 & 1.00 & 499 & 0.74 & 1.00 & -0.01 & {$[-0.56]$} & 0.58 \\
NConnected & 7071 & 4.28 & 1.50 & 499 & 5.53 & 1.75 & 1.25 & {$[3.19]$} & 0.00 \\
NCross & 7071 & 1.17 & 1.00 & 499 & 1.11 & 1.00 & -0.06 & {$[-1.16]$} & 0.25 \\
AvgNum & 7071 & 2.30 & 1.13 & 499 & 2.96 & 1.38 & 0.66 & {$[3.77]$} & 0.00 \\
TotalCrossOwn & 7071 & 0.10 & 0.07 & 499 & 0.09 & 0.07 & -0.01 & {$[-1.29]$} & 0.20 \\
\hline
\end{tabular}

Panel B: Post-M\&A Period

\begin{tabular}{|c|c|c|c|c|c|c|c|c|c|}
\hline \multirow[t]{2}{*}{ Variable } & \multicolumn{3}{|c|}{ Controls } & \multicolumn{3}{|c|}{ Treatment } & \multicolumn{3}{|c|}{ Treatment - Controls } \\
\hline & $\mathrm{N}$ & Mean & Median & $\mathrm{N}$ & Mean & Median & Mean Diff & t Value & $\operatorname{Pr}>|t|$ \\
\hline CrossDummy & 6666 & 0.80 & 1.00 & 508 & 0.87 & 1.00 & 0.07 & {$[4.20]$} & 0.00 \\
\hline NConnected & 6666 & 6.07 & 2.25 & 508 & 7.81 & 4.00 & 1.75 & [3.78] & 0.00 \\
\hline NCross & 6666 & 1.46 & 1.25 & 508 & 1.56 & 1.50 & 0.10 & [1.73] & 0.08 \\
\hline AvgNum & 6666 & 3.25 & 1.63 & 508 & 4.07 & 2.54 & 0.82 & [3.69] & 0.00 \\
\hline TotalCrossOwn & 6666 & 0.12 & 0.10 & 508 & 0.13 & 0.11 & 0.01 & {$[2.75]$} & 0.01 \\
\hline
\end{tabular}

Panel C: Regressions of Common Ownership on Treat and Post dummies

\begin{tabular}{|c|c|c|c|c|c|c|c|c|c|c|}
\hline \multirow{2}{*}{$\begin{array}{c}\text { Variables } \\
\text { Treat }\end{array}$} & \multicolumn{2}{|c|}{ CrossDummy } & \multicolumn{2}{|c|}{ NConnected } & \multicolumn{2}{|c|}{ NumCross } & \multicolumn{2}{|c|}{ AvgNum } & \multicolumn{2}{|c|}{ TotalCrossOwn } \\
\hline & 0.025 & {$[1.15]$} & -1.074 & {$[-3.43]$} & 0.024 & {$[0.46]$} & -0.428 & {$[-2.57]$} & 0.001 & {$[0.22]$} \\
\hline Post & 0.012 & [1.45] & 0.154 & [1.32] & 0.069 & [3.61] & 0.019 & {$[0.30]$} & 0.007 & [4.05] \\
\hline Treat $\times$ Post & 0.046 & [2.12] & 0.973 & [3.12] & 0.159 & [3.14] & 0.489 & [2.96] & 0.015 & [3.38] \\
\hline Size & 0.036 & [5.99] & 0.750 & [8.65] & 0.115 & [8.18] & 0.314 & [6.82] & 0.010 & {$[8.28]$} \\
\hline BTM & 0.030 & [4.54] & 0.476 & [5.05] & 0.156 & [10.19] & 0.191 & [3.81] & 0.013 & [9.76] \\
\hline AssetG & 0.012 & [1.73] & 0.046 & [0.45] & 0.019 & [1.11] & -0.010 & {$[-0.18]$} & 0.000 & {$[0.15]$} \\
\hline Loss & 0.000 & {$[-0.03]$} & 0.165 & [1.38] & 0.051 & [2.65] & 0.024 & {$[0.38]$} & 0.006 & {$[3.20]$} \\
\hline $\mathrm{N}$ & \multicolumn{2}{|c|}{14744} & \multicolumn{2}{|c|}{14744} & \multicolumn{2}{|c|}{14744} & \multicolumn{2}{|c|}{14744} & \multicolumn{2}{|c|}{14744} \\
\hline RSQ & \multicolumn{2}{|c|}{$53.6 \%$} & \multicolumn{2}{|c|}{$78.2 \%$} & \multicolumn{2}{|c|}{$69.4 \%$} & \multicolumn{2}{|c|}{$71.9 \%$} & \multicolumn{2}{|c|}{$68.1 \%$} \\
\hline Fixed Effects & \multicolumn{2}{|c|}{ Firm + Year } & \multicolumn{2}{|c|}{ Firm + Year } & \multicolumn{2}{|c|}{ Firm + Year } & \multicolumn{2}{|c|}{ Firm + Year } & \multicolumn{2}{|c|}{ Firm + Year } \\
\hline
\end{tabular}


Table 3: Regression of Annual Returns on the Current and Future Earnings

This table reports the difference-in-difference test results using institution mergers as exogenous shocks to common ownership. The dependent variable is the buy-and-hold return for year $t$, measured over the 12-month period ending three months after the firm's fiscal year $t-1$ end. The main independent variable is $\mathrm{X} 2$, which is the sum of income available to common shareholders before extraordinary items for the two years following year $t$, deflated by market value of equity three months after the fiscal year $t-1$ end. $\mathrm{R} 2$ is the buy-and-hold return for the two-year period following year $t$, starting three months after the year fiscal year- $t$ end. 10 is the total institutional ownership. Num_IO is the number of institutional owners. Variable definitions are provided in Appendix A. A firm is classified as a treatment if it is block-held by one of the merging institutions during the quarter immediately before the merger announcement date and at least one of its same-industry rivals are block-held by the other party to the merger during the same pre-merger quarter. A firm is considered as a control if it is block-held by the same institution (that holds the treatment) and none of its same-industry rivals are block-held by the other party to the merger during the same premerger quarter. Treat is a dummy variable that equals one if a firm is a treatment stock and zero if it is a control. Post is a dummy that equals one for the post-merger period and zero for the pre-merger period. To avoid the simultaneity of X2 and R2 pre- and post-mergers, our sample periods are $t-4$ to $t-2$ and $t+1$ to $t+3$, where year $t$ is the merger announcement year. $t$-statistics are calculated using clustered standard errors by firm level and reported in parentheses.

\begin{tabular}{|c|c|c|c|c|c|c|c|c|c|c|}
\hline Variables & (1) & $(2)$ & (3) & (4) & (5) & (6) & (7) & (8) & (9) & (10) \\
\hline \multirow[t]{2}{*}{ Lagged X } & -0.975 & -0.747 & -0.988 & -0.775 & -0.993 & -0.774 & -0.972 & -0.740 & -0.958 & -0.717 \\
\hline & {$[-5.61]$} & {$[-4.58]$} & {$[-5.97]$} & {$[-4.96]$} & {$[-6.00]$} & {$[-4.96]$} & {$[-5.68]$} & {$[-4.59]$} & {$[-5.90]$} & {$[-4.69]$} \\
\hline \multirow[t]{2}{*}{$x$} & 0.270 & 0.382 & 0.266 & 0.310 & 0.276 & 0.326 & 0.311 & 0.378 & 0.353 & 0.407 \\
\hline & {$[1.25]$} & {$[2.33]$} & {$[1.26]$} & [1.89] & {$[1.32]$} & {$[2.01]$} & [1.48] & {$[2.27]$} & [1.70] & [2.49] \\
\hline \multirow[t]{2}{*}{$x 2$} & 1.030 & 0.800 & 0.962 & 0.737 & 0.970 & 0.741 & 1.008 & 0.782 & 0.960 & 0.753 \\
\hline & [3.71] & {$[5.71]$} & [3.36] & {$[5.14]$} & [3.39] & [5.20] & [3.36] & {$[5.13]$} & [3.77] & [5.31] \\
\hline \multirow[t]{2}{*}{$\mathrm{R} 2$} & -0.182 & -0.186 & -0.197 & -0.186 & -0.194 & -0.184 & -0.198 & -0.194 & -0.198 & -0.196 \\
\hline & {$[-5.36]$} & {$[-6.65]$} & {$[-5.52]$} & {$[-6.30]$} & {$[-5.51]$} & {$[-6.28]$} & {$[-5.80]$} & {$[-6.15]$} & {$[-5.71]$} & {$[-6.10]$} \\
\hline \multirow[t]{2}{*}{ Lagged $\mathrm{X} \times$ Post } & 0.250 & 0.165 & 0.389 & 0.260 & 0.400 & 0.259 & 0.406 & 0.232 & 0.382 & 0.195 \\
\hline & {$[1.06]$} & {$[0.82]$} & [1.73] & [1.33] & {$[1.79]$} & [1.32] & [1.74] & {$[1.16]$} & {$[1.74]$} & {$[1.00]$} \\
\hline \multirow[t]{2}{*}{$\mathrm{X} \times$ Post } & -0.894 & -0.747 & -0.751 & -0.641 & -0.761 & -0.656 & -0.794 & -0.697 & -0.808 & -0.706 \\
\hline & {$[-3.30]$} & {$[-3.82]$} & {$[-2.91]$} & {$[-3.34]$} & {$[-2.95]$} & {$[-3.43]$} & {$[-3.12]$} & {$[-3.66]$} & {$[-3.21]$} & {$[-3.75]$} \\
\hline \multirow[t]{2}{*}{$\mathrm{X} 2 \times$ Post } & -0.335 & -0.158 & -0.350 & -0.146 & -0.359 & -0.149 & -0.387 & -0.194 & -0.351 & -0.167 \\
\hline & {$[-0.99]$} & {$[-0.70]$} & {$[-1.03]$} & {$[-0.64]$} & {$[-1.06]$} & {$[-0.65]$} & {$[-1.09]$} & {$[-0.80]$} & {$[-1.10]$} & {$[-0.71]$} \\
\hline \multirow[t]{2}{*}{$\mathrm{R} 2 \times$ Post } & -0.032 & -0.021 & 0.033 & 0.017 & 0.026 & 0.012 & 0.015 & 0.017 & 0.024 & 0.027 \\
\hline & {$[-0.79]$} & {$[-0.58]$} & {$[0.80]$} & {$[0.46]$} & {$[0.64]$} & [0.32] & [0.37] & {$[0.42]$} & [0.59] & {$[0.66]$} \\
\hline \multirow[t]{2}{*}{ Lagged $X \times$ Treat } & 0.527 & 0.482 & 0.432 & 0.445 & 0.44 & 0.444 & 0.433 & 0.642 & 0.394 & 0.557 \\
\hline & {$[1.28]$} & {$[0.96]$} & [1.14] & {$[0.95]$} & {$[1.17]$} & {$[0.96]$} & [1.00] & {$[1.33]$} & [0.94] & [1.22] \\
\hline \multirow[t]{2}{*}{$\mathrm{X} \times$ Treat } & 0.292 & 0.410 & 0.269 & 0.391 & 0.262 & 0.370 & 0.132 & 0.380 & 0.166 & 0.460 \\
\hline & {$[0.80]$} & [1.43] & {$[0.82]$} & {$[1.38]$} & {$[0.80]$} & [1.32] & {$[0.40]$} & {$[1.21]$} & {$[0.51]$} & [1.46] \\
\hline \multirow[t]{2}{*}{$\mathrm{X} 2 \times$ Treat } & -0.963 & -0.615 & -0.900 & -0.593 & -0.920 & -0.614 & -1.040 & -0.653 & -0.977 & -0.616 \\
\hline & {$[-2.76]$} & {$[-1.86]$} & {$[-2.61]$} & {$[-1.83]$} & {$[-2.67]$} & {$[-1.91]$} & {$[-2.79]$} & {$[-1.76]$} & {$[-2.86]$} & [-1.69] \\
\hline \multirow[t]{2}{*}{ R2 $\times$ Treat } & 0.007 & -0.025 & 0.028 & -0.013 & 0.025 & -0.015 & 0.009 & -0.027 & -0.002 & -0.028 \\
\hline & {$[0.10]$} & {$[-0.41]$} & {$[0.45]$} & {$[-0.22]$} & {$[0.41]$} & {$[-0.26]$} & [0.15] & {$[-0.42]$} & {$[-0.04]$} & {$[-0.44]$} \\
\hline \multirow[t]{2}{*}{ Lagged $\mathrm{X} \times$ Post $\times$ Treat } & -0.804 & -0.493 & -0.804 & -0.570 & -0.814 & -0.560 & -0.817 & -0.660 & -0.743 & -0.546 \\
\hline & {$[-1.29]$} & {$[-0.72]$} & {$[-1.40]$} & {$[-0.87]$} & {$[-1.42]$} & {$[-0.86]$} & [-1.33] & {$[-0.97]$} & {$[-1.22]$} & {$[-0.82]$} \\
\hline \multirow[t]{2}{*}{$\mathrm{X} \times$ Post $\times$ Treat } & -2.143 & -3.128 & -2.24 & -3.141 & -2.255 & -3.112 & -2.113 & -2.998 & -2.234 & -3.219 \\
\hline & {$[-1.18]$} & {$[-2.22]$} & {$[-1.27]$} & {$[-2.22]$} & {$[-1.28]$} & {$[-2.21]$} & {$[-1.23]$} & {$[-2.13]$} & {$[-1.28]$} & {$[-2.27]$} \\
\hline \multirow[t]{2}{*}{$\mathrm{X} 2 \times$ Post $\times$ Treat } & 2.065 & 2.157 & 2.017 & 2.142 & 2.031 & 2.163 & 1.938 & 2.036 & 1.878 & 1.977 \\
\hline & {$[2.30]$} & [2.78] & [2.30] & {$[2.76]$} & [2.32] & [2.79] & [2.19] & [2.48] & [2.12] & [2.41] \\
\hline \multirow[t]{2}{*}{$\mathrm{R} 2 \times$ Post $\times$ Treat } & -0.063 & -0.067 & -0.079 & -0.076 & -0.075 & -0.074 & -0.062 & -0.073 & -0.061 & -0.08 \\
\hline & {$[-0.56]$} & {$[-0.68]$} & {$[-0.74]$} & {$[-0.80]$} & {$[-0.70]$} & {$[-0.77]$} & {$[-0.61]$} & {$[-0.73]$} & {$[-0.58]$} & {$[-0.79]$} \\
\hline \multirow[t]{2}{*}{ Treat } & 0.016 & 0.008 & -0.026 & 0.014 & -0.057 & -0.019 & & & & \\
\hline & {$[0.27]$} & [0.13] & {$[-0.44]$} & {$[0.24]$} & {$[-0.97]$} & {$[-0.34]$} & & & & \\
\hline Post & 0.146 & 0.058 & 0.012 & 0.024 & -0.238 & -0.134 & -0.241 & -0.127 & & \\
\hline & {$[5.46]$} & [2.47] & {$[0.40]$} & {$[0.81]$} & {$[-2.94]$} & [-1.98] & {$[-2.90]$} & {$[-1.85]$} & & \\
\hline Treat $\times$ Post & -0.108 & -0.063 & -0.035 & -0.060 & -0.040 & -0.070 & -0.061 & -0.076 & -0.046 & -0.055 \\
\hline & {$[-1.50]$} & {$[-0.84]$} & {$[-0.51]$} & {$[-0.85]$} & {$[-0.57]$} & {$[-0.99]$} & {$[-0.82]$} & {$[-0.99]$} & {$[-0.63]$} & {$[-0.74]$} \\
\hline InvME & & 12.988 & & 13.116 & & 13.122 & & 12.925 & & 12.626 \\
\hline & & [3.07] & & {$[3.06]$} & & [3.09] & & {$[3.06]$} & & [3.18] \\
\hline BTM & & 0.477 & & 0.402 & & 0.407 & & 0.441 & & 0.44 \\
\hline & & [11.96] & & [10.72] & & [10.90] & & [10.73] & & {$[10.80]$} \\
\hline AssetG & & 0.265 & & 0.239 & & 0.235 & & 0.217 & & 0.21 \\
\hline & & [8.27] & & {$[8.21]$} & & [8.23] & & [7.59] & & [7.55] \\
\hline Loss & & -0.188 & & -0.185 & & -0.186 & & -0.196 & & -0.198 \\
\hline & & {$[-5.85]$} & & {$[-6.06]$} & & {$[-6.19]$} & & {$[-6.65]$} & & {$[-6.86]$} \\
\hline 10 & & -0.276 & & -0.16 & & -0.173 & & -0.21 & & -0.236 \\
\hline & & [-3.39] & & {$[-1.89]$} & & {$[-2.09]$} & & {$[-2.60]$} & & {$[-2.86]$} \\
\hline Num_IO & & 0.108 & & 0.055 & & 0.062 & & 0.075 & & 0.08 \\
\hline & & [3.63] & & [1.95] & & {$[2.26]$} & & {$[2.82]$} & & [3.04] \\
\hline Fixed Effects & & & & & Firm + & Merger & Firm $\times N$ & + Year & Firm $\times$ Merg & ear×Merger \\
\hline $\mathrm{N}$ & 11,579 & 11,230 & 11,578 & 11,229 & 11,578 & 11,229 & 11,565 & 11,213 & 11,561 & 11,209 \\
\hline$R^{2}$ & $34.6 \%$ & $48.8 \%$ & $42.1 \%$ & $53.0 \%$ & $42.4 \%$ & $53.3 \%$ & $45.4 \%$ & $56.1 \%$ & $47.1 \%$ & $57.4 \%$ \\
\hline
\end{tabular}


Table 4: Variance Ratios

This table reports the difference-in-difference test using institution mergers as exogenous shocks to common ownership. The dependent variable is the quarterly variance ratios. The variance ratio is calculated from the natural logarithm of absolute value of the ratio of the variance of 5-day returns in a given quarter to 5 times the variance of one-day returns in the same quarter. A firm is classified as a treatment if it is block-held by one of the merging institutions during the quarter immediately before the merger announcement date and at least one of its same-industry rivals are block-held by the other party to the merger during the same pre-merger quarter. A firm is considered as a control if it is block-held by the same institution (that holds the treatment) and none of its same-industry rivals are block-held by the other party to the merger during the same pre-merger quarter. Treat is a dummy variable that equals one if a firm is a treatment stock and zero if it is a control. Post is a dummy that equals one for the post-merger period and zero for the pre-merger period. Definitions of variables are provided in Appendix A. The sample period is $t-3$ to $t-1$ and $t+1$ to $t+3$, where year $t$ is the merger announcement year. $t$-statistics are calculated using clustered standard errors by firm level and reported in parentheses.

\begin{tabular}{|c|c|c|c|c|c|c|c|c|c|c|}
\hline Variables & $(1)$ & $(2)$ & (3) & $(4)$ & (5) & (6) & (7) & (8) & (9) & (10) \\
\hline \multirow[t]{2}{*}{ Treat $\times$ Post } & -0.016 & -0.014 & -0.017 & -0.017 & -0.017 & -0.016 & -0.016 & -0.015 & -0.017 & -0.017 \\
\hline & {$[-2.56]$} & {$[-2.24]$} & {$[-2.62]$} & {$[-2.49]$} & {$[-2.54]$} & {$[-2.42]$} & {$[-2.38]$} & {$[-2.25]$} & {$[-2.57]$} & {$[-2.49]$} \\
\hline \multirow[t]{2}{*}{ Size } & & -0.013 & & -0.010 & & -0.010 & & -0.011 & & -0.011 \\
\hline & & {$[-6.45]$} & & {$[-4.81]$} & & {$[-4.69]$} & & {$[-4.20]$} & & {$[-4.35]$} \\
\hline \multirow[t]{2}{*}{ InvPrc } & & 0.012 & & 0.016 & & 0.016 & & 0.016 & & 0.013 \\
\hline & & [1.60] & & {$[2.03]$} & & [2.03] & & [1.92] & & [1.55] \\
\hline \multirow[t]{2}{*}{ Amihud } & & 0.477 & & 0.448 & & 0.452 & & 0.365 & & 0.372 \\
\hline & & [1.85] & & {$[1.76]$} & & [1.79] & & [1.43] & & [1.52] \\
\hline \multirow[t]{2}{*}{ BidAsk Spread } & & -0.056 & & -0.083 & & -0.081 & & -0.060 & & -0.056 \\
\hline & & {$[-1.74]$} & & {$[-2.55]$} & & {$[-2.49]$} & & {$[-1.79]$} & & {$[-1.70]$} \\
\hline \multirow[t]{2}{*}{ BTM } & & 4.874 & & 5.004 & & 4.991 & & 4.641 & & 4.728 \\
\hline & & [2.31] & & {$[2.30]$} & & [2.30] & & {$[2.04]$} & & {$[2.06]$} \\
\hline \multirow[t]{2}{*}{ AnnRet } & & 0.001 & & 0.002 & & 0.002 & & 0.002 & & 0.002 \\
\hline & & [1.12] & & [1.28] & & [1.22] & & [1.10] & & [1.11] \\
\hline \multirow[t]{2}{*}{ Volatility } & & 0.002 & & 0.004 & & 0.004 & & 0.003 & & 0.001 \\
\hline & & [0.33] & & {$[0.59]$} & & {$[0.61]$} & & {$[0.38]$} & & {$[0.20]$} \\
\hline \multirow[t]{2}{*}{ Gross Profitability } & & 0.003 & & 0.001 & & 0.001 & & -0.003 & & -0.001 \\
\hline & & {$[0.34]$} & & {$[0.08]$} & & {$[0.10]$} & & {$[-0.30]$} & & {$[-0.18]$} \\
\hline \multirow[t]{2}{*}{$x$} & & -0.005 & & -0.006 & & -0.006 & & -0.005 & & -0.006 \\
\hline & & {$[-1.63]$} & & {$[-1.88]$} & & {$[-1.89]$} & & {$[-1.74]$} & & {$[-1.94]$} \\
\hline \multirow[t]{2}{*}{10} & & -0.005 & & -0.009 & & -0.010 & & -0.010 & & -0.010 \\
\hline & & {$[-1.01]$} & & {$[-1.77]$} & & {$[-1.86]$} & & {$[-1.78]$} & & {$[-1.80]$} \\
\hline \multirow[t]{2}{*}{ Post } & -0.008 & -0.009 & 0.001 & -0.001 & 0.002 & -0.003 & 0.002 & -0.003 & & \\
\hline & {$[-4.60]$} & {$[-4.75]$} & [0.49] & {$[-0.53]$} & {$[0.26]$} & {$[-0.43]$} & [0.29] & {$[-0.42]$} & & \\
\hline \multirow[t]{2}{*}{ Treat } & 0.025 & 0.020 & 0.016 & 0.015 & 0.017 & 0.016 & & & & \\
\hline & [3.42] & [2.87] & {$[2.34]$} & {$[2.23]$} & {$[2.62]$} & {$[2.51]$} & & & & \\
\hline Fixed Effects & \multicolumn{2}{|c|}{ Firm } & \multicolumn{2}{|c|}{ Firm + Year } & \multicolumn{2}{|c|}{ Firm + Year + Merger } & \multicolumn{2}{|c|}{ Firm $\times$ Merger + Year } & \multicolumn{2}{|c|}{ Firm $\times$ Merger + Year $\times$ Merge } \\
\hline $\mathrm{N}$ & 51,727 & 50,660 & 51,727 & 50,660 & 51,727 & 50,660 & 51,727 & 50,660 & 51,727 & 50,660 \\
\hline$R^{2}$ & $8.3 \%$ & $8.6 \%$ & $8.6 \%$ & $8.8 \%$ & $8.6 \%$ & $8.8 \%$ & $9.5 \%$ & $9.7 \%$ & $9.7 \%$ & $9.9 \%$ \\
\hline
\end{tabular}


Table 5: Geographical Distance and Social Connection

This table studies whether common ownership facilitates information flow. First, we estimate the level of difficulty of information diffusion between treatment firms using the geographical distance and social connection. The geographical distance (social connection) is the average distance (social connection) between treatment firms that are connected through an institution merger. Then, we re-define the treatment group from the subsample of firms in the original treatment group that are above (below) median of the geographical distance (or social connection) during the year immediately before the merger announcement year. Treat is a dummy variable that equals one if a firm is a treatment stock and zero if it is a control. Post is a dummy that equals one for the post-merger period and zero for the pre-merger period. Definitions of variables are provided in Appendix A. The sample period is $t-3$ to $t-1$ ( $t-4$ to $t-2$ for earnings-return regressions) and $t+1$ to $t+3$, where year $t$ is the merger announcement year. $t$-statistics are calculated using clustered standard errors by firm level and reported in parentheses.

Panel A: Geographical Distance - Earnings Informativeness

\begin{tabular}{|c|c|c|c|c|c|c|c|c|}
\hline \multirow[b]{2}{*}{ Variables } & \multicolumn{4}{|c|}{ Remote Peers } & \multicolumn{4}{|c|}{ Close Peers } \\
\hline & $(1)$ & $(2)$ & (3) & $(4)$ & (5) & $(6)$ & (7) & $(8)$ \\
\hline \multirow[t]{2}{*}{ Lagged $\mathrm{X} \times$ Post $\times$ Treat } & -0.901 & -0.786 & -0.736 & -0.450 & -0.233 & -0.273 & -0.394 & -0.368 \\
\hline & {$[-0.72]$} & {$[-0.62]$} & {$[-0.52]$} & {$[-0.34]$} & {$[-0.43]$} & {$[-0.50]$} & {$[-0.71]$} & {$[-0.68]$} \\
\hline \multirow[t]{2}{*}{$\mathrm{X} \times$ Post $\times$ Treat } & -4.855 & -4.815 & -4.526 & -4.804 & 1.375 & 1.354 & 0.988 & 0.894 \\
\hline & {$[-3.66]$} & {$[-3.65]$} & {$[-3.38]$} & {$[-3.61]$} & {$[1.85]$} & [1.85] & [1.34] & [1.21] \\
\hline \multirow[t]{2}{*}{$\mathrm{X} 2 \times$ Post $\times$ Treat } & 2.686 & 2.710 & 2.688 & 2.606 & -0.317 & -0.287 & -0.557 & -0.583 \\
\hline & [3.90] & [3.93] & [3.64] & [3.57] & {$[-0.73]$} & {$[-0.68]$} & {$[-1.13]$} & {$[-1.16]$} \\
\hline \multirow[t]{2}{*}{$\mathrm{R} 2 \times$ Post $\times$ Treat } & -0.137 & -0.136 & -0.135 & -0.138 & 0.225 & 0.232 & 0.242 & 0.224 \\
\hline & {$[-1.45]$} & {$[-1.42]$} & {$[-1.26]$} & {$[-1.25]$} & {$[2.64]$} & {$[2.74]$} & {$[2.83]$} & {$[2.60]$} \\
\hline Controls & Yes & Yes & Yes & Yes & Yes & Yes & Yes & Yes \\
\hline Fixed Effects & $F+Y$ & $F+Y+M$ & $F \times M+Y$ & $F \times M+Y \times M$ & $F+Y$ & $F+Y+M$ & $F \times M+Y$ & $F \times M+Y \times M$ \\
\hline $\mathrm{N}$ & 11,229 & 11,229 & 11,213 & 11,209 & 11,229 & 11,229 & 11,213 & 11,209 \\
\hline$R^{2}$ & $54.2 \%$ & $54.5 \%$ & $57.3 \%$ & $58.6 \%$ & $50.1 \%$ & $50.4 \%$ & $54.0 \%$ & $55.3 \%$ \\
\hline
\end{tabular}

Panel B: Geographical Distance - Variance Ratio

\begin{tabular}{|c|c|c|c|c|c|c|c|c|}
\hline \multirow[b]{2}{*}{ Variables } & \multicolumn{4}{|c|}{ Remote Peers } & \multicolumn{4}{|c|}{ Close Peers } \\
\hline & (1) & $(2)$ & (3) & (4) & $(5)$ & $(6)$ & (7) & (8) \\
\hline \multirow[t]{2}{*}{ Treat $\times$ Post } & -0.019 & -0.019 & -0.019 & -0.022 & -0.012 & -0.011 & -0.009 & -0.009 \\
\hline & {$[-2.11]$} & {$[-2.09]$} & {$[-2.08]$} & {$[-2.45]$} & {$[-1.26]$} & {$[-1.21]$} & {$[-1.01]$} & {$[-0.98]$} \\
\hline \multirow[t]{2}{*}{ Post } & -0.002 & -0.003 & -0.003 & & -0.003 & -0.004 & -0.004 & \\
\hline & {$[-0.68]$} & {$[-0.53]$} & {$[-0.49]$} & & {$[-0.99]$} & {$[-0.61]$} & {$[-0.60]$} & \\
\hline \multirow[t]{2}{*}{ Treat } & 0.012 & 0.013 & & & 0.016 & 0.017 & & \\
\hline & {$[1.40]$} & [1.61] & & & {$[1.54]$} & [1.65] & & \\
\hline Controls & Yes & Yes & Yes & Yes & Yes & Yes & Yes & Yes \\
\hline Fixed Effects & $F+Y$ & $F+Y+M$ & $F \times M+Y$ & $\mathrm{~F} \times \mathrm{M}+\mathrm{Y} \times \mathrm{M}$ & $F+Y$ & $F+Y+M$ & $F \times M+Y$ & $F \times M+Y \times M$ \\
\hline $\mathrm{N}$ & 50,660 & 50,660 & 50,660 & 50,660 & 50,660 & 50,660 & 50,660 & 50,660 \\
\hline$R^{2}$ & $8.8 \%$ & $8.8 \%$ & $9.7 \%$ & $9.9 \%$ & $8.8 \%$ & $8.8 \%$ & $9.6 \%$ & $9.8 \%$ \\
\hline
\end{tabular}

Panel C: Social Connection - Earnings Informativeness

\begin{tabular}{|c|c|c|c|c|c|c|c|c|}
\hline \multirow[b]{2}{*}{ Variables } & \multicolumn{4}{|c|}{ Less Connected Peers } & \multicolumn{4}{|c|}{ More Connected Peers } \\
\hline & (1) & $(2)$ & (3) & $(4)$ & (5) & (6) & (7) & (8) \\
\hline \multirow[t]{2}{*}{ Lagged $\mathrm{X} \times$ Post $\times$ Treat } & -0.392 & -0.380 & -0.340 & -0.169 & -0.993 & -0.998 & -1.392 & -1.352 \\
\hline & {$[-0.41]$} & {$[-0.40]$} & {$[-0.32]$} & {$[-0.17]$} & {$[-1.28]$} & {$[-1.28]$} & {$[-1.79]$} & {$[-1.76]$} \\
\hline \multirow[t]{2}{*}{$\mathrm{X} \times$ Post $\times$ Treat } & -3.813 & -3.778 & -3.667 & -3.843 & 1.173 & 1.216 & 0.896 & 0.684 \\
\hline & {$[-2.48]$} & {$[-2.47]$} & {$[-2.27]$} & {$[-2.37]$} & {$[1.40]$} & [1.47] & {$[1.02]$} & {$[0.76]$} \\
\hline \multirow[t]{2}{*}{$\mathrm{X} 2 \times$ Post $\times$ Treat } & 2.526 & 2.562 & 2.476 & 2.409 & -0.394 & -0.418 & -0.492 & -0.562 \\
\hline & [3.29] & [3.36] & [3.02] & [2.96] & {$[-0.73]$} & {$[-0.78]$} & {$[-0.90]$} & {$[-1.00]$} \\
\hline \multirow[t]{2}{*}{$\mathrm{R} 2 \times$ Post $\times$ Treat } & -0.127 & -0.130 & -0.147 & -0.160 & 0.080 & 0.085 & 0.079 & 0.072 \\
\hline & {$[-1.03]$} & {$[-1.04]$} & {$[-1.08]$} & {$[-1.14]$} & {$[0.97]$} & {$[1.02]$} & [0.93] & [0.83] \\
\hline Controls & Yes & Yes & Yes & Yes & Yes & Yes & Yes & Yes \\
\hline Fixed Effects & $F+Y$ & $F+Y+M$ & $F \times M+Y$ & $\mathrm{~F} \times \mathrm{M}+\mathrm{Y} \times \mathrm{M}$ & $F+Y$ & $F+Y+M$ & $F \times M+Y$ & $F \times M+Y \times M$ \\
\hline $\mathrm{N}$ & 11,229 & 11,229 & 11,213 & 11,209 & 11,229 & 11,229 & 11,213 & 11,209 \\
\hline$R^{2}$ & $53.7 \%$ & $54.0 \%$ & $56.8 \%$ & $58.0 \%$ & $50.0 \%$ & $50.4 \%$ & $54.0 \%$ & $55.3 \%$ \\
\hline
\end{tabular}

Panel D: Social Connection - Variance Ratio

\begin{tabular}{|c|c|c|c|c|c|c|c|c|}
\hline \multirow[b]{2}{*}{ Variables } & \multicolumn{4}{|c|}{ Less Connected Peers } & \multicolumn{4}{|c|}{ More Connected Peers } \\
\hline & (1) & $(2)$ & (3) & (4) & (5) & (6) & (7) & (8) \\
\hline \multirow[t]{2}{*}{ Treat $\times$ Post } & -0.022 & -0.021 & -0.018 & -0.021 & -0.008 & -0.008 & -0.009 & -0.010 \\
\hline & {$[-2.33]$} & {$[-2.27]$} & {$[-1.94]$} & {$[-2.22]$} & {$[-0.96]$} & {$[-0.93]$} & {$[-1.06]$} & {$[-1.08]$} \\
\hline \multirow[t]{2}{*}{ Post } & -0.002 & -0.003 & -0.003 & & -0.003 & -0.004 & -0.004 & \\
\hline & {$[-0.74]$} & {$[-0.51]$} & {$[-0.51]$} & & {$[-0.93]$} & {$[-0.64]$} & {$[-0.59]$} & \\
\hline \multirow[t]{2}{*}{ Treat } & 0.022 & 0.023 & & & 0.005 & 0.006 & & \\
\hline & {$[2.46]$} & {$[2.56]$} & & & {$[0.43]$} & {$[0.60]$} & & \\
\hline Controls & Yes & Yes & Yes & Yes & Yes & Yes & Yes & Yes \\
\hline Fixed Effects & $F+Y$ & $F+Y+M$ & $F \times M+Y$ & $F \times M+Y \times M$ & $F+Y$ & $F+Y+M$ & $F \times M+Y$ & $F \times M+Y \times M$ \\
\hline $\mathrm{N}$ & 50,660 & 50,660 & 50,660 & 50,660 & 50,660 & 50,660 & 50,660 & 50,660 \\
\hline$R^{2}$ & $8.8 \%$ & $8.8 \%$ & $9.7 \%$ & $9.9 \%$ & $8.8 \%$ & $8.8 \%$ & $9.6 \%$ & $9.8 \%$ \\
\hline
\end{tabular}




\section{Table 6: Informed Trading and Bid-Ask Spread}

This table examines whether common ownership increases the likelihood of informed trading and reduces information asymmetry. Specifically, Panel A uses probability of informed trading (PIN) as the dependent variable, and Panel B uses quarterly average bid-ask spread as the dependent variable. PIN is calculated following Chen, Goldstein and Jiang (2007). A firm is classified as a treatment if it is block-held by one of the merging institutions during the quarter immediately before the merger announcement date and at least one of its same-industry rivals are block-held by the other party to the merger during the same pre-merger quarter. A firm is considered as a control if it is block-held by the same institution (that holds the treatment) and none of its sameindustry rivals are block-held by the other party to the merger during the same pre-merger quarter. Treat is a dummy variable that equals one if a firm is a treatment stock and zero if it is a control. Post is a dummy that equals one for the post-merger period and zero for the pre-merger period. Definitions of variables are provided in Appendix A. The sample period is $t-3$ to $t-1$ and $t+1$ to $t+3$, where year $t$ is the merger announcement year. $t$-statistics are calculated using clustered standard errors by firm level and reported in parentheses.

\begin{tabular}{|c|c|c|c|c|c|c|c|c|c|c|}
\hline Variables & (1) & (2) & (3) & (4) & $(5)$ & (6) & (7) & (8) & (9) & (10) \\
\hline \multirow{2}{*}{ Treat $\times$ Post } & 0.014 & 0.020 & 0.013 & 0.015 & 0.013 & 0.016 & 0.012 & 0.015 & 0.008 & 0.012 \\
\hline & {$[2.11]$} & [3.18] & {$[1.86]$} & [2.47] & {$[1.92]$} & {$[2.53]$} & {$[1.74]$} & [2.28] & [1.22] & {$[1.95]$} \\
\hline \multirow[t]{2}{*}{ Size } & & -0.033 & & -0.029 & & -0.029 & & -0.029 & & -0.030 \\
\hline & & {$[-17.56]$} & & {$[-15.36]$} & & {$[-15.39]$} & & {$[-14.76]$} & & {$[-15.52]$} \\
\hline \multirow[t]{2}{*}{ Amihud } & & 1.266 & & 1.294 & & 1.288 & & 1.267 & & 1.174 \\
\hline & & [3.97] & & {$[4.36]$} & & {$[4.36]$} & & {$[4.30]$} & & {$[4.27]$} \\
\hline \multirow[t]{2}{*}{ Volatility } & & -0.147 & & -0.394 & & -0.388 & & -0.359 & & -0.380 \\
\hline & & {$[-1.90]$} & & {$[-4.24]$} & & {$[-4.16]$} & & {$[-3.72]$} & & {$[-4.05]$} \\
\hline \multirow[t]{2}{*}{ BTM } & & 0.005 & & 0.006 & & 0.006 & & 0.006 & & 0.006 \\
\hline & & {$[4.45]$} & & {$[4.94]$} & & [4.94] & & {$[4.75]$} & & [4.97] \\
\hline \multirow[t]{2}{*}{ Gross Profitability } & & 0.006 & & 0.008 & & 0.008 & & 0.008 & & 0.006 \\
\hline & & {$[0.85]$} & & [1.11] & & {$[1.18]$} & & [1.05] & & {$[0.86]$} \\
\hline \multirow[t]{2}{*}{$\mathrm{x}$} & & 0.007 & & 0.007 & & 0.007 & & 0.007 & & 0.007 \\
\hline & & {$[3.36]$} & & [3.41] & & {$[3.42]$} & & [3.37] & & [3.54] \\
\hline \multirow[t]{2}{*}{10} & & -0.020 & & -0.028 & & -0.027 & & -0.028 & & -0.026 \\
\hline & & {$[-3.81]$} & & {$[-5.44]$} & & {$[-5.44]$} & & {$[-5.46]$} & & {$[-5.23]$} \\
\hline \multirow[t]{2}{*}{ Post } & -0.024 & -0.021 & 0.003 & -0.000 & -0.001 & -0.008 & -0.001 & -0.008 & & \\
\hline & {$[-11.66]$} & {$[-11.50]$} & {$[0.98]$} & {$[-0.17]$} & {$[-0.26]$} & {$[-1.61]$} & {$[-0.23]$} & {$[-1.61]$} & & \\
\hline \multirow[t]{2}{*}{ Treat } & 0.007 & -0.002 & -0.006 & -0.008 & -0.004 & -0.007 & & & & \\
\hline & {$[0.94]$} & {$[-0.30]$} & {$[-0.99]$} & {$[-1.41]$} & {$[-0.66]$} & {$[-1.17]$} & & & & \\
\hline Fixed Effects & \multicolumn{2}{|c|}{ Firm } & \multicolumn{2}{|c|}{ Firm + Year } & \multicolumn{2}{|c|}{ Firm + Year + Merger } & \multicolumn{2}{|c|}{ Firm $\times$ Merger + Year } & \multicolumn{2}{|c|}{ Firm $\times$ Merger + Year $\times$ Merge } \\
\hline $\mathrm{N}$ & 7,444 & 7,156 & 7,444 & 7,156 & 7,444 & 7,156 & 7,439 & 7,153 & 7,438 & 7,152 \\
\hline $\mathrm{R}^{2}$ & $71.1 \%$ & $76.9 \%$ & $74.1 \%$ & $78.7 \%$ & $74.2 \%$ & $78.8 \%$ & $75.4 \%$ & $79.7 \%$ & $76.3 \%$ & $80.6 \%$ \\
\hline \multicolumn{11}{|c|}{ Panel B: Bid-Ask Spread } \\
\hline & (1) & $(2)$ & (3) & (4) & (5) & (6) & (7) & (8) & (9) & $(10)$ \\
\hline \multirow[t]{2}{*}{ Treat $\times$ Post } & -0.014 & -0.003 & -0.009 & -0.004 & -0.009 & -0.004 & -0.010 & -0.005 & -0.010 & -0.005 \\
\hline & {$[-2.39]$} & {$[-1.47]$} & {$[-1.82]$} & {$[-1.72]$} & {$[-1.89]$} & {$[-1.82]$} & {$[-2.07]$} & {$[-1.97]$} & {$[-2.11]$} & {$[-1.91]$} \\
\hline \multirow{2}{*}{ Size } & & 0.002 & & 0.003 & & 0.003 & & 0.003 & & 0.003 \\
\hline & & {$[2.40]$} & & {$[2.62]$} & & {$[2.62]$} & & {$[2.84]$} & & {$[2.92]$} \\
\hline \multirow[t]{2}{*}{ Amihud } & & -0.563 & & -0.524 & & -0.532 & & -0.459 & & -0.492 \\
\hline & & {$[-3.00]$} & & {$[-2.83]$} & & {$[-2.87]$} & & {$[-2.93]$} & & {$[-2.99]$} \\
\hline Volatility & & 0.164 & & 0.160 & & 0.160 & & 0.160 & & 0.160 \\
\hline & & [75.12] & & {$[63.92]$} & & {$[64.63]$} & & [66.88] & & {$[67.94]$} \\
\hline BTM & & -0.000 & & 0.001 & & 0.001 & & 0.002 & & 0.002 \\
\hline & & {$[-0.29]$} & & [1.13] & & {$[1.32]$} & & {$[2.40]$} & & {$[2.41]$} \\
\hline Gross Profitability & & 0.006 & & 0.007 & & 0.008 & & 0.009 & & 0.008 \\
\hline & & {$[1.31]$} & & [1.78] & & {$[1.85]$} & & [1.94] & & {$[1.80]$} \\
\hline$x$ & & -0.021 & & -0.021 & & -0.021 & & -0.020 & & -0.020 \\
\hline & & {$[-6.17]$} & & {$[-6.03]$} & & {$[-5.99]$} & & {$[-5.64]$} & & {$[-5.63]$} \\
\hline 10 & & -0.001 & & -0.003 & & -0.003 & & -0.003 & & -0.003 \\
\hline & & {$[-0.30]$} & & {$[-1.57]$} & & {$[-1.55]$} & & {$[-1.64]$} & & {$[-1.65]$} \\
\hline Post & 0.015 & -0.001 & 0.002 & 0.001 & 0.012 & 0.004 & 0.012 & 0.004 & & \\
\hline & {$[9.36]$} & {$[-1.61]$} & {$[0.72]$} & {$[0.67]$} & [3.77] & {$[2.01]$} & [3.83] & [2.09] & & \\
\hline Treat & 0.026 & 0.003 & 0.016 & 0.001 & 0.014 & 0.001 & & & & \\
\hline & {$[5.08]$} & [1.34] & [3.34] & [0.43] & [2.91] & {$[0.61]$} & & & & \\
\hline Fixed Effects & & & & & Firm + & Merger & Firm $\times 1$ & + Year & Firm $\times$ Mer & ear×Merger \\
\hline $\mathrm{N}$ & 13,522 & 12,787 & 13,522 & 12,787 & 13,522 & 12,787 & 13,518 & 12,779 & 13,517 & 12,777 \\
\hline$R^{2}$ & $48.7 \%$ & $88.6 \%$ & $65.7 \%$ & $89.3 \%$ & $66.0 \%$ & $89.4 \%$ & $69.3 \%$ & $90.0 \%$ & $70.3 \%$ & $90.3 \%$ \\
\hline
\end{tabular}


Table 7: Stock Returns and Holding Changes

This table examines the relation between stock returns and contemporaneous trading activities, proxied by holding changes, of merging institutions. The holding change ( $\Delta \mathrm{H})$ of a merging institution for Firm $i$ is defined from $\mathrm{H}_{\mathrm{it},}-\mathrm{H}_{\mathrm{it}-1}$, where $\mathrm{H}_{\mathrm{t}, \mathrm{t}}$ is the percentage holding by the institution in year $t$ in Firm $i$. A firm is classified as a treatment if it is block-held by one of the merging institutions during the quarter immediately before the merger announcement date and at least one of its same-industry rivals are block-held by the other party to the merger during the same pre-merger quarter. A firm is considered as a control if it is block-held by the same institution (that holds the treatment) and none of its same-industry rivals are block-held by the other party to the merger during the same pre-merger quarter. Treat is a dummy variable that equals one if a firm is a treatment stock and zero if it is a control. Post is a dummy that equals one for the post-merger period and zero for the pre-merger period. Definitions of variables are provided in Appendix A. The sample period is $t-3$ to $t-1$ and $t+1$ to $t+3$, where year $t$ is the merger announcement year. $t$-statistics are calculated using clustered standard errors by firm level and reported in parentheses.

\begin{tabular}{|c|c|c|c|c|c|c|c|c|c|c|}
\hline Variables & $(1)$ & (2) & (3) & (4) & (5) & (6) & (7) & (8) & (9) & (10) \\
\hline \multirow[t]{2}{*}{$\Delta \mathrm{H}$} & 0.100 & 0.117 & -0.442 & -0.347 & -0.399 & -0.313 & -0.457 & -0.277 & -0.425 & -0.248 \\
\hline & {$[0.30]$} & {$[0.37]$} & {$[-1.36]$} & {$[-1.13]$} & {$[-1.23]$} & {$[-1.01]$} & {$[-1.36]$} & {$[-0.87]$} & {$[-1.35]$} & {$[-0.79]$} \\
\hline \multirow[t]{2}{*}{$\Delta \mathrm{H} \times$ Post } & -0.643 & -0.727 & -0.637 & -0.597 & -0.704 & -0.682 & -0.697 & -0.761 & -0.376 & -0.549 \\
\hline & {$[-1.48]$} & {$[-1.76]$} & {$[-1.48]$} & {$[-1.46]$} & {$[-1.62]$} & {$[-1.65]$} & {$[-1.54]$} & {$[-1.77]$} & {$[-0.88]$} & {$[-1.30]$} \\
\hline \multirow[t]{2}{*}{$\Delta \mathrm{H} \times$ Treat } & -1.443 & -1.997 & -0.958 & -1.600 & -1.216 & -1.867 & -1.193 & -1.807 & -1.263 & -1.895 \\
\hline & {$[-1.32]$} & {$[-1.69]$} & {$[-0.97]$} & {$[-1.54]$} & {$[-1.24]$} & {$[-1.83]$} & {$[-1.09]$} & {$[-1.72]$} & {$[-1.16]$} & {$[-1.77]$} \\
\hline \multirow[t]{2}{*}{$\Delta \mathbf{H} \times$ Post $\times$ Treat } & 2.406 & 3.071 & 2.465 & 2.965 & 2.722 & 3.299 & 2.600 & 3.166 & 2.271 & 3.026 \\
\hline & [2.09] & [2.50] & {$[2.38]$} & [2.72] & {$[2.62]$} & [3.07] & {$[2.26]$} & {$[2.84]$} & [1.97] & {$[2.65]$} \\
\hline \multirow[t]{2}{*}{$x$} & -0.621 & -0.435 & -0.515 & -0.422 & -0.511 & -0.417 & -0.470 & -0.350 & -0.446 & -0.343 \\
\hline & {$[-3.02]$} & [-1.94] & {$[-2.61]$} & {$[-1.92]$} & [-2.59] & [-1.89] & {$[-2.65]$} & [-1.81] & {$[-2.51]$} & {$[-1.77]$} \\
\hline \multirow[t]{2}{*}{$\mathrm{X} 2$} & 0.793 & 0.732 & 0.716 & 0.673 & 0.716 & 0.674 & 0.700 & 0.656 & 0.684 & 0.651 \\
\hline & [4.07] & [3.99] & [3.72] & [3.68] & {$[3.72]$} & [3.69] & [3.63] & [3.69] & [3.70] & [3.68] \\
\hline \multirow[t]{2}{*}{ R2 } & -0.197 & -0.207 & -0.181 & -0.186 & -0.182 & -0.187 & -0.192 & -0.196 & -0.190 & -0.194 \\
\hline & {$[-9.24]$} & [-10.29] & {$[-7.55]$} & {$[-9.16]$} & {$[-7.62]$} & [-9.19] & [-7.99] & {$[-9.44]$} & {$[-8.15]$} & {$[-9.18]$} \\
\hline \multirow[t]{2}{*}{ Treat } & 0.017 & 0.009 & -0.027 & 0.016 & -0.053 & -0.019 & & & & \\
\hline & {$[0.31]$} & [0.17] & {$[-0.53]$} & {$[0.32]$} & [-1.09] & {$[-0.39]$} & & & & \\
\hline \multirow[t]{2}{*}{ Post } & 0.101 & 0.024 & -0.018 & -0.001 & -0.182 & -0.078 & -0.182 & -0.071 & & \\
\hline & [6.28] & [1.28] & {$[-0.61]$} & {$[-0.04]$} & {$[-2.52]$} & {$[-1.34]$} & {$[-2.42]$} & [-1.17] & & \\
\hline \multirow[t]{2}{*}{ Treat $\times$ Post } & -0.006 & 0.039 & 0.077 & 0.046 & 0.069 & 0.035 & 0.018 & -0.021 & 0.021 & -0.009 \\
\hline & {$[-0.08]$} & [0.57] & [1.13] & [0.69] & [1.03] & [0.53] & {$[0.33]$} & {$[-0.37]$} & [0.38] & {$[-0.17]$} \\
\hline \multirow[t]{2}{*}{ InvME } & & 14.230 & & 14.156 & & 14.200 & & 14.083 & & 13.767 \\
\hline & & [3.24] & & [3.20] & & [3.23] & & [3.15] & & [3.31] \\
\hline \multirow[t]{2}{*}{ BTM } & & 0.494 & & 0.412 & & 0.418 & & 0.456 & & 0.452 \\
\hline & & [10.61] & & [9.35] & & [9.50] & & [9.77] & & [9.76] \\
\hline \multirow[t]{2}{*}{ AssetG } & & 0.247 & & 0.223 & & 0.221 & & 0.221 & & 0.218 \\
\hline & & [4.35] & & [4.22] & & [4.21] & & [4.51] & & {$[4.46]$} \\
\hline \multirow[t]{2}{*}{ Loss } & & -0.208 & & -0.203 & & -0.205 & & -0.209 & & -0.209 \\
\hline & & [-4.93] & & {$[-5.13]$} & & {$[-5.21]$} & & {$[-5.86]$} & & {$[-5.98]$} \\
\hline \multirow[t]{2}{*}{10} & & -0.311 & & -0.163 & & -0.180 & & -0.271 & & -0.308 \\
\hline & & {$[-3.05]$} & & {$[-1.62]$} & & {$[-1.84]$} & & {$[-3.05]$} & & {$[-3.32]$} \\
\hline \multirow[t]{2}{*}{ Num_IO } & & 0.101 & & 0.041 & & 0.048 & & 0.075 & & 0.086 \\
\hline & & {$[2.78]$} & & {$[1.20]$} & & {$[1.48]$} & & {$[2.63]$} & & {$[2.97]$} \\
\hline Fixed Effects & \multicolumn{2}{|c|}{ Firm } & \multicolumn{2}{|c|}{ Firm + Year } & \multicolumn{2}{|c|}{ Firm + Year + Merger } & \multicolumn{2}{|c|}{ Firm×Merger + Year } & \multicolumn{2}{|c|}{ Firm $\times$ Merger + Year $\times$ Merger } \\
\hline $\mathrm{N}$ & 11,929 & 11,546 & 11,928 & 11,545 & 11,928 & 11,545 & 11,914 & 11,525 & 11,911 & 11,521 \\
\hline $\mathrm{R}^{2}$ & $26.8 \%$ & $42.1 \%$ & $35.4 \%$ & $46.8 \%$ & $35.7 \%$ & $47.1 \%$ & $39.4 \%$ & $51.2 \%$ & $41.3 \%$ & $52.5 \%$ \\
\hline
\end{tabular}




\section{Table 8: Holding Changes and Price Informativeness}

This table investigates the relation between the improvement of price efficiency and common owners' trading activities. Specifically, we introduce a dummy variable, Above (Below), that equals one if absolute value of holdings changes $(|\Delta \mathrm{H}|$ ) in year (quarter) $t$ is above (below) the median value, zero otherwise. Then, we interact Above (Below) with Treat dummy to analyze whether the effect of common ownership is stronger in the subsample of treatment firms that are above (below) the median of $|\Delta \mathrm{H}|$. The holding change $(\Delta \mathrm{H})$ of a merging institution for Firm $i$ is defined from $\mathrm{H}_{\mathrm{i}, \mathrm{t}}-\mathrm{H}_{\mathrm{i}, \mathrm{t}-1}$, where $\mathrm{H}_{\mathrm{i}, \mathrm{t}}$ is the percentage holding by the institution in year (quarter) $t$ in Firm $i$. Treat is a dummy variable that equals one if a firm is a treatment stock and zero if it is a control. Post is a dummy that equals one for the post-merger period and zero for the pre-merger period. Definitions of variables are provided in Appendix A. The sample period is $t-3$ to $t-1$ ( $t-4$ to $t-2$ for earnings-return regressions) and $t+1$ to $t+3$, where year $t$ is the merger announcement year. $t$-statistics are calculated using clustered standard errors by firm level and reported in parentheses.

Panel A: Earnings Informativeness

\begin{tabular}{|c|c|c|c|c|c|c|c|c|}
\hline Variables & $(1)$ & (2) & (3) & (4) & (5) & (6) & (7) & (8) \\
\hline \multirow[t]{2}{*}{$\mathrm{X} \times$ Treat $\times$ Post $\times$ Below } & 0.392 & 0.090 & 0.383 & 0.132 & 0.079 & -0.196 & -0.022 & -0.429 \\
\hline & {$[0.83]$} & {$[0.21]$} & {$[0.81]$} & {$[0.30]$} & {$[0.15]$} & {$[-0.41]$} & {$[-0.04]$} & {$[-0.90]$} \\
\hline \multirow[t]{2}{*}{$\mathrm{X} 2 \times$ Treat $\times$ Post $\times$ Below } & 0.486 & 0.369 & 0.489 & 0.387 & 0.403 & 0.318 & 0.304 & 0.226 \\
\hline & {$[1.20]$} & {$[0.80]$} & {$[1.21]$} & {$[0.85]$} & {$[0.92]$} & {$[0.64]$} & {$[0.72]$} & {$[0.46]$} \\
\hline \multirow[t]{2}{*}{$\mathrm{X} \times$ Treat $\times$ Post $\times$ Above } & -6.908 & -6.590 & -6.995 & -6.596 & -6.967 & -6.477 & -6.983 & -6.541 \\
\hline & {$[-3.77]$} & {$[-4.76]$} & {$[-3.82]$} & {$[-4.79]$} & {$[-3.49]$} & {$[-4.42]$} & {$[-3.56]$} & {$[-4.50]$} \\
\hline \multirow[t]{2}{*}{$\mathrm{X} 2 \times$ Treat $\times$ Post $\times$ Above } & 2.218 & 2.078 & 2.224 & 2.098 & 2.033 & 1.914 & 1.991 & 1.869 \\
\hline & {$[3.56]$} & {$[4.18]$} & {$[3.60]$} & {$[4.25]$} & {$[3.01]$} & {$[3.49]$} & {$[3.02]$} & [3.43] \\
\hline Controls & No & Yes & No & Yes & No & Yes & No & Yes \\
\hline Fixed Effects & \multicolumn{2}{|c|}{$F+Y$} & \multicolumn{2}{|c|}{$F+Y+M$} & \multicolumn{2}{|c|}{$\mathrm{F} \times \mathrm{M}+\mathrm{Y}$} & \multicolumn{2}{|c|}{$F \times M+Y \times M$} \\
\hline $\mathrm{N}$ & 11,578 & 11,229 & 11,578 & 11,229 & 11,565 & 11,213 & 11,561 & 11,209 \\
\hline $\mathrm{R}^{2}$ & $44.4 \%$ & $54.4 \%$ & $44.7 \%$ & $54.7 \%$ & $47.4 \%$ & $57.3 \%$ & $49.1 \%$ & $58.6 \%$ \\
\hline \multicolumn{9}{|l|}{ Panel B: Variance Ratio } \\
\hline Variables & $(1)$ & (2) & (3) & $(4)$ & $(5)$ & (6) & (7) & (8) \\
\hline \multirow[t]{2}{*}{ Treat $\times$ Post $\times$ Below } & -0.022 & -0.022 & -0.021 & -0.021 & -0.019 & -0.019 & -0.020 & -0.021 \\
\hline & {$[-2.01]$} & {$[-1.97]$} & {$[-1.96]$} & {$[-1.93]$} & {$[-1.68]$} & {$[-1.70]$} & {$[-1.78]$} & {$[-1.84]$} \\
\hline \multirow[t]{2}{*}{ Treat $\times$ Post $\times$ Above } & -0.027 & -0.026 & -0.026 & -0.025 & -0.031 & -0.030 & -0.033 & -0.032 \\
\hline & {$[-2.65]$} & {$[-2.55]$} & {$[-2.55]$} & {$[-2.45]$} & {$[-2.95]$} & {$[-2.86]$} & {$[-3.08]$} & {$[-2.99]$} \\
\hline Controls & No & Yes & No & Yes & No & Yes & No & Yes \\
\hline Fixed Effects & \multicolumn{2}{|c|}{$F+Y$} & \multicolumn{2}{|c|}{$F+Y+M$} & \multicolumn{2}{|c|}{$F \times M+Y$} & \multicolumn{2}{|c|}{$F \times M+Y \times M$} \\
\hline Observations & 34,315 & 33,695 & 34,315 & 33,695 & 34,296 & 33,677 & 34,295 & 33,676 \\
\hline R-squared & $9.6 \%$ & $9.8 \%$ & $9.7 \%$ & $9.9 \%$ & $11.2 \%$ & $11.4 \%$ & $11.5 \%$ & $11.6 \%$ \\
\hline
\end{tabular}


Table 9: Quasi-Natural Experiment - Q-Investment Relation

This table uses institution mergers as exogenous shock to common ownership to examine the effects of common ownership on the Q-investment sensitivity. We use CAPXRND, Investment, RND, and DisExp as proxies for corporate investment. Q is the market value of equity plus book value of total assets minus book value of equity, scaled by book value of total assets. All independent variables are measured at $t-1$, except CF, R3, and KZ4, which are contemporaneous with the dependent variables. Definitions of variables are provided in Appendix A. A firm is classified as a treatment if it is block-held by one of the merging institutions during the quarter immediately before the merger announcement date and at least one of its same-industry rivals are block-held by the other party to the merger during the same pre-merger quarter. A firm is considered as a control if it is block-held by the same institution (that holds the treatment) and none of its same-industry rivals are block-held by the other party to the merger during the same pre-merger quarter. Treat is a dummy variable that equals one if a firm is a treatment stock and zero if it is a control. Post is a dummy that equals one for the post-merger period and zero for the pre-merger period. The sample period is $t-3$ to $t-1$ and $t+1$ to $t+3$, where year $t$ is the merger announcement year. $t$-statistics are calculated using clustered standard errors by firm level and reported in parentheses.

\begin{tabular}{|c|c|c|c|c|c|c|c|c|}
\hline & (1) & (2) & (3) & (4) & (5) & (6) & (7) & (8) \\
\hline Variables & \multicolumn{2}{|c|}{ CAPXRND } & \multicolumn{2}{|c|}{ Investment } & \multicolumn{2}{|c|}{ RND } & \multicolumn{2}{|c|}{ DisExp } \\
\hline \multirow[t]{2}{*}{$Q$} & 1.763 & 1.695 & 2.122 & 2.020 & 0.952 & 0.944 & 1.366 & 1.355 \\
\hline & [6.64] & [6.51] & [4.74] & [4.55] & [4.39] & {$[4.35]$} & [4.64] & [4.54] \\
\hline \multirow[t]{2}{*}{$\mathrm{CF}$} & 7.704 & 7.649 & 11.949 & 11.588 & 2.488 & 2.523 & 3.925 & 4.075 \\
\hline & [3.10] & [3.16] & [1.76] & [1.78] & [1.54] & [1.59] & [2.24] & [2.34] \\
\hline \multirow[t]{2}{*}{ Post $\times Q$} & -0.179 & -0.140 & 0.465 & 0.544 & -0.423 & -0.433 & -0.781 & -0.782 \\
\hline & {$[-0.78]$} & {$[-0.63]$} & [1.28] & [1.51] & {$[-2.29]$} & {$[-2.32]$} & {$[-2.66]$} & {$[-2.57]$} \\
\hline \multirow[t]{2}{*}{ Post $\times$ CF } & 1.437 & 1.405 & 5.799 & 5.903 & 2.805 & 2.834 & 1.036 & 0.965 \\
\hline & [0.53] & [0.54] & [0.94] & [0.99] & [1.49] & [1.51] & [0.49] & {$[0.46]$} \\
\hline \multirow[t]{2}{*}{ Treat $\times Q$} & 0.179 & 0.362 & -0.985 & -0.848 & -0.108 & -0.045 & -0.196 & -0.137 \\
\hline & {$[0.21]$} & {$[0.42]$} & {$[-0.90]$} & {$[-0.76]$} & {$[-0.18]$} & {$[-0.08]$} & {$[-0.29]$} & {$[-0.20]$} \\
\hline \multirow[t]{2}{*}{ Treat $\times$ CF } & 2.011 & 1.647 & 0.264 & 0.647 & 0.040 & -0.202 & -0.006 & -0.56 \\
\hline & [0.31] & {$[0.26]$} & {$[0.02]$} & {$[0.06]$} & {$[0.01]$} & {$[-0.05]$} & {$[-0.00]$} & {$[-0.14]$} \\
\hline \multirow[t]{2}{*}{ Treat $\times$ Post $\times \mathbf{Q}$} & 3.682 & 3.545 & 5.898 & 5.917 & 3.606 & 3.598 & 3.868 & 3.855 \\
\hline & [1.96] & [1.91] & [1.71] & [1.73] & [2.13] & [2.14] & [2.21] & [2.19] \\
\hline \multirow[t]{2}{*}{ Treat $\times$ Post $\times C F$} & -7.657 & -6.718 & -28.108 & -27.274 & -7.497 & -6.998 & -7.359 & -6.693 \\
\hline & {$[-0.60]$} & {$[-0.53]$} & {$[-1.06]$} & {$[-1.06]$} & {$[-0.69]$} & {$[-0.65]$} & {$[-0.65]$} & {$[-0.58]$} \\
\hline \multirow[t]{2}{*}{ INVAT } & 0.145 & 0.150 & 0.193 & 0.196 & 0.096 & 0.099 & 0.106 & 0.107 \\
\hline & [3.88] & [4.16] & {$[3.24]$} & [3.32] & [3.09] & [3.21] & [3.38] & {$[3.44]$} \\
\hline \multirow[t]{2}{*}{ Post } & -1.121 & & -2.076 & & 0.321 & & 0.888 & \\
\hline & {$[-1.61]$} & & {$[-1.78]$} & & {$[0.81]$} & & [1.43] & \\
\hline \multirow[t]{2}{*}{ Treat $\times$ Post } & -3.755 & -3.498 & -4.681 & -4.651 & -5.497 & -5.595 & -6.223 & -6.375 \\
\hline & {$[-1.23]$} & {$[-1.15]$} & {$[-1.12]$} & {$[-1.13]$} & {$[-1.90]$} & {$[-1.94]$} & {$[-2.09]$} & {$[-2.14]$} \\
\hline \multirow[t]{2}{*}{ Ret } & -0.057 & -0.031 & -0.123 & -0.137 & 0.045 & 0.050 & 0.066 & 0.061 \\
\hline & {$[-0.42]$} & {$[-0.22]$} & {$[-0.26]$} & {$[-0.29]$} & {$[0.50]$} & {$[0.55]$} & {$[0.71]$} & {$[0.69]$} \\
\hline \multirow[t]{2}{*}{ LEV } & -6.736 & -6.893 & -23.661 & -23.925 & -1.813 & -1.870 & -2.190 & -2.199 \\
\hline & {$[-5.72]$} & {$[-6.12]$} & {$[-8.02]$} & {$[-8.30]$} & {$[-2.86]$} & {$[-2.87]$} & {$[-2.18]$} & {$[-2.17]$} \\
\hline \multirow[t]{2}{*}{$\mathrm{CASH}$} & -2.991 & -2.796 & 4.248 & 4.490 & -2.668 & -2.695 & -2.332 & -2.278 \\
\hline & {$[-3.63]$} & {$[-3.50]$} & {$[2.21]$} & {$[2.44]$} & {$[-3.77]$} & {$[-3.83]$} & {$[-2.71]$} & {$[-2.62]$} \\
\hline \multirow{2}{*}{ SALEG } & 0.576 & 0.561 & -0.865 & -0.899 & 0.301 & 0.271 & 0.551 & 0.525 \\
\hline & [1.37] & {$[1.42]$} & {$[-1.50]$} & {$[-1.64]$} & {$[0.96]$} & {$[0.86]$} & {$[1.56]$} & {$[1.46]$} \\
\hline \multirow[t]{2}{*}{ Tangibility } & 8.899 & 8.975 & 13.700 & 13.389 & 1.494 & 1.596 & 1.295 & 1.326 \\
\hline & {$[5.00]$} & {$[5.12]$} & [3.20] & [3.16] & {$[2.22]$} & {$[2.37]$} & [1.63] & [1.60] \\
\hline \multirow[t]{2}{*}{10} & -1.013 & -0.952 & -0.630 & -0.214 & -1.392 & -1.370 & -1.263 & -1.242 \\
\hline & {$[-1.40]$} & {$[-1.35]$} & {$[-0.38]$} & {$[-0.13]$} & {$[-2.65]$} & {$[-2.64]$} & {$[-2.04]$} & {$[-2.01]$} \\
\hline \multirow[t]{2}{*}{ KZ4 } & 0.172 & 0.167 & -0.058 & -0.043 & -0.007 & -0.003 & -0.046 & -0.050 \\
\hline & [0.91] & {$[0.89]$} & {$[-0.12]$} & {$[-0.09]$} & {$[-0.05]$} & {$[-0.02]$} & {$[-0.17]$} & {$[-0.19]$} \\
\hline Fixed Effects & $F \times M+Y$ & $F \times M+Y \times M$ & $F \times M+Y$ & $F \times M+Y \times M$ & $F \times M+Y$ & $F \times M+Y \times M$ & $F \times M+Y$ & $F \times M+Y \times M$ \\
\hline $\mathrm{N}$ & 11,533 & 11,531 & 11,597 & 11,595 & 11,597 & 11,595 & 11,597 & 11,595 \\
\hline$R^{2}$ & $77.7 \%$ & $78.2 \%$ & $48.2 \%$ & $49.4 \%$ & $86.2 \%$ & $86.4 \%$ & $84.2 \%$ & $84.4 \%$ \\
\hline
\end{tabular}




\section{Table 10: Robustness - Alternative Control Group}

This table utilizes an alternative control group to test the robustness of our main difference-in-difference analyses based on institution mergers as exogenous shocks. A firm is classified as a treatment if it is block-held by one of the merging institutions during the quarter immediately before the merger announcement date and at least one of its sameindustry rivals are block-held by the other party to the merger during the same pre-merger quarter. We identify firms in the alternative control sample as follows. First, for each treatment firm, we select firms that are in the same SIC 4-digit industry group with the treatment firm, but are not block-held by the merging institutions. Then, we match five closest firms to each treatment firm based on size. Treat is a dummy variable that equals one if a firm is a treatment stock and zero if it is a control. Post is a dummy that equals one for the post-merger period and zero for the pre-merger period. The sample period is $t-3$ to $t-1$ ( $t-4$ to $t-2$ for earnings-return regressions) and $t+1$ to $t+3$, where year $t$ is the merger announcement year. Definitions of variables are provided in Appendix A. t-statistics are calculated using clustered standard errors by firm level and reported in parentheses.

\begin{tabular}{|c|c|c|c|c|c|c|c|c|}
\hline & (1) & $(2)$ & (3) & (4) & (5) & $(6)$ & (7) & (8) \\
\hline Panel A & \multicolumn{8}{|c|}{ Annual Returns } \\
\hline \multirow[t]{2}{*}{$\mathrm{X} \times$ Post $\times$ Treat } & -2.657 & -3.74 & -2.685 & -3.756 & -2.367 & -3.472 & -2.559 & -3.548 \\
\hline & {$[-1.55]$} & {$[-2.66]$} & {$[-1.56]$} & {$[-2.70]$} & {$[-1.40]$} & {$[-2.41]$} & {$[-1.41]$} & {$[-2.43]$} \\
\hline \multirow[t]{2}{*}{$\mathrm{X} 2 \times$ Post $\times$ Treat } & 2.268 & 1.675 & 2.269 & 1.658 & 2.006 & 1.428 & 1.933 & 1.435 \\
\hline & [2.18] & {$[2.13]$} & {$[2.16]$} & {$[2.13]$} & [1.93] & {$[1.73]$} & [1.93] & {$[1.77]$} \\
\hline $\mathrm{N}$ & 4,004 & 3,879 & 4,004 & 3,879 & 4,003 & 3,878 & 3,993 & 3,868 \\
\hline$R^{2}$ & $36.4 \%$ & $56.7 \%$ & $36.6 \%$ & $57.0 \%$ & $37.3 \%$ & $57.7 \%$ & $40.6 \%$ & $60.6 \%$ \\
\hline Fixed Effects & \multicolumn{2}{|c|}{$F+Y$} & \multicolumn{2}{|c|}{$F+Y+M$} & \multicolumn{2}{|c|}{$F \times M+Y$} & \multicolumn{2}{|c|}{$F \times M+Y \times M$} \\
\hline Controls & No & Yes & No & Yes & No & Yes & No & Yes \\
\hline Panel B & \multicolumn{8}{|c|}{ Variance Ratios } \\
\hline \multirow[t]{2}{*}{ Treat $\times$ Post } & -0.013 & -0.014 & -0.013 & -0.014 & -0.013 & -0.014 & -0.014 & -0.014 \\
\hline & {$[-1.68]$} & {$[-1.74]$} & {$[-1.71]$} & {$[-1.78]$} & {$[-1.72]$} & {$[-1.74]$} & {$[-1.73]$} & {$[-1.78]$} \\
\hline $\mathrm{N}$ & 20,034 & 19,124 & 20,034 & 19,124 & 20,034 & 19,124 & 20,034 & 19,124 \\
\hline $\mathrm{R}^{2}$ & $11.1 \%$ & $11.8 \%$ & $11.2 \%$ & $11.9 \%$ & $11.3 \%$ & $12.0 \%$ & $12.0 \%$ & $12.6 \%$ \\
\hline Fixed Effects & \multicolumn{2}{|c|}{$F+Y$} & \multicolumn{2}{|c|}{$F+Y+M$} & \multicolumn{2}{|c|}{$F \times M+Y$} & \multicolumn{2}{|c|}{$F \times M+Y \times M$} \\
\hline Controls & No & Yes & No & Yes & No & Yes & No & Yes \\
\hline Panel C & \multicolumn{2}{|c|}{ CAPXRND } & \multicolumn{2}{|c|}{ Investment } & \multicolumn{2}{|c|}{ RND } & \multicolumn{2}{|c|}{ DisExp } \\
\hline Treat $\times$ Post $\times Q$ & 3.785 & 3.525 & 5.465 & 5.285 & 3.267 & 2.974 & 3.092 & 2.912 \\
\hline & {$[2.00]$} & [1.97] & [1.61] & [1.69] & [1.97] & [1.93] & {$[1.70]$} & {$[1.71]$} \\
\hline $\mathrm{N}$ & 4,275 & 4,260 & 4,326 & 4,311 & 4,326 & 4,311 & 4,326 & 4,311 \\
\hline $\mathrm{R} 2$ & $60.4 \%$ & $62.2 \%$ & $39.5 \%$ & $41.5 \%$ & $81.7 \%$ & $82.9 \%$ & $81.6 \%$ & $82.7 \%$ \\
\hline $\begin{array}{l}\text { Fixed Effects } \\
\text { Controls }\end{array}$ & $\mathrm{F} \times \mathrm{M}+\mathrm{Y}$ & $F \times M+Y \times M$ & $F \times M+Y$ & $F \times M+Y \times M$ & $F \times M+Y$ & $\mathrm{~F} \times \mathrm{M}+\mathrm{Y} \times \mathrm{M}$ & $F \times M+Y$ & $\mathrm{~F} \times \mathrm{M}+\mathrm{Y} \times \mathrm{N}$ \\
\hline
\end{tabular}


Table 11: Falsificaton Tests

This table reports the falsification test results. The sample period for the tests is $t-7$ to $t-5$ and $t-3$ to $t-1$, where $t$ is the merger announcement year. We use year $t-4$ as the base year for the tests. Post is a dummy that equals one for the period between $t-3$ and $t-1$ and zero otherwise. A firm is classified as a treatment if it is block-held by one of the merging institutions during the quarter immediately before the merger announcement date and at least one of its same-industry rivals are block-held by the other party to the merger during the same pre-merger quarter. A firm is considered as a control if it is block-held by the same institution (that holds the treatment) and none of its same-industry rivals are block-held by the other party to the merger during the same pre-merger quarter. Treat is a dummy variable that equals one if a firm is a treatment stock and zero if it is a control. Definitions of variables are provided in Appendix A. $t$-statistics are calculated using clustered standard errors by firm level and reported in parentheses.

\begin{tabular}{|c|c|c|c|c|c|c|c|c|}
\hline & $(1)$ & $(2)$ & (3) & $(4)$ & $(5)$ & (6) & $(7)$ & $(8)$ \\
\hline Panel A & \multicolumn{8}{|c|}{ Annual Returns } \\
\hline \multirow[t]{2}{*}{$\mathrm{X} \times$ Post $\times$ Treat } & 0.375 & 0.335 & 0.361 & 0.31 & 0.358 & 0.35 & 0.432 & 0.416 \\
\hline & [0.94] & [0.94] & {$[0.90]$} & {$[0.87]$} & [0.89] & {$[0.95]$} & [1.10] & [1.15] \\
\hline \multirow{2}{*}{$\mathrm{X} 2 \times$ Post $\times$ Treat } & -0.035 & -0.311 & -0.032 & -0.306 & 0.023 & -0.277 & -0.051 & -0.332 \\
\hline & {$[-0.08]$} & {$[-1.04]$} & {$[-0.07]$} & {$[-1.02]$} & {$[0.05]$} & {$[-0.89]$} & {$[-0.13]$} & {$[-1.11]$} \\
\hline $\mathrm{N}$ & 11,572 & 11,285 & 11,572 & 11,285 & 11,541 & 11,251 & 11,539 & 11,248 \\
\hline $\mathrm{R}^{2}$ & $33.5 \%$ & $45.5 \%$ & $33.8 \%$ & $45.8 \%$ & $35.1 \%$ & $47.5 \%$ & $36.5 \%$ & $48.5 \%$ \\
\hline Fixed Effects & \multicolumn{2}{|c|}{$F+Y$} & \multicolumn{2}{|c|}{$F+Y+M$} & \multicolumn{2}{|c|}{$F \times M+Y$} & \multicolumn{2}{|c|}{$F \times M+Y \times M$} \\
\hline Controls & No & Yes & No & Yes & No & Yes & No & Yes \\
\hline Panel B & \multicolumn{8}{|c|}{ Variance Ratios } \\
\hline \multirow[t]{2}{*}{ Treat $\times$ Post } & 0.004 & 0.004 & 0.004 & 0.003 & 0.004 & 0.004 & 0.002 & 0.001 \\
\hline & {$[0.53]$} & {$[0.48]$} & {$[0.50]$} & {$[0.41]$} & {$[0.59]$} & {$[0.48]$} & {$[0.33]$} & {$[0.12]$} \\
\hline $\mathrm{N}$ & 51,937 & 49,626 & 51,937 & 49,626 & 51,937 & 49,626 & 51,937 & 49,626 \\
\hline $\mathrm{R}^{2}$ & $9.2 \%$ & $9.6 \%$ & $9.3 \%$ & $9.7 \%$ & $10.3 \%$ & $10.6 \%$ & $10.5 \%$ & $10.9 \%$ \\
\hline Fixed Effects & \multicolumn{2}{|c|}{$F+Y$} & \multicolumn{2}{|c|}{$F+Y+M$} & \multicolumn{2}{|c|}{$F \times M+Y$} & \multicolumn{2}{|c|}{$F \times M+Y \times M$} \\
\hline Controls & No & Yes & No & Yes & No & Yes & No & Yes \\
\hline Panel C & \multicolumn{2}{|c|}{ CAPXRND } & \multicolumn{2}{|c|}{ Investment } & \multicolumn{2}{|c|}{ RND } & \multicolumn{2}{|c|}{ DisExp } \\
\hline \multirow[t]{2}{*}{ Treat $\times$ Post $\times Q$} & 0.129 & 0.228 & -0.003 & 0.142 & -0.273 & -0.248 & -0.595 & -0.574 \\
\hline & [0.15] & {$[0.26]$} & {$[-0.00]$} & {$[0.12]$} & {$[-0.50]$} & {$[-0.46]$} & {$[-1.04]$} & {$[-1.02]$} \\
\hline $\mathrm{N}$ & 11,716 & 11,715 & 11,798 & 11,797 & 11,798 & 11,797 & 11,798 & 11,797 \\
\hline$R^{2}$ & $73.0 \%$ & $73.7 \%$ & $44.6 \%$ & $45.7 \%$ & $82.9 \%$ & $83.0 \%$ & $82.8 \%$ & $82.9 \%$ \\
\hline $\begin{array}{l}\text { Fixed Effects } \\
\text { Controls }\end{array}$ & $\mathrm{F} \times \mathrm{M}+\mathrm{Y}$ & $\mathrm{F} \times \mathrm{M}+\mathrm{Y} \times \mathrm{M}$ & $F \times M+Y$ & $F \times M+Y \times M$ & $F \times M+Y$ & $\mathrm{~F} \times \mathrm{M}+\mathrm{Y} \times \mathrm{M}$ & $F \times M+Y$ & $F \times M+Y \times M$ \\
\hline
\end{tabular}




\section{Table 12: Excluding Financial Crisis}

This table studies whether our results are driven by mergers during the financial crisis. Specifically, we run the main difference-in-difference test, excluding the institutional mergers for which effective dates are in the period of the financial crisis. We define the period of 07/2007 to 12/2009 as the financial crisis period. A firm is classified as a treatment if it is block-held by one of the merging institutions during the quarter immediately before the merger announcement date and at least one of its same-industry rivals are block-held by the other party to the merger during the same pre-merger quarter. A firm is considered as a control if it is block-held by the same institution (that holds the treatment) and none of its same-industry rivals are block-held by the other party to the merger during the same pre-merger quarter. Treat is a dummy variable that equals one if a firm is a treatment stock and zero if it is a control. Post is a dummy that equals one for the post-merger period and zero for the pre-merger period. The sample period is $t-3$ to $t-1$ ( $t-4$ to $t-2$ for earnings-return regressions) and $t+1$ to $t+3$, where year $t$ is the merger announcement year. Definitions of variables are provided in Appendix A. $t$-statistics are calculated using clustered standard errors by firm level and reported in parentheses.

\begin{tabular}{|c|c|c|c|c|c|c|c|c|}
\hline & (1) & (2) & (3) & (4) & (5) & (6) & (7) & (8) \\
\hline Panel A & \multicolumn{8}{|c|}{ Annual Returns } \\
\hline \multirow[t]{2}{*}{$\mathrm{X} \times$ Post $\times$ Treat } & -0.180 & -0.479 & -0.177 & -0.455 & -0.289 & -0.627 & -0.320 & -0.748 \\
\hline & {$[-0.34]$} & {$[-1.05]$} & {$[-0.33]$} & {$[-1.01]$} & {$[-0.52]$} & {$[-1.34]$} & {$[-0.56]$} & {$[-1.55]$} \\
\hline \multirow[t]{2}{*}{$\mathrm{X} 2 \times$ Post $\times$ Treat } & 1.350 & 0.953 & 1.363 & 0.983 & 1.374 & 0.948 & 1.252 & 0.845 \\
\hline & {$[2.45]$} & {$[1.82]$} & {$[2.48]$} & [1.87] & {$[2.48]$} & {$[1.71]$} & {$[2.41]$} & [1.55] \\
\hline $\mathrm{N}$ & 4,070 & 3,924 & 4,070 & 3,924 & 4,065 & 3,919 & 4,061 & 3,915 \\
\hline$R^{2}$ & $46.8 \%$ & $55.9 \%$ & $47.1 \%$ & $56.1 \%$ & $47.6 \%$ & $56.6 \%$ & $49.7 \%$ & $58.5 \%$ \\
\hline Fixed Effects & \multicolumn{2}{|c|}{$F+Y$} & \multicolumn{2}{|c|}{$F+Y+M$} & \multicolumn{2}{|c|}{$F \times M+Y$} & \multicolumn{2}{|c|}{$F \times M+Y \times M$} \\
\hline Controls & No & Yes & No & Yes & No & Yes & No & Yes \\
\hline Panel B & \multicolumn{8}{|c|}{ Variance Ratios } \\
\hline \multirow{2}{*}{ Treat $\times$ Post } & -0.020 & -0.019 & -0.019 & -0.018 & -0.018 & -0.018 & -0.020 & -0.020 \\
\hline & {$[-2.55]$} & {$[-2.37]$} & {$[-2.51]$} & {$[-2.31]$} & {$[-2.36]$} & {$[-2.22]$} & {$[-2.56]$} & {$[-2.45]$} \\
\hline $\mathrm{N}$ & 20,601 & 19,877 & 20,601 & 19,877 & 20,601 & 19,877 & 20,601 & 19,877 \\
\hline$R^{2}$ & $11.6 \%$ & $12.0 \%$ & $11.7 \%$ & $12.0 \%$ & $12.0 \%$ & $12.3 \%$ & $12.4 \%$ & $12.7 \%$ \\
\hline Fixed Effects & \multicolumn{2}{|c|}{$F+Y$} & \multicolumn{2}{|c|}{$F+Y+M$} & \multicolumn{2}{|c|}{$F \times M+Y$} & \multicolumn{2}{|c|}{$\mathrm{F} \times \mathrm{M}+\mathrm{Y} \times \mathrm{M}$} \\
\hline Controls & No & Yes & No & Yes & No & Yes & No & Yes \\
\hline Panel C & \multicolumn{2}{|c|}{ CAPXRND } & \multicolumn{2}{|c|}{ Investment } & \multicolumn{2}{|c|}{ RND } & \multicolumn{2}{|c|}{ DisExp } \\
\hline \multirow[t]{2}{*}{ Treat $\times$ Post $\times Q$} & 4.665 & 4.546 & 6.608 & 6.679 & 3.877 & 3.895 & 3.893 & 3.887 \\
\hline & [2.34] & [2.26] & [1.77] & [1.78] & {$[2.14]$} & [2.13] & {$[2.11]$} & {$[2.08]$} \\
\hline $\mathrm{N}$ & 4,478 & 4,476 & 4,533 & 4,531 & 4,533 & 4,531 & 4,533 & 4,531 \\
\hline $\mathrm{R}^{2}$ & $74.3 \%$ & $75.1 \%$ & $47.6 \%$ & $49.6 \%$ & $81.6 \%$ & $81.9 \%$ & $80.6 \%$ & $81.0 \%$ \\
\hline Fixed Effects & $\mathrm{F} \times \mathrm{M}+\mathrm{Y}$ & $F \times M+Y \times M$ & $\mathrm{~F} \times \mathrm{M}+\mathrm{Y}$ & $\mathrm{F} \times \mathrm{M}+\mathrm{Y} \times \mathrm{M}$ & $\mathrm{F} \times \mathrm{M}+\mathrm{Y}$ & $\mathrm{F} \times \mathrm{M}+\mathrm{Y} \times \mathrm{M}$ & $\mathrm{F} \times \mathrm{M}+\mathrm{Y}$ & $F \times M+Y \times M$ \\
\hline Controls & \multicolumn{8}{|c|}{ Yes } \\
\hline
\end{tabular}


Table A1: Summary Statistics - OLS

Panel A shows the descriptive statistics of key variables, and Panel B reports the correlations. The upper right corner of Panel B reports Pearson correlations and the lower left corner of the panel provides Spearman correlations. The variable definitions are provided in Appendix A. The sample includes US public firms for the period of $1980-2014$.

Panel A: Descriptive Statistics

\begin{tabular}{|c|c|c|c|c|c|c|c|c|c|c|c|c|c|c|c|c|}
\hline Variable & \multicolumn{2}{|c|}{$\mathrm{N}$} & \multicolumn{2}{|c|}{ Mean } & \multicolumn{2}{|c|}{ STD } & \multicolumn{2}{|c|}{$\mathrm{P} 10$} & \multicolumn{2}{|c|}{$\mathrm{P} 25$} & \multicolumn{2}{|c|}{ Median } & \multicolumn{2}{|c|}{ P75 } & \multicolumn{2}{|c|}{$\mathrm{P} 90$} \\
\hline CrossDummy & \multicolumn{2}{|c|}{114661} & \multicolumn{2}{|c|}{0.427} & \multicolumn{2}{|c|}{0.495} & \multicolumn{2}{|c|}{0.000} & \multicolumn{2}{|c|}{0.000} & \multicolumn{2}{|c|}{0.000} & 1.0 & & 1.0 & 000 \\
\hline NConnected & 114 & 661 & 2.1 & 99 & 5.6 & & 0.0 & & 0.0 & & 0.0 & & 1.7 & & 6.0 & 000 \\
\hline NCross & 114 & 661 & 0.5 & 48 & 0.8 & & 0.0 & & 0.0 & & 0.0 & & 1.0 & & 1.7 & 750 \\
\hline AvgNum & 114 & 661 & 1.3 & 80 & 3.0 & & 0.0 & & 0.0 & & 0.0 & & 1.3 & & 4.0 & 000 \\
\hline TotalCrossOwn & 114 & 661 & 0.0 & 46 & 0.0 & & 0.0 & & 0.0 & & 0.0 & & 0.0 & & 0.1 & 154 \\
\hline 10 & 114 & 661 & 0.3 & 58 & 0.3 & & 0.0 & & 0.0 & & 0.2 & & 0.5 & & & 814 \\
\hline$x$ & 114 & 661 & $-0 . c$ & 25 & 0.2 & & -0.2 & & $-0 . c$ & & 0.0 & & 0.0 & & 0.1 & 131 \\
\hline X3 & $95<$ & 472 & 0.0 & 12 & 0.6 & & -0.5 & & -0. & & 0.1 & & 0.2 & & & 532 \\
\hline RET & 113 & 865 & 0.1 & 79 & 0.9 & & -0.5 & & -0.2 & & 0.0 & & 0.3 & & 0.8 & 393 \\
\hline R3 & 895 & 904 & 0.5 & 15 & 1.8 & & -0.6 & & -0.3 & & 0.1 & & 0.8 & & 1.8 & 835 \\
\hline SIZE & 114 & 661 & 11. & 748 & 2.1 & & 9.0 & & 10. & & 11. & 501 & 13. & & 14. & 638 \\
\hline BTM & 111 & 090 & -0.6 & 580 & 0.9 & & $-1 . \varepsilon$ & & -1.2 & & -0.6 & 00 & -0.6 & & 0.4 & 413 \\
\hline Variance Ratio (Annual) & 114 & 198 & 0.2 & 67 & 0.2 & & 0.0 & & 0.1 & & 0.2 & & 0.3 & & 0.5 & 571 \\
\hline Amihud & 112 & 092 & 0.0 & 07 & 0.0 & & 0.0 & & 0.0 & & 0.0 & & 0.0 & & 0.0 & 010 \\
\hline BidAsk Spread & 114 & 661 & 0.1 & 92 & 0.0 & & 0.0 & & 0.1 & & 0.1 & & 0.2 & & 0.3 & 319 \\
\hline Q & 107 & 170 & 1.9 & 56 & 2.0 & & 0.8 & & 1.0 & & 1.3 & & 2.0 & & 3.4 & 495 \\
\hline AssetGrowth & 106 & 175 & 12. & 382 & 40.0 & & -19. & & $-4 . \varepsilon$ & & 5.5 & & 18. & & 44. & 863 \\
\hline CAPXRND & 104 & 940 & 12. & 590 & 13.6 & & 1.6 & & 3.8 & & 8.3 & & 16. & & 27. & 893 \\
\hline & & & & & & & & & & & & & & & & \\
\hline & CrossDummy & NConnected & NCross & AvgNum & TotalCrossOwn & 10 & $\mathrm{X}$ & $\mathrm{X} 3$ & AnnRet & R3 & SIZE & BTM & VR & $\mathrm{Q}$ & AssetGrowth & CAPXRND \\
\hline CrossDummy & & 0.450 & 0.731 & 0.516 & 0.686 & 0.537 & 0.029 & 0.032 & 0.006 & 0.002 & 0.338 & -0.016 & -0.168 & -0.005 & -0.008 & 0.037 \\
\hline & & {$[0.00]$} & {$[0.00]$} & {$[0.00]$} & {$[0.00]$} & {$[0.00]$} & {$[0.00]$} & {$[0.00]$} & {$[0.05]$} & {$[0.46]$} & {$[0.00]$} & {$[0.00]$} & {$[0.00]$} & {$[0.10]$} & [0.01] & {$[0.00]$} \\
\hline NConnected & 0.951 & & 0.704 & 0.911 & 0.668 & 0.364 & -0.006 & -0.013 & 0.007 & 0.003 & 0.228 & -0.078 & -0.115 & 0.067 & 0.006 & 0.123 \\
\hline & {$[0.00]$} & & {$[0.00]$} & {$[0.00]$} & {$[0.00]$} & {$[0.00]$} & {$[0.06]$} & {$[0.00]$} & {$[0.02]$} & {$[0.38]$} & {$[0.00]$} & {$[0.00]$} & {$[0.00]$} & {$[0.00]$} & {$[0.04]$} & {$[0.00]$} \\
\hline NCross & 0.952 & 0.977 & & 0.599 & 0.952 & 0.559 & 0.013 & 0.015 & 0.000 & 0.002 & 0.310 & -0.018 & -0.156 & 0.012 & -0.014 & 0.041 \\
\hline & {$[0.00]$} & {$[0.00]$} & & {$[0.00]$} & {$[0.00]$} & {$[0.00]$} & {$[0.00]$} & {$[0.00]$} & {$[1.00]$} & {$[0.50]$} & {$[0.00]$} & {$[0.00]$} & {$[0.00]$} & {$[0.00]$} & {$[0.00]$} & {$[0.00]$} \\
\hline AvgNum & 0.951 & 0.997 & 0.965 & & 0.567 & 0.338 & -0.003 & -0.007 & 0.012 & 0.005 & 0.228 & -0.068 & -0.113 & 0.059 & 0.007 & 0.124 \\
\hline & {$[0.00]$} & {$[0.00]$} & {$[0.00]$} & & {$[0.00]$} & {$[0.00]$} & {$[0.29]$} & {$[0.02]$} & {$[0.00]$} & {$[0.14]$} & {$[0.00]$} & {$[0.00]$} & {$[0.00]$} & {$[0.00]$} & {$[0.02]$} & {$[0.00]$} \\
\hline TotalCrossOwn & 0.951 & 0.972 & 0.994 & 0.961 & & 0.543 & -0.001 & 0.004 & -0.002 & 0.002 & 0.288 & -0.021 & -0.146 & 0.015 & -0.013 & 0.044 \\
\hline & {$[0.00]$} & {$[0.00]$} & {$[0.00]$} & {$[0.00]$} & & {$[0.00]$} & {$[0.86]$} & {$[0.24]$} & [0.57] & {$[0.60]$} & {$[0.00]$} & {$[0.00]$} & {$[0.00]$} & {$[0.00]$} & {$[0.00]$} & {$[0.00]$} \\
\hline 10 & 0.552 & 0.558 & 0.582 & 0.546 & 0.583 & & 0.167 & 0.140 & 0.028 & -0.029 & 0.713 & -0.086 & -0.312 & 0.014 & 0.015 & -0.063 \\
\hline & {$[0.00]$} & {$[0.00]$} & {$[0.00]$} & {$[0.00]$} & {$[0.00]$} & & {$[0.00]$} & {$[0.00]$} & {$[0.00]$} & {$[0.00]$} & {$[0.00]$} & {$[0.00]$} & {$[0.00]$} & {$[0.00]$} & {$[0.00]$} & {$[0.00]$} \\
\hline$x$ & -0.001 & -0.021 & -0.012 & -0.020 & -0.014 & 0.183 & & 0.452 & 0.077 & -0.039 & 0.218 & -0.121 & -0.099 & -0.014 & 0.129 & -0.066 \\
\hline & [0.87] & {$[0.00]$} & {$[0.00]$} & {$[0.00]$} & {$[0.00]$} & {$[0.00]$} & & {$[0.00]$} & {$[0.00]$} & {$[0.00]$} & {$[0.00]$} & {$[0.00]$} & {$[0.00]$} & {$[0.00]$} & {$[0.00]$} & {$[0.00]$} \\
\hline $\mathrm{x} 3$ & 0.017 & 0.001 & 0.009 & 0.002 & 0.008 & 0.180 & 0.545 & & 0.052 & 0.230 & 0.160 & 0.051 & -0.073 & -0.081 & 0.039 & -0.154 \\
\hline & {$[0.00]$} & [0.87] & [0.01] & [0.54] & [0.02] & {$[0.00]$} & {$[0.00]$} & & {$[0.00]$} & {$[0.00]$} & {$[0.00]$} & {$[0.00]$} & [0.00] & {$[0.00]$} & {$[0.00]$} & {$[0.00]$} \\
\hline AnnRet & 0.023 & 0.023 & 0.024 & 0.023 & 0.022 & 0.121 & 0.377 & 0.329 & & -0.077 & -0.077 & 0.114 & -0.094 & 0.217 & 0.266 & 0.127 \\
\hline & [0.00] & [0.00] & {$[0.00]$} & {$[0.00]$} & [0.00] & {$[0.00]$} & {$[0.00]$} & {$[0.00]$} & & {$[0.00]$} & {$[0.00]$} & {$[0.00]$} & {$[0.00]$} & {$[0.00]$} & {$[0.00]$} & {$[0.00]$} \\
\hline R3 & 0.018 & 0.019 & 0.022 & 0.020 & 0.021 & 0.074 & 0.127 & 0.500 & -0.049 & & -0.047 & 0.091 & 0.014 & -0.087 & 0.002 & -0.021 \\
\hline & [0.00] & {$[0.00]$} & {$[0.00]$} & {$[0.00]$} & [0.00] & {$[0.00]$} & {$[0.00]$} & {$[0.00]$} & {$[0.00]$} & & {$[0.00]$} & {$[0.00]$} & {$[0.00]$} & {$[0.00]$} & [0.62] & {$[0.00]$} \\
\hline SIZE & 0.362 & 0.365 & 0.375 & 0.358 & 0.373 & 0.774 & 0.167 & 0.159 & 0.018 & 0.064 & & -0.273 & -0.349 & 0.107 & 0.008 & -0.017 \\
\hline & {$[0.00]$} & {$[0.00]$} & {$[0.00]$} & {$[0.00]$} & {$[0.00]$} & {$[0.00]$} & {$[0.00]$} & {$[0.00]$} & {$[0.00]$} & {$[0.00]$} & & {$[0.00]$} & {$[0.00]$} & {$[0.00]$} & {$[0.01]$} & {$[0.00]$} \\
\hline BTM & -0.030 & -0.039 & -0.026 & -0.038 & -0.029 & -0.106 & 0.100 & 0.132 & 0.150 & 0.152 & -0.302 & & 0.106 & -0.549 & -0.180 & -0.293 \\
\hline & {$[0.00]$} & {$[0.00]$} & {$[0.00]$} & {$[0.00]$} & [0.00] & {$[0.00]$} & {$[0.00]$} & {$[0.00]$} & {$[0.00]$} & {$[0.00]$} & {$[0.00]$} & & {$[0.00]$} & {$[0.00]$} & {$[0.00]$} & {$[0.00]$} \\
\hline Variance Ratio & -0.150 & -0.153 & -0.156 & -0.151 & -0.155 & -0.292 & -0.086 & -0.078 & -0.122 & -0.014 & -0.335 & 0.105 & & -0.080 & -0.085 & -0.048 \\
\hline & {$[0.00]$} & {$[0.00]$} & {$[0.00]$} & {$[0.00]$} & {$[0.00]$} & {$[0.00]$} & {$[0.00]$} & {$[0.00]$} & {$[0.00]$} & {$[0.00]$} & {$[0.00]$} & {$[0.00]$} & & {$[0.00]$} & {$[0.00]$} & {$[0.00]$} \\
\hline$Q$ & 0.051 & 0.067 & 0.052 & 0.066 & 0.054 & 0.151 & -0.049 & -0.045 & 0.225 & -0.178 & 0.284 & -0.784 & -0.146 & & 0.256 & 0.365 \\
\hline & {$[0.00]$} & {$[0.00]$} & {$[0.00]$} & {$[0.00]$} & {$[0.00]$} & {$[0.00]$} & {$[0.00]$} & {$[0.00]$} & {$[0.00]$} & {$[0.00]$} & {$[0.00]$} & {$[0.00]$} & {$[0.00]$} & & {$[0.00]$} & {$[0.00]$} \\
\hline AssetGrowth & 0.010 & 0.010 & 0.007 & 0.010 & 0.007 & 0.090 & 0.285 & 0.303 & 0.354 & 0.040 & 0.093 & -0.201 & -0.111 & 0.297 & & 0.336 \\
\hline & {$[0.00]$} & {$[0.00]$} & {$[0.03]$} & {$[0.00]$} & {$[0.02]$} & {$[0.00]$} & {$[0.00]$} & {$[0.00]$} & {$[0.00]$} & {$[0.00]$} & {$[0.00]$} & {$[0.00]$} & {$[0.00]$} & {$[0.00]$} & & {$[0.00]$} \\
\hline CAPXRND & 0.063 & 0.095 & 0.064 & 0.096 & 0.065 & 0.020 & -0.042 & -0.071 & 0.105 & -0.072 & 0.073 & -0.303 & -0.070 & 0.391 & 0.293 & \\
\hline & {$[0.00]$} & {$[0.00]$} & {$[0.00]$} & {$[0.00]$} & {$[0.00]$} & {$[0.00]$} & {$[0.00]$} & {$[0.00]$} & {$[0.00]$} & {$[0.00]$} & {$[0.00]$} & {$[0.00]$} & {$[0.00]$} & {$[0.00]$} & {$[0.00]$} & \\
\hline
\end{tabular}


Table A2: Regressions of Annual Returns on Current and Future Earnings

This table reports the regression results of the annual returns on the current and future earnings. Panel A shows the results of pooled regressions, while Panel B provides the Fama-MacBeth regression results. The dependent variable is the buy-and-hold return for year $t$, measured over the 12-month period ending three months after the firm's fiscal year- $t$ end. CO measures the common ownership during year $t$. We use the five different proxies for common ownership. Except for CrossDummy, $\mathrm{CO}$ is the decile score of the common ownership variables, scaled between zero and one. Each year, stocks are sorted based on their common ownership measures into deciles. Then, the decile ranks are normalized on a scale of zero to one. CO Index is the average of all five proxies of common ownership. $\mathrm{IO}$ is the residual institutional ownership orthogonalized from the $\mathrm{CO}$ variables. Specifically, IO is obtained from the residuals of the regression of total institutional ownership on Crossdummy and TotalCrossOwn. $\mathrm{O}$ is also a decile rank, normalized between zero and one. Definitions of other explanatory variables are provided in Appendix A. Year and Firm Fixed Effects are included in the pooled regressions. $t$-statistics are calculated using clustered standard errors by firm level and reported in parentheses. The sample period is $1980-2014$.

\begin{tabular}{|c|c|c|c|c|c|c|c|c|c|c|c|c|}
\hline \multirow[b]{2}{*}{ Variables } & (1) & (2) & (3) & (4) & (5) & (6) & (7) & $(8)$ & (9) & (10) & (11) & (12) \\
\hline & \multicolumn{2}{|c|}{ CrossDummy } & \multicolumn{2}{|c|}{ NConnected } & \multicolumn{2}{|c|}{ NCross } & \multicolumn{2}{|c|}{ AvgNum } & \multicolumn{2}{|c|}{ TotalCrossOwn } & \multicolumn{2}{|c|}{ CO Index } \\
\hline \multirow[t]{2}{*}{ Lagged X } & -0.665 & -0.407 & -0.664 & -0.435 & -0.655 & -0.444 & -0.672 & -0.437 & -0.665 & -0.443 & -0.662 & -0.417 \\
\hline & {$[-13.52]$} & {$[-5.15]$} & {$[-9.25]$} & {$[-4.79]$} & {$[-9.06]$} & {$[-4.91]$} & {$[-9.41]$} & {$[-4.79]$} & {$[-9.21]$} & {$[-4.89]$} & {$[-9.94]$} & {$[-4.65]$} \\
\hline \multirow[t]{2}{*}{$x$} & 0.476 & 0.600 & 0.380 & 0.488 & 0.363 & 0.482 & 0.392 & 0.503 & 0.397 & 0.517 & 0.452 & 0.569 \\
\hline & [8.04] & {$[5.60]$} & {$[3.90]$} & {$[3.82]$} & {$[3.69]$} & {$[3.70]$} & [4.14] & {$[3.82]$} & {$[4.05]$} & {$[4.00]$} & {$[5.22]$} & [4.46] \\
\hline \multirow[t]{2}{*}{ X3 } & 0.114 & -0.071 & 0.086 & -0.097 & 0.054 & -0.134 & 0.092 & -0.096 & 0.065 & -0.126 & 0.080 & -0.111 \\
\hline & [4.09] & {$[-1.75]$} & {$[2.08]$} & {$[-1.91]$} & {$[1.30]$} & {$[-2.64]$} & [2.23] & {$[-1.88]$} & {$[1.58]$} & {$[-2.44]$} & {$[2.11]$} & {$[-2.25]$} \\
\hline \multirow[t]{2}{*}{ R3 } & -0.077 & -0.094 & -0.078 & -0.096 & -0.08 & -0.097 & -0.079 & -0.097 & -0.081 & -0.097 & -0.079 & -0.098 \\
\hline & {$[-11.72]$} & {$[-7.69]$} & {$[-8.28]$} & {$[-6.35]$} & {$[-8.22]$} & {$[-6.29]$} & {$[-8.23]$} & {$[-6.20]$} & {$[-8.26]$} & {$[-6.25]$} & {$[-8.96]$} & {$[-6.59]$} \\
\hline \multirow[t]{2}{*}{$\mathrm{CO}$} & -0.053 & -0.056 & -0.106 & -0.138 & -0.111 & -0.141 & -0.097 & -0.126 & -0.111 & -0.140 & -0.097 & -0.120 \\
\hline & {$[-5.06]$} & {$[-4.20]$} & {$[-5.78]$} & {$[-5.85]$} & {$[-6.29]$} & {$[-5.93]$} & {$[-5.43]$} & {$[-5.59]$} & {$[-6.35]$} & {$[-5.84]$} & {$[-5.95]$} & {$[-5.54]$} \\
\hline \multirow[t]{2}{*}{ Lagged X×CO } & -0.008 & -0.142 & 0.002 & -0.098 & -0.018 & -0.087 & 0.018 & -0.095 & 0.001 & -0.09 & -0.005 & -0.132 \\
\hline & {$[-0.11]$} & {$[-2.01]$} & {$[0.02]$} & {$[-0.90]$} & {$[-0.15]$} & {$[-0.81]$} & {$[0.16]$} & {$[-0.87]$} & {$[0.01]$} & {$[-0.83]$} & {$[-0.05]$} & {$[-1.30]$} \\
\hline \multirow[t]{2}{*}{$\mathrm{x} \times \mathrm{CO}$} & -0.393 & -0.373 & -0.152 & -0.184 & -0.119 & -0.172 & -0.175 & -0.21 & -0.189 & -0.234 & -0.305 & -0.323 \\
\hline & {$[-4.20]$} & {$[-3.66]$} & {$[-0.99]$} & {$[-1.24]$} & {$[-0.76]$} & {$[-1.13]$} & {$[-1.15]$} & {$[-1.35]$} & {$[-1.23]$} & {$[-1.57]$} & {$[-2.18]$} & {$[-2.26]$} \\
\hline \multirow[t]{2}{*}{$\mathrm{X} 3 \times \mathrm{CO}$} & 0.098 & 0.122 & 0.138 & 0.162 & 0.207 & 0.234 & 0.127 & 0.158 & 0.183 & 0.216 & 0.157 & 0.189 \\
\hline & [2.43] & [2.91] & {$[2.06]$} & [2.44] & {$[3.08]$} & [3.53] & [1.89] & [2.34] & [2.75] & [3.25] & {$[2.56]$} & [3.05] \\
\hline \multirow[t]{2}{*}{$\mathrm{R} 3 \times \mathrm{CO}$} & 0.008 & 0.023 & 0.009 & 0.026 & 0.014 & 0.028 & 0.011 & 0.027 & 0.015 & 0.028 & 0.012 & 0.029 \\
\hline & [0.84] & [1.96] & {$[0.62]$} & [1.35] & {$[0.84]$} & [1.36] & {$[0.69]$} & {$[1.32]$} & {$[0.92]$} & [1.34] & {$[0.83]$} & [1.61] \\
\hline \multirow[t]{2}{*}{ InvME } & & 1.830 & & 1.764 & & 1.763 & & 1.767 & & 1.765 & & 1.783 \\
\hline & & [5.67] & & [5.61] & & {$[5.60]$} & & {$[5.61]$} & & [5.61] & & [5.62] \\
\hline \multirow[t]{2}{*}{ BTM } & & 0.317 & & 0.320 & & 0.320 & & 0.320 & & 0.320 & & 0.319 \\
\hline & & [25.99] & & [26.07] & & [26.08] & & [26.10] & & [26.06] & & [26.05] \\
\hline \multirow{2}{*}{ AssetGrowth } & & 0.134 & & 0.135 & & 0.134 & & 0.135 & & 0.134 & & 0.135 \\
\hline & & {$[5.56]$} & & [5.53] & & [5.52] & & [5.53] & & [5.53] & & [5.55] \\
\hline \multirow[t]{2}{*}{ Loss } & & -0.276 & & -0.274 & & -0.272 & & -0.274 & & -0.273 & & -0.275 \\
\hline & & [-19.34] & & {$[-19.52]$} & & {$[-19.47]$} & & {$[-19.42]$} & & {$[-19.50]$} & & {$[-19.46]$} \\
\hline \multirow[t]{2}{*}{10} & & -0.003 & & -0.032 & & -0.034 & & -0.025 & & -0.033 & & -0.029 \\
\hline & & {$[-0.13]$} & & {$[-1.23]$} & & {$[-1.25]$} & & {$[-1.00]$} & & {$[-1.24]$} & & {$[-1.06]$} \\
\hline \multirow[t]{2}{*}{ Lagged X × 10} & & -0.285 & & -0.239 & & -0.231 & & -0.241 & & -0.233 & & -0.251 \\
\hline & & {$[-2.41]$} & & {$[-2.08]$} & & {$[-2.01]$} & & {$[-2.09]$} & & {$[-2.03]$} & & {$[-2.16]$} \\
\hline \multirow[t]{2}{*}{$x \times 10$} & & -0.422 & & -0.311 & & -0.305 & & -0.317 & & -0.319 & & -0.351 \\
\hline & & {$[-2.29]$} & & {$[-1.78]$} & & {$[-1.75]$} & & {$[-1.79]$} & & {$[-1.83]$} & & [-1.96] \\
\hline$X 3 \times 10$ & & 0.534 & & 0.527 & & 0.532 & & 0.528 & & 0.532 & & 0.534 \\
\hline & & [7.82] & & [7.88] & & [7.99] & & {$[7.87]$} & & {$[7.96]$} & & [7.91] \\
\hline $\mathrm{R} 3 \times 10$ & & -0.022 & & -0.022 & & -0.022 & & -0.022 & & -0.022 & & -0.021 \\
\hline & & {$[-1.36]$} & & {$[-1.28]$} & & {$[-1.32]$} & & {$[-1.27]$} & & {$[-1.32]$} & & {$[-1.27]$} \\
\hline $\mathrm{N}$ & 78,693 & 76,731 & 78,693 & 76,731 & 78,693 & 76,731 & 78,693 & 76,731 & 78,693 & 76,731 & 78,693 & 76,731 \\
\hline RSQ & $21.4 \%$ & $29.9 \%$ & $21.3 \%$ & $29.7 \%$ & $21.3 \%$ & $29.8 \%$ & $21.3 \%$ & $29.7 \%$ & $21.3 \%$ & $29.8 \%$ & $21.3 \%$ & $29.8 \%$ \\
\hline
\end{tabular}

\begin{tabular}{|c|c|c|c|c|c|c|c|c|c|c|c|c|}
\hline \multirow[b]{2}{*}{ Variables } & (1) & (2) & (3) & (4) & (5) & (6) & (7) & (8) & (9) & (10) & (11) & (12) \\
\hline & \multicolumn{2}{|c|}{ CrossDummy } & \multicolumn{2}{|c|}{ NConnected } & \multicolumn{2}{|c|}{ NCross } & \multicolumn{2}{|c|}{ AvgNum } & \multicolumn{2}{|c|}{ TotalCrossOwn } & \multicolumn{2}{|c|}{ CO Index } \\
\hline \multirow[t]{2}{*}{ Lagged X } & -0.630 & -0.367 & -0.640 & -0.316 & -0.638 & -0.319 & -0.645 & -0.320 & -0.650 & -0.323 & -0.636 & -0.324 \\
\hline & {$[-6.72]$} & {$[-5.26]$} & {$[-5.78]$} & {$[-3.53]$} & {$[-5.82]$} & {$[-3.62]$} & {$[-5.80]$} & {$[-3.50]$} & {$[-5.90]$} & {$[-3.61]$} & {$[-6.05]$} & {$[-3.90]$} \\
\hline \multirow[t]{2}{*}{$X(t)$} & 0.491 & 0.485 & 0.496 & 0.535 & 0.511 & 0.548 & 0.497 & 0.537 & 0.537 & 0.569 & 0.505 & 0.529 \\
\hline & {$[7.44]$} & {$[5.60]$} & {$[6.07]$} & [4.88] & {$[6.12]$} & {$[4.98]$} & {$[6.17]$} & {$[4.88]$} & [6.59] & {$[5.27]$} & {$[6.70]$} & [5.17] \\
\hline \multirow[t]{2}{*}{ X3 } & 0.115 & -0.033 & 0.079 & -0.092 & 0.067 & -0.101 & 0.080 & -0.091 & 0.071 & -0.097 & 0.085 & -0.078 \\
\hline & {$[4.09]$} & {$[-1.00]$} & {$[2.30]$} & {$[-2.38]$} & {$[1.96]$} & {$[-2.59]$} & {$[2.37]$} & {$[-2.38]$} & {$[2.16]$} & {$[-2.58]$} & {$[2.74]$} & {$[-2.14]$} \\
\hline \multirow[t]{2}{*}{ R3 } & -0.041 & -0.044 & -0.039 & -0.044 & -0.037 & -0.042 & -0.039 & -0.044 & -0.038 & -0.043 & -0.039 & -0.043 \\
\hline & {$[-4.74]$} & {$[-5.30]$} & {$[-5.14]$} & {$[-4.45]$} & {$[-5.23]$} & {$[-4.48]$} & {$[-5.00]$} & {$[-4.48]$} & {$[-5.38]$} & {$[-4.60]$} & {$[-5.10]$} & {$[-4.78]$} \\
\hline \multirow[t]{2}{*}{$\mathrm{CO}$} & -0.034 & 0.017 & -0.049 & 0.042 & -0.061 & 0.023 & -0.048 & 0.042 & -0.060 & 0.026 & -0.051 & 0.029 \\
\hline & {$[-2.38]$} & {$[0.99]$} & {$[-1.88]$} & {$[1.36]$} & {$[-2.40]$} & {$[0.79]$} & {$[-1.90]$} & [1.39] & {$[-2.36]$} & {$[0.89]$} & {$[-2.21]$} & [1.07] \\
\hline \multirow[t]{2}{*}{ Lagged X × CO } & -0.096 & -0.271 & -0.114 & -0.392 & -0.115 & -0.397 & -0.102 & -0.375 & -0.092 & -0.394 & -0.113 & -0.376 \\
\hline & {$[-1.03]$} & {$[-2.68]$} & {$[-0.76]$} & {$[-2.35]$} & {$[-0.81]$} & {$[-2.49]$} & {$[-0.66]$} & {$[-2.25]$} & {$[-0.64]$} & {$[-2.42]$} & {$[-0.83]$} & {$[-2.49]$} \\
\hline \multirow[t]{2}{*}{$\mathrm{X} \times \mathrm{CO}$} & 0.020 & -0.016 & -0.001 & -0.094 & -0.026 & -0.117 & -0.003 & -0.098 & -0.083 & -0.164 & -0.012 & -0.083 \\
\hline & {$[0.24]$} & {$[-0.19]$} & {$[-0.01]$} & {$[-0.70]$} & {$[-0.20]$} & {$[-0.85]$} & {$[-0.03]$} & {$[-0.72]$} & {$[-0.66]$} & {$[-1.23]$} & {$[-0.10]$} & {$[-0.67]$} \\
\hline \multirow[t]{2}{*}{$\mathrm{X} 3 \times \mathrm{CO}$} & 0.108 & 0.120 & 0.157 & 0.196 & 0.185 & 0.217 & 0.156 & 0.194 & 0.174 & 0.210 & 0.154 & 0.182 \\
\hline & [3.42] & [3.86] & [3.39] & [3.88] & {$[4.00]$} & [4.50] & [3.35] & [3.83] & [4.03] & [4.67] & {$[3.60]$} & [4.11] \\
\hline \multirow[t]{2}{*}{$\mathrm{R} 3 \times \mathrm{CO}$} & -0.014 & -0.005 & -0.019 & -0.005 & -0.024 & -0.008 & -0.018 & -0.004 & -0.022 & -0.007 & -0.019 & -0.005 \\
\hline & {$[-1.40]$} & {$[-0.54]$} & {$[-1.44]$} & {$[-0.35]$} & {$[-1.67]$} & {$[-0.61]$} & {$[-1.37]$} & {$[-0.28]$} & {$[-1.66]$} & {$[-0.57]$} & {$[-1.49]$} & {$[-0.45]$} \\
\hline \multirow[t]{2}{*}{ InvME } & & 1.987 & & 2.040 & & 1.972 & & 2.045 & & 1.986 & & 2.015 \\
\hline & & {$[7.57]$} & & [7.68] & & {$[7.64]$} & & [7.66] & & {$[7.68]$} & & [7.67] \\
\hline \multirow[t]{2}{*}{ BTM } & & 0.087 & & 0.087 & & 0.087 & & 0.087 & & 0.087 & & 0.087 \\
\hline & & {$[5.03]$} & & [4.98] & & {$[4.96]$} & & [4.99] & & [4.99] & & [4.99] \\
\hline \multirow[t]{2}{*}{ AssetGrowth } & & 0.184 & & 0.183 & & 0.184 & & 0.183 & & 0.184 & & 0.184 \\
\hline & & [6.05] & & [6.05] & & {$[6.03]$} & & {$[6.06]$} & & [6.04] & & [6.04] \\
\hline \multirow[t]{2}{*}{ Loss } & & -0.127 & & -0.128 & & -0.129 & & -0.128 & & -0.129 & & -0.128 \\
\hline & & {$[-8.46]$} & & {$[-8.39]$} & & {$[-8.41]$} & & {$[-8.40]$} & & {$[-8.35]$} & & {$[-8.40]$} \\
\hline \multirow[t]{2}{*}{10} & & 0.087 & & 0.090 & & 0.085 & & 0.091 & & 0.085 & & 0.088 \\
\hline & & [2.93] & & [2.98] & & {$[2.87]$} & & [3.00] & & [2.85] & & [2.92] \\
\hline \multirow[t]{2}{*}{ Lagged X × 10} & & -0.519 & & -0.514 & & -0.505 & & -0.520 & & -0.503 & & -0.516 \\
\hline & & {$[-4.42]$} & & {$[-4.32]$} & & {$[-4.33]$} & & {$[-4.28]$} & & {$[-4.46]$} & & {$[-4.39]$} \\
\hline \multirow[t]{2}{*}{$x \times 10$} & & -0.266 & & -0.280 & & -0.277 & & -0.281 & & -0.276 & & -0.278 \\
\hline & & {$[-2.27]$} & & {$[-2.34]$} & & {$[-2.32]$} & & {$[-2.35]$} & & {$[-2.31]$} & & {$[-2.33]$} \\
\hline$x 3 \times 10$ & & 0.420 & & 0.425 & & 0.424 & & 0.425 & & 0.422 & & 0.424 \\
\hline & & {$[7.86]$} & & [7.95] & & {$[7.93]$} & & [7.94] & & [7.84] & & [7.89] \\
\hline $\mathrm{R} 3 \times 1 \mathrm{O}$ & & -0.033 & & -0.035 & & -0.035 & & -0.035 & & -0.035 & & -0.034 \\
\hline & & {$[-2.14]$} & & {$[-2.23]$} & & {$[-2.26]$} & & {$[-2.20]$} & & {$[-2.25]$} & & {$[-2.21]$} \\
\hline Avg. N & 2402 & 2334 & 2402 & 2334 & 2402 & 2334 & 2402 & 2334 & 2402 & 2334 & 2402 & 2334 \\
\hline Avg. $\mathrm{R}^{2}$ & $9.9 \%$ & $18.4 \%$ & $9.8 \%$ & $18.4 \%$ & $9.8 \%$ & $18.3 \%$ & $9.8 \%$ & $18.4 \%$ & $9.8 \%$ & $18.3 \%$ & $9.8 \%$ & $18.4 \%$ \\
\hline
\end{tabular}


Table A3: Variance Ratio Tests

This table reports the results of regression of variance ratios on the common ownership and control variables. The dependent variables are the variance ratios for year $t$, or the ratios for the quarter $q$. The variance ratio is calculated from the natural logarithm of absolute value of the ratio of the variance of 5-day returns in a given quarter (resp., year) to 5 times the variance of one-day returns in the same quarter (resp., year). CO measures the common ownership during year $t-1$ (quarter $q-1$ ). We use the five different measures of common ownership. Except for CrossDummy, $\mathrm{CO}$ is the decile score of the common ownership variables, scaled between zero and one. Each year (quarter), stocks are sorted based on their common ownership measures into deciles. Then, the decile ranks are normalized on a scale of zero to one. CO Index is the average of all five proxies of common ownership. 10 is the residual institutional ownership orthogonalized from the $\mathrm{CO}$ variables. Specifically, $1 \mathrm{O}$ is obtained from the residuals of the regression of total institutional ownership on Crossdummy and TotalCrossOwn. IO is also a decile rank, normalized between zero and one. Definitions of other explanatory variables are provided in Appendix A. Year and Firm Fixed Effects are included. $t$-statistics are calculated using clustered standard errors by firm level and reported in parentheses. The sample period is $1980-2014$.

Panel A: Annual Variance Ratios

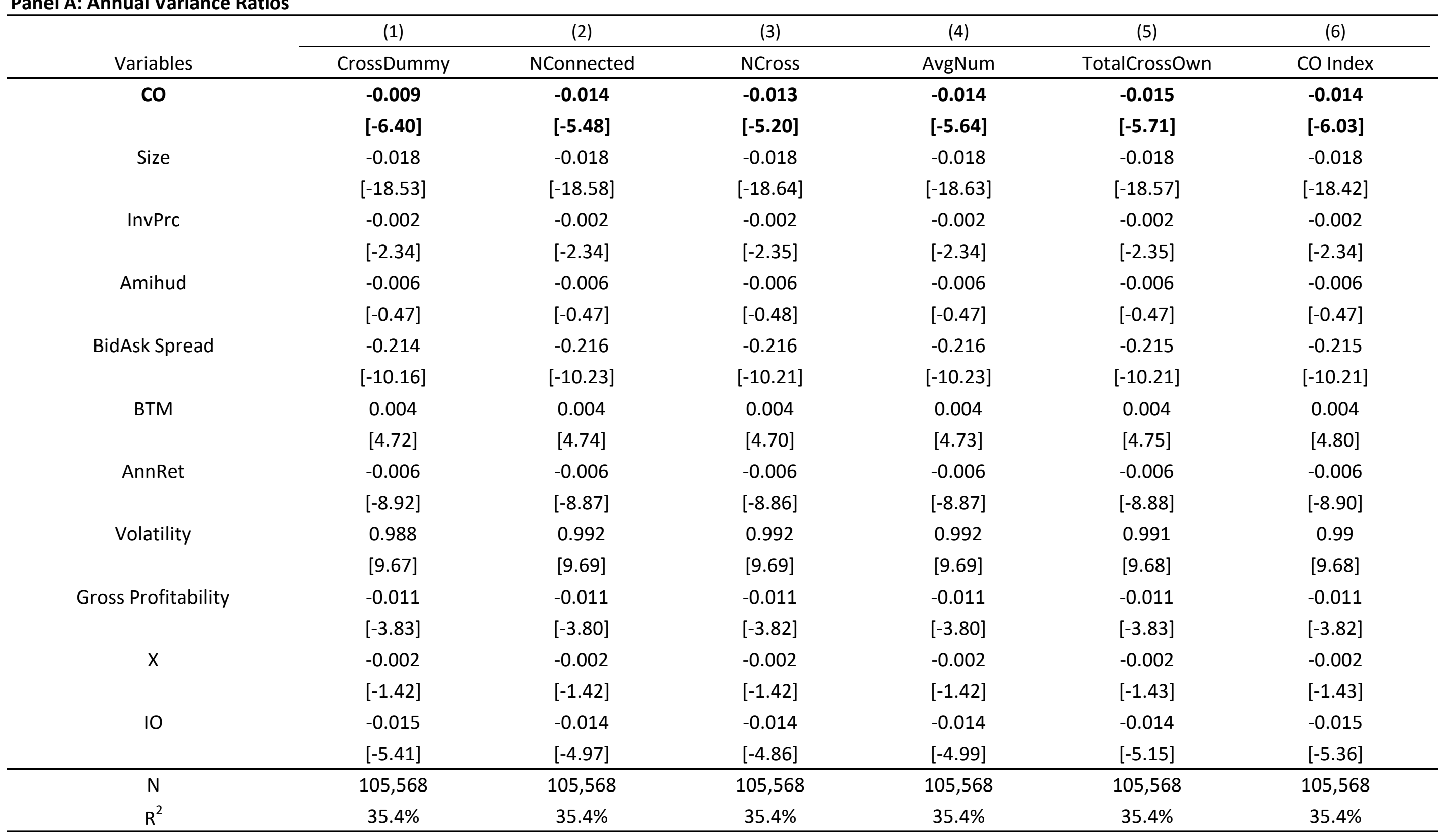

Panel B: Quarterly Variance Ratios

\begin{tabular}{|c|c|c|c|c|c|c|}
\hline & (1) & $(2)$ & (3) & (4) & (5) & (6) \\
\hline Variables & CrossDummy & NConnected & NCross & AvgNum & TotalCrossOwn & CO Index \\
\hline \multirow[t]{2}{*}{ CO } & -0.006 & -0.010 & -0.012 & -0.009 & -0.012 & -0.010 \\
\hline & {$[-6.21]$} & {$[-5.46]$} & {$[-6.66]$} & {$[-5.26]$} & {$[-6.40]$} & {$[-6.24]$} \\
\hline \multirow[t]{2}{*}{ Size } & -0.013 & -0.013 & -0.012 & -0.013 & -0.012 & -0.012 \\
\hline & [-19.11] & {$[-19.17]$} & {$[-18.87]$} & {$[-19.32]$} & {$[-18.94]$} & {$[-18.95]$} \\
\hline InvPrc & -0.002 & -0.002 & -0.002 & -0.002 & -0.002 & -0.002 \\
\hline \multirow[t]{2}{*}{ Amihud } & 4.395 & 4.378 & 4.403 & 4.366 & 4.413 & 4.403 \\
\hline & {$[0.83]$} & {$[0.83]$} & {$[0.84]$} & {$[0.83]$} & {$[0.84]$} & {$[0.83]$} \\
\hline \multirow[t]{2}{*}{ BidAsk Spread } & -0.105 & -0.105 & -0.105 & -0.105 & -0.105 & -0.105 \\
\hline & {$[-10.54]$} & {$[-10.56]$} & {$[-10.56]$} & {$[-10.56]$} & {$[-10.56]$} & {$[-10.56]$} \\
\hline \multirow[t]{2}{*}{ BTM } & 0.004 & 0.004 & 0.004 & 0.004 & 0.004 & 0.004 \\
\hline & [5.47] & {$[5.46]$} & [5.57] & [5.42] & [5.53] & [5.53] \\
\hline AnnRet & -0.002 & -0.002 & -0.002 & -0.002 & -0.002 & -0.002 \\
\hline \multirow[t]{2}{*}{ Volatility } & 0.702 & 0.703 & 0.702 & 0.703 & 0.702 & 0.702 \\
\hline & [11.62] & [11.62] & [11.62] & [11.62] & [11.62] & [11.62] \\
\hline \multirow[t]{2}{*}{ Gross Profitability } & -0.005 & -0.005 & -0.005 & -0.005 & -0.005 & -0.005 \\
\hline & {$[-2.56]$} & {$[-2.53]$} & {$[-2.56]$} & {$[-2.53]$} & {$[-2.56]$} & {$[-2.55]$} \\
\hline \multirow[t]{2}{*}{$x$} & -0.001 & -0.001 & -0.001 & -0.001 & -0.001 & -0.001 \\
\hline & {$[-1.25]$} & {$[-1.24]$} & {$[-1.26]$} & {$[-1.24]$} & {$[-1.25]$} & {$[-1.25]$} \\
\hline \multirow[t]{2}{*}{10} & -0.019 & -0.018 & -0.020 & -0.017 & -0.019 & -0.019 \\
\hline & {$[-8.78]$} & {$[-8.39]$} & {$[-9.01]$} & {$[-8.29]$} & {$[-8.88]$} & {$[-8.81]$} \\
\hline $\mathrm{N}$ & 383,075 & 383,075 & 383,075 & 383,075 & 383,075 & 383,075 \\
\hline $\mathrm{R}^{2}$ & $12.6 \%$ & $12.6 \%$ & $12.6 \%$ & $12.6 \%$ & $12.6 \%$ & $12.6 \%$ \\
\hline
\end{tabular}


Table A4: Cross-Sectional Analyses — Information Environment

This table examines whether the effects of common ownership on the price informativeness varies according to firms' informational environment. Panel A examines the price informativeness with respect to future earnings, while Panel B uses quarterly variance ratios to study the extent to which share prices are influenced by noisy trading. A dummy variable, D, measures firms' information environment. Specifically, D takes one if a firm displays characteristics that are related to high information asymmetry. Each year (each quarter for Panel B), firms are sorted into two groups using the median values of Size, Residual Institutional Ownership (IO), Idiosyncratic Volatility (IVOL), PIN, and Information Cost Index (InfoCost). Then, D equals one if a firm is small, has low Residual IO, high IVOL, high PIN, or high InfoCost. Finally, D is interacted with common ownership variables to examine the differential effects of common ownership for each subsample of sorting variables. Variable definitions are provided in Appendix A. Year and Firm Fixed Effects are included. $t$ statistics are calculated using clustered standard errors by firm level and reported in parentheses. The sample period is 1980-2014.

\begin{tabular}{|c|c|c|c|c|c|c|c|c|c|c|}
\hline \multirow{3}{*}{ Sort Variables } & (1) & (2) & (3) & (4) & (5) & (6) & (7) & (8) & (9) & (10) \\
\hline & \multicolumn{2}{|c|}{ Size } & \multicolumn{2}{|c|}{ Residual IO } & \multicolumn{2}{|c|}{ IVOL } & \multicolumn{2}{|c|}{ PIN } & \multicolumn{2}{|c|}{ InfoCost } \\
\hline & CrossDummy & CO Index & CrossDummy & CO Index & CrossDummy & CO Index & CrossDummy & CO Index & CrossDummy & CO Index \\
\hline \multirow{2}{*}{ Lagged X } & -0.101 & -0.135 & -0.167 & -0.260 & -0.102 & -0.129 & -0.467 & -0.436 & -0.047 & -0.103 \\
\hline & {$[-0.86]$} & {$[-0.99]$} & {$[-0.86]$} & {$[-1.25]$} & {$[-0.97]$} & {$[-1.05]$} & {$[-2.47]$} & {$[-1.98]$} & {$[-0.30]$} & {$[-0.57]$} \\
\hline \multirow[t]{2}{*}{$\mathrm{x}$} & 0.764 & 0.705 & 0.979 & 0.905 & 0.668 & 0.661 & 0.730 & 0.693 & 0.491 & 0.313 \\
\hline & {$[4.25]$} & [3.44] & {$[4.62]$} & [3.95] & [4.93] & [4.14] & {$[2.78]$} & {$[2.27]$} & {$[2.07]$} & {$[1.20]$} \\
\hline \multirow[t]{2}{*}{$\mathrm{x} 3$} & 0.060 & 0.089 & -0.097 & -0.076 & 0.033 & -0.010 & -0.250 & -0.233 & 0.004 & 0.024 \\
\hline & {$[0.85]$} & {$[1.08]$} & {$[-1.04]$} & {$[-0.72]$} & {$[0.62]$} & {$[-0.16]$} & {$[-2.46]$} & {$[-1.93]$} & {$[0.04]$} & {$[0.22]$} \\
\hline \multirow[t]{2}{*}{ R3 } & -0.092 & -0.105 & -0.077 & -0.083 & -0.085 & -0.089 & -0.109 & -0.115 & -0.140 & -0.148 \\
\hline & {$[-4.88]$} & {$[-4.71]$} & {$[-3.69]$} & {$[-3.33]$} & {$[-4.94]$} & {$[-4.04]$} & {$[-7.21]$} & {$[-5.34]$} & {$[-8.18]$} & {$[-7.34]$} \\
\hline \multirow[t]{2}{*}{ D } & 0.441 & 0.489 & 0.090 & 0.131 & 0.185 & 0.227 & -0.139 & -0.114 & -0.038 & -0.035 \\
\hline & [19.43] & {$[16.68]$} & [4.15] & {$[4.65]$} & [12.94] & [11.57] & {$[-6.20]$} & {$[-4.07]$} & {$[-2.20]$} & {$[-1.53]$} \\
\hline \multirow[t]{2}{*}{ Lagged X $\times D$} & -0.217 & -0.140 & -0.113 & 0.000 & -0.254 & -0.190 & 0.173 & 0.169 & -0.459 & -0.526 \\
\hline & {$[-2.48]$} & {$[-1.21]$} & {$[-0.79]$} & {$[-0.00]$} & {$[-3.30]$} & {$[-1.81]$} & {$[0.95]$} & {$[0.77]$} & {$[-2.80]$} & {$[-2.54]$} \\
\hline \multirow[t]{2}{*}{$X \times D$} & -0.098 & -0.045 & -0.321 & -0.249 & -0.039 & -0.067 & 0.004 & 0.110 & 0.507 & 0.455 \\
\hline & {$[-0.85]$} & {$[-0.29]$} & {$[-1.94]$} & {$[-1.29]$} & {$[-0.43]$} & {$[-0.51]$} & {$[0.02]$} & {$[0.41]$} & [2.72] & [1.69] \\
\hline \multirow[t]{2}{*}{$X 3 \times D$} & -0.150 & -0.233 & -0.017 & -0.105 & -0.101 & -0.081 & 0.129 & 0.077 & 0.033 & 0.067 \\
\hline & {$[-2.92]$} & {$[-3.49]$} & {$[-0.22]$} & {$[-1.15]$} & {$[-2.39]$} & {$[-1.40]$} & [1.46] & {$[0.70]$} & {$[0.38]$} & {$[0.57]$} \\
\hline \multirow[t]{2}{*}{$\mathrm{R} 3 \times \mathrm{D}$} & 0.002 & 0.024 & -0.004 & 0.004 & -0.012 & -0.011 & 0.023 & 0.027 & 0.012 & 0.027 \\
\hline & {$[0.15]$} & [1.23] & {$[-0.24]$} & {$[0.18]$} & {$[-0.85]$} & {$[-0.60]$} & {$[1.45]$} & [1.12] & {$[0.64]$} & {$[0.96]$} \\
\hline \multirow[t]{2}{*}{$\mathrm{CO}$} & 0.001 & 0.005 & -0.016 & -0.044 & -0.028 & -0.051 & -0.060 & -0.098 & 0.052 & 0.085 \\
\hline & [0.11] & {$[0.21]$} & {$[-1.01]$} & {$[-1.70]$} & {$[-2.14]$} & {$[-2.23]$} & {$[-2.57]$} & {$[-2.55]$} & [3.02] & [2.88] \\
\hline \multirow[t]{2}{*}{ Lagged X $\times$ CO } & 0.079 & 0.108 & 0.004 & 0.095 & -0.031 & -0.018 & 0.020 & -0.046 & -0.115 & -0.089 \\
\hline & {$[0.95]$} & {$[0.82]$} & {$[0.04]$} & [0.54] & {$[-0.44]$} & {$[-0.15]$} & {$[0.10]$} & {$[-0.18]$} & {$[-0.86]$} & {$[-0.44]$} \\
\hline \multirow[t]{2}{*}{$\mathrm{X} \times \mathrm{CO}$} & -0.143 & -0.142 & -0.514 & -0.470 & -0.186 & -0.238 & -0.102 & -0.084 & -0.112 & 0.068 \\
\hline & {$[-1.47]$} & {$[-0.88]$} & {$[-2.79]$} & {$[-2.15]$} & {$[-2.37]$} & {$[-1.79]$} & {$[-0.50]$} & {$[-0.28]$} & {$[-0.65]$} & {$[0.26]$} \\
\hline \multirow[t]{2}{*}{$\mathrm{X} 3 \times \mathrm{CO}$} & -0.056 & -0.103 & 0.018 & -0.025 & 0.128 & 0.194 & -0.008 & -0.034 & -0.050 & -0.071 \\
\hline & {$[-1.09]$} & {$[-1.30]$} & {$[0.25]$} & {$[-0.24]$} & [3.38] & [2.98] & {$[-0.08]$} & {$[-0.25]$} & {$[-0.65]$} & {$[-0.60]$} \\
\hline \multirow[t]{2}{*}{$\mathrm{R} 3 \times \mathrm{CO}$} & 0.045 & 0.070 & 0.046 & 0.064 & 0.014 & 0.019 & 0.057 & 0.071 & 0.052 & 0.073 \\
\hline & {$[3.42]$} & {$[3.30]$} & [3.13] & {$[2.69]$} & {$[1.08]$} & {$[0.89]$} & {$[2.98]$} & [2.33] & {$[3.73]$} & [3.43] \\
\hline \multirow[t]{2}{*}{$\mathrm{D} \times \mathrm{CO}$} & -0.048 & -0.131 & -0.108 & -0.180 & -0.080 & -0.153 & 0.077 & 0.032 & 0.035 & 0.027 \\
\hline & {$[-2.15]$} & {$[-3.65]$} & {$[-4.67]$} & {$[-5.09]$} & {$[-4.16]$} & {$[-5.03]$} & {$[2.96]$} & {$[0.80]$} & [1.55] & {$[0.79]$} \\
\hline \multirow[t]{2}{*}{$\mathrm{D} \times$ Lagged $\mathrm{X} \times \mathrm{CO}$} & -0.386 & -0.501 & -0.310 & -0.453 & -0.238 & -0.328 & -0.291 & -0.309 & -0.122 & -0.014 \\
\hline & {$[-3.40]$} & {$[-2.91]$} & {$[-2.31]$} & {$[-2.20]$} & {$[-2.29]$} & [-1.99] & {$[-1.30]$} & {$[-1.01]$} & {$[-0.56]$} & {$[-0.05]$} \\
\hline $\mathrm{D} \times \mathrm{X} \times \mathrm{CO}$ & -0.399 & -0.389 & 0.114 & 0.057 & -0.251 & -0.139 & -0.610 & -0.823 & -0.607 & -0.596 \\
\hline & {$[-2.88]$} & [-1.85] & [0.57] & {$[0.22]$} & {$[-1.91]$} & {$[-0.70]$} & {$[-2.30]$} & {$[-2.32]$} & {$[-2.18]$} & {$[-1.74]$} \\
\hline $\mathrm{D} \times \mathrm{X3} \times \mathrm{CO}$ & 0.231 & 0.371 & 0.164 & 0.329 & -0.046 & -0.074 & 0.260 & 0.369 & 0.191 & 0.145 \\
\hline & [3.43] & [3.68] & [2.08] & [2.74] & {$[-0.74]$} & {$[-0.78]$} & [2.38] & [2.37] & [1.58] & {$[0.83]$} \\
\hline $\mathrm{D} \times \mathrm{R} 3 \times \mathrm{CO}$ & -0.041 & -0.083 & -0.040 & -0.063 & 0.013 & 0.014 & -0.072 & -0.084 & -0.007 & -0.023 \\
\hline & {$[-2.27]$} & {$[-3.09]$} & {$[-2.09]$} & {$[-2.11]$} & {$[0.68]$} & {$[0.45]$} & {$[-3.15]$} & {$[-2.30]$} & {$[-0.28]$} & {$[-0.59]$} \\
\hline Controls & Yes & Yes & Yes & Yes & Yes & Yes & Yes & Yes & Yes & Yes \\
\hline $\mathrm{N}$ & 76,731 & 76,731 & 76,731 & 76,731 & 76,729 & 76,729 & 43,410 & 43,410 & 43,905 & 43,905 \\
\hline $\mathrm{R}^{2}$ & $31.4 \%$ & $31.3 \%$ & $30.0 \%$ & $30.0 \%$ & $30.3 \%$ & $30.2 \%$ & $34.3 \%$ & $34.2 \%$ & $35.4 \%$ & $35.2 \%$ \\
\hline
\end{tabular}

\begin{tabular}{|c|c|c|c|c|c|c|c|c|c|c|}
\hline \multirow{3}{*}{ Sort Variables } & (1) & (2) & (3) & (4) & (5) & (6) & (7) & (8) & (9) & (10) \\
\hline & \multicolumn{2}{|c|}{ Size } & \multicolumn{2}{|c|}{ Residual IO } & \multicolumn{2}{|c|}{ IVOL } & \multicolumn{2}{|c|}{ PIN } & \multicolumn{2}{|c|}{ InfoCost } \\
\hline & CrossDummy & CO Index & CrossDummy & CO Index & CrossDummy & CO Index & CrossDummy & CO Index & CrossDummy & CO Index \\
\hline \multirow[t]{2}{*}{$\mathrm{CO}$} & -0.006 & -0.011 & -0.005 & -0.010 & -0.003 & -0.007 & -0.002 & -0.005 & -0.003 & -0.007 \\
\hline & [-4.93] & {$[-5.63]$} & {$[-4.84]$} & {$[-5.24]$} & {$[-2.80]$} & {$[-3.56]$} & {$[-1.24]$} & {$[-2.34]$} & {$[-2.44]$} & [-2.99] \\
\hline \multirow[t]{2}{*}{ D } & 0.001 & 0.000 & -0.003 & -0.002 & 0.013 & 0.013 & 0.009 & 0.009 & 0.006 & 0.007 \\
\hline & [0.59] & {$[0.01]$} & {$[-1.56]$} & {$[-1.02]$} & [10.44] & [8.12] & [6.63] & {$[4.75]$} & [4.49] & [3.82] \\
\hline \multirow[t]{2}{*}{$D \times C O$} & -0.002 & 0.000 & -0.004 & -0.004 & -0.005 & -0.005 & -0.006 & -0.005 & -0.003 & -0.005 \\
\hline & {$[-1.00]$} & {$[0.12]$} & {$[-2.22]$} & {$[-1.46]$} & {$[-3.64]$} & {$[-2.04]$} & {$[-3.63]$} & {$[-1.61]$} & {$[-2.05]$} & {$[-1.83]$} \\
\hline \multirow[t]{2}{*}{ Size } & -0.012 & -0.012 & -0.012 & -0.012 & -0.012 & -0.012 & -0.011 & -0.011 & -0.009 & -0.008 \\
\hline & {$[-17.89]$} & [-17.79] & {$[-18.98]$} & [-18.83] & {$[-18.41]$} & [-18.29] & {$[-12.58]$} & {$[-12.43]$} & {$[-10.82]$} & {$[-10.65]$} \\
\hline \multirow[t]{2}{*}{ InvPrc } & -0.002 & -0.002 & -0.002 & -0.002 & 0.000 & 0.000 & 0.011 & 0.011 & 0.016 & 0.016 \\
\hline & {$[-2.48]$} & {$[-2.47]$} & {$[-2.51]$} & {$[-2.49]$} & {$[-0.09]$} & {$[-0.08]$} & [7.96] & [7.98] & [5.77] & [5.73] \\
\hline \multirow[t]{2}{*}{ Amihud } & 4.409 & 4.406 & 4.388 & 4.366 & 18.410 & 18.434 & -4.780 & -4.823 & 412.646 & 413.266 \\
\hline & {$[0.84]$} & {$[0.84]$} & {$[0.83]$} & [0.83] & [3.64] & [3.65] & {$[-1.14]$} & {$[-1.16]$} & [3.87] & [3.87] \\
\hline \multirow[t]{2}{*}{ BidAsk Spread } & -0.105 & -0.105 & -0.105 & -0.105 & -0.122 & -0.123 & -0.084 & -0.084 & -0.080 & -0.080 \\
\hline & {$[-10.54]$} & {$[-10.56]$} & {$[-10.54]$} & {$[-10.56]$} & {$[-11.81]$} & [-11.83] & {$[-8.89]$} & {$[-8.90]$} & {$[-9.13]$} & {$[-9.15]$} \\
\hline \multirow[t]{2}{*}{ BTM } & 0.004 & 0.004 & 0.004 & 0.004 & 0.004 & 0.004 & 0.002 & 0.002 & 0.004 & 0.004 \\
\hline & [5.51] & [5.52] & [5.64] & [5.63] & {$[5.67]$} & [5.63] & [2.76] & [2.79] & {$[4.25]$} & [4.34] \\
\hline \multirow[t]{2}{*}{ AnnRet } & -0.002 & -0.002 & -0.002 & -0.002 & -0.002 & -0.002 & -0.001 & -0.001 & 0.000 & 0.000 \\
\hline & {$[-3.84]$} & {$[-3.84]$} & {$[-3.98]$} & {$[-4.01]$} & {$[-3.84]$} & {$[-3.88]$} & {$[-2.34]$} & {$[-2.38]$} & {$[0.43]$} & {$[0.43]$} \\
\hline \multirow[t]{2}{*}{ Volatility } & 0.702 & 0.702 & 0.701 & 0.702 & 0.663 & 0.665 & 0.436 & 0.437 & 0.573 & 0.571 \\
\hline & [11.62] & {$[11.62]$} & [11.61] & [11.61] & [9.64] & [9.64] & [7.81] & [7.80] & [9.94] & [9.90] \\
\hline \multirow[t]{2}{*}{ Gross Profitability } & -0.005 & -0.005 & -0.005 & -0.005 & -0.005 & -0.005 & -0.006 & -0.006 & 0.005 & 0.006 \\
\hline & {$[-2.56]$} & {$[-2.55]$} & {$[-2.54]$} & {$[-2.56]$} & {$[-2.32]$} & {$[-2.36]$} & {$[-2.45]$} & {$[-2.44]$} & [1.71] & [1.74] \\
\hline \multirow[t]{2}{*}{$x$} & -0.001 & -0.001 & -0.001 & -0.001 & -0.001 & -0.001 & 0.000 & 0.000 & -0.004 & -0.004 \\
\hline & {$[-1.26]$} & {$[-1.25]$} & {$[-1.27]$} & {$[-1.26]$} & {$[-1.28]$} & {$[-1.27]$} & {$[-0.63]$} & {$[-0.62]$} & {$[-1.43]$} & {$[-1.44]$} \\
\hline \multirow[t]{2}{*}{10} & -0.019 & -0.019 & -0.025 & -0.025 & -0.017 & -0.017 & -0.018 & -0.018 & -0.019 & -0.020 \\
\hline & {$[-8.78]$} & {$[-8.72]$} & {$[-8.82]$} & {$[-8.74]$} & {$[-7.94]$} & {$[-7.90]$} & {$[-6.38]$} & {$[-6.15]$} & {$[-7.41]$} & {$[-7.64]$} \\
\hline $\mathrm{N}$ & 383,075 & 383,075 & 383,075 & 383,075 & 374,598 & 374,598 & 223,717 & 223,717 & 207,574 & 207,574 \\
\hline $\mathrm{R}^{2}$ & $12.6 \%$ & $12.6 \%$ & $12.6 \%$ & $12.6 \%$ & $12.2 \%$ & $12.2 \%$ & $13.7 \%$ & $13.7 \%$ & $8.3 \%$ & $8.3 \%$ \\
\hline
\end{tabular}


Table A5: Q-Investment Relation and Common Ownership

This table shows the regressions of various corporate investment proxies on $Q$ and its interaction with common ownership variables. We use CAPXRND, Investment, RND, and DisExp as the dependent variables. $Q$ is the market value of equity plus book value of total assets minus book value of equity, scaled by book value of total assets. All independent variables are measured at $t-1$, except CF, R3, and KZ4, which are contemporaneous with the dependent variables. Definitions of variables are provided in Appendix A. Year and Firm Fixed Effects are included. $t$-statistics are calculated using clustered standard errors by firm level and reported in parentheses. The sample period is $1980-2014$.

\begin{tabular}{|c|c|c|c|c|c|c|c|c|}
\hline \multirow{3}{*}{ Variables } & (1) & $(2)$ & (3) & (4) & (5) & (6) & (7) & (8) \\
\hline & \multicolumn{2}{|c|}{ CAPXRND } & \multicolumn{2}{|c|}{ Investment } & \multicolumn{2}{|c|}{ RND } & \multicolumn{2}{|c|}{ DisExp } \\
\hline & CrossDummy & CO Index & CrossDummy & CO Index & CrossDummy & CO Index & CrossDummy & CO Index \\
\hline \multirow[t]{2}{*}{$Q$} & 0.810 & 0.773 & 0.877 & 0.900 & 0.430 & 0.425 & 0.533 & 0.543 \\
\hline & [9.23] & [7.09] & [8.32] & [6.63] & [8.77] & [6.73] & [10.34] & {$[8.26]$} \\
\hline \multirow[t]{2}{*}{$\mathrm{CO}$} & -1.163 & -2.647 & -1.318 & -2.416 & -1.134 & -1.999 & -1.138 & -2.014 \\
\hline & {$[-5.04]$} & {$[-7.18]$} & {$[-3.82]$} & {$[-4.41]$} & {$[-8.58]$} & {$[-9.21]$} & {$[-7.46]$} & {$[-8.13]$} \\
\hline \multirow[t]{2}{*}{$Q \times C O$} & 0.238 & 0.281 & 0.186 & 0.109 & 0.143 & 0.134 & 0.119 & 0.080 \\
\hline & [2.59] & [1.96] & [1.41] & [0.52] & [2.58] & [1.54] & [1.93] & {$[0.84]$} \\
\hline \multirow[t]{2}{*}{$\mathrm{CF}$} & 11.314 & 7.907 & 17.309 & 13.686 & 2.094 & 0.070 & 2.905 & 0.728 \\
\hline & [13.41] & [7.55] & [15.30] & [9.58] & [4.02] & {$[0.11]$} & [4.70] & {$[0.92]$} \\
\hline \multirow[t]{2}{*}{$\mathrm{CF} \times \mathrm{CO}$} & 2.855 & 9.601 & 5.780 & 12.833 & 3.866 & 7.739 & 3.651 & 7.864 \\
\hline & [2.96] & [6.10] & [4.42] & {$[6.00]$} & [6.17] & [7.40] & [5.12] & [6.59] \\
\hline \multirow[t]{2}{*}{ INVAT } & 0.065 & 0.063 & 0.081 & 0.078 & 0.036 & 0.035 & 0.040 & 0.039 \\
\hline & [9.05] & [8.71] & [8.44] & [8.21] & [8.71] & [8.40] & {$[8.72]$} & [8.44] \\
\hline \multirow[t]{2}{*}{ R3 } & 0.011 & -0.002 & -0.113 & -0.125 & 0.224 & 0.216 & 0.268 & 0.259 \\
\hline & {$[0.22]$} & {$[-0.04]$} & {$[-1.61]$} & {$[-1.80]$} & [7.21] & [6.98] & [7.72] & [7.51] \\
\hline \multirow[t]{2}{*}{ CASH } & -1.102 & -1.100 & -0.016 & -0.013 & -1.154 & -1.157 & -1.283 & -1.285 \\
\hline & {$[-5.64]$} & {$[-5.63]$} & {$[-0.06]$} & {$[-0.05]$} & {$[-8.69]$} & {$[-8.72]$} & {$[-8.53]$} & [-8.55] \\
\hline \multirow[t]{2}{*}{ LEV } & -6.638 & -6.633 & -11.651 & -11.630 & -1.684 & -1.672 & -2.133 & -2.118 \\
\hline & {$[-18.08]$} & {$[-18.08]$} & {$[-19.48]$} & {$[-19.45]$} & {$[-7.76]$} & {$[-7.71]$} & {$[-8.43]$} & {$[-8.38]$} \\
\hline \multirow[t]{2}{*}{ SALEG } & 0.240 & 0.233 & 0.397 & 0.391 & -0.058 & -0.063 & 0.016 & 0.011 \\
\hline & [2.38] & [2.31] & {$[2.86]$} & [2.81] & {$[-0.92]$} & {$[-1.01]$} & [0.23] & {$[0.15]$} \\
\hline \multirow[t]{2}{*}{ Tangibility } & 11.962 & 11.945 & 11.658 & 11.627 & 1.638 & 1.620 & 1.824 & 1.806 \\
\hline & [22.54] & [22.57] & [15.68] & [15.65] & [6.87] & {$[6.80]$} & [6.33] & {$[6.28]$} \\
\hline \multirow[t]{2}{*}{10} & -1.068 & -1.327 & -0.216 & -0.367 & -1.302 & -1.420 & -1.347 & -1.462 \\
\hline & {$[-4.03]$} & {$[-4.80]$} & {$[-0.53]$} & {$[-0.88]$} & {$[-7.87]$} & {$[-8.11]$} & {$[-6.90]$} & [-7.12] \\
\hline \multirow[t]{2}{*}{ KZ4 } & -0.009 & -0.008 & 0.151 & 0.151 & -0.023 & -0.023 & -0.029 & -0.030 \\
\hline & {$[-0.19]$} & {$[-0.17]$} & {$[2.08]$} & [2.08] & {$[-0.86]$} & {$[-0.86]$} & {$[-0.82]$} & {$[-0.84]$} \\
\hline $\mathrm{N}$ & 71,464 & 71,464 & 72,198 & 72,198 & 72,198 & 72,198 & 72,198 & 72,198 \\
\hline$R^{2}$ & $70.3 \%$ & $70.4 \%$ & $48.4 \%$ & $48.4 \%$ & $83.9 \%$ & $83.9 \%$ & $81.7 \%$ & $81.7 \%$ \\
\hline
\end{tabular}

